Portland State University

PDXScholar

1994

\title{
A Study of Personal Attributes Associated with Marginality and Failure of Preservice Teachers in the Terminal Field Experience
}

Sharon Irene Bancroft

Portland State University

Follow this and additional works at: https://pdxscholar.library.pdx.edu/open_access_etds Let us know how access to this document benefits you.

\section{Recommended Citation}

Bancroft, Sharon Irene, "A Study of Personal Attributes Associated with Marginality and Failure of Preservice Teachers in the Terminal Field Experience" (1994). Dissertations and Theses. Paper 1160. https://doi.org/10.15760/etd.1159

This Dissertation is brought to you for free and open access. It has been accepted for inclusion in Dissertations and Theses by an authorized administrator of PDXScholar. Please contact us if we can make this document more accessible: pdxscholar@pdx.edu. 


\section{A STUDY OF PERSONAL ATTRIBUTES ASSOCIATED WITH MARGINALITY AND FAILURE OF PRESERVICE TEACHERS IN THE TERMINAL FIELD EXPERIENCE}

by

SHARON IRENE BANCROFT

A dissertation submitted in partial fulfillment of the requirements for the degree of

DOCTOR OF EDUCATION

in

ADMINISTRATION AND SUPERVISION

Portland State University

1994 


\section{DISSERTATION APPROVAL}

The abstract and dissertation of Sharon Irene Bancroft for the Doctor of Education in Educational Leadership: Administration and Supervision were presented December 9, 1993, and accepted by the dissertation committee and the doctoral program

COMMITTEE APPROVALS:

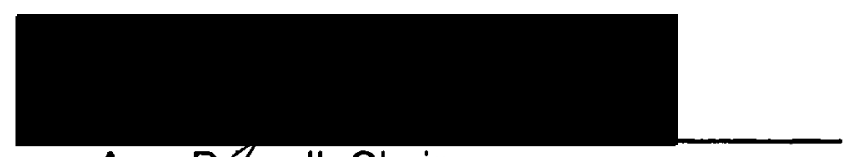

Amy Durscoll, Chair

Áhdrea Bowman

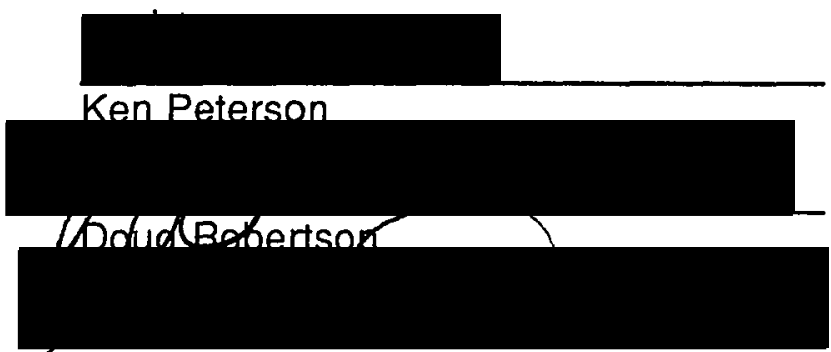

Sherwin Davidson, Representative Office of Graduate Studies

DOCTORAL PROGRAM APPROVAL:

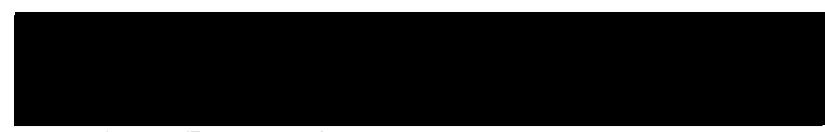

Robert B. Everhart, Dean

School of Education

by on

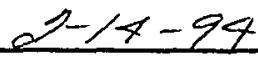




\begin{abstract}
An abstract of the dissertation of Sharon Irene Bancroft for the Doctor of Education in Educational Leadership: Administration and Supervision presented December 9, 1993.
\end{abstract}

Title: A Study of Personal Attributes Associated with Marginality and Failure of Preservice Teachers in the Terminal Field Experience

This study examines the impact of personal attributes on student teachers' failure to pass or marginal success in the terminal field experience. Interviews were conducted of faculty at five Washington and two Oregon teacher education programs, who served as supervisors of student teaching. The interview was of the "depth" type described by Masserik $(1981$, ) openended, interactive, and designed to encourage the sharing of case histories and subjective experience according to interpretive inquiry protocol as outlined by Lincoln and Guba (1985.) Its goal was to surface fundamental assumptions about and idiosyncratic language used to describe those attributes deemed critical to a preservice teacher's success. The format was flexible, to allow . respondents to guide and determine the final shape of the study (Goetz and LeCompte, 1984.) 
Interviews were tape-recorded, and transcripts re-submitted to respondents for additions, corrections, and elaborations. Interview transcripts were analyzed by a process of modified analytic induction (Bogdan and Biklan, 1982) and comparative analysis (Spradley, 1979) for recurring precepts and constructs related to personal attributes and the labels used to identify them. These were further collapsed into categories of cover and included terms, and used to construct a taxonomic model of personal attributes implicated in failure and marginality in student teachers.

Initial categories which emerged were Extrapersonal, Irremediable, Intrapersonal and Interpersonal Attributes. Respondents' identified as critical the Intrapersonal and interpersonal categories, which were further collapsed into three major attribute domains: Efficacy (including ego strength, locus of control, flexibility, and reflection;) Relatedness (including empathy, selfassertion, and people-skills;) and Heartfeltedness (including belief system, commitment, effort and passion.) Additional attributes identified by respondents as bridging and connecting the domains were imagination, authenticity, responsiveness and with-it-ness.

Several themes emerged: 1) Respondents ascribe failure and marginality primarily to personal attributes, citing technical incompetence as causal only in combination with attribute deficits; 2) reluctance to judge subjectively produces formal evaluations that do not adequately reflect the role of personal attributes; 3) pressure to pass marginal students is seen as both cause and effect of a failure of the gatekeeping function; and 4) early identification of personal attributes likely to require and/or intractable to remediation is deemed essential. 


\section{TABLE OF CONTENTS}

PAGE

LIST OF TABLES AND A FIGURE

CHAPTER

I INTRODUCTION ............................................................... 1

II REVIEW OF THE LITERATURE ......................................... 27

III RESEARCH DESIGN AND METHODOLOGY ................... 41

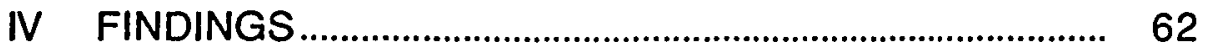

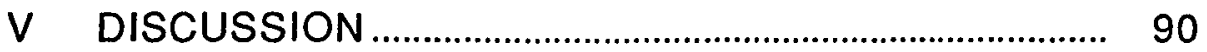

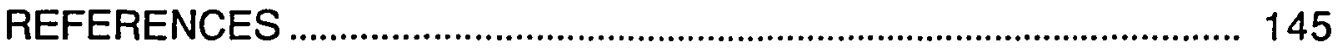

APPENDICES

A INTERVIEW FORMAT ...................................................... 157

B INFORMED CONSENT FORM .......................................... 159

C ASSURANCES AND EXPLANATIONS ............................. 161

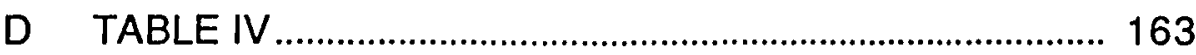




\section{LIST OF TABLES AND A FIGURE}

TABLE PAGE

I Sample Record from Stage 1 Data Input.............................................. 55

II Sample Record from Stage II Data Sort ............................................... 57

III Sample Record from Stage III Data Sort .............................................. 59

IV Data Sort by Attribute/Domain and Respondent/Student Teacher... 163

FIGURE: A Taxonomy of Teacher Attributes/Attribute-Deficits...................... 91 


\section{CHAPTER I}

\section{INTRODUCTION}

\section{The Problem}

New schools of thought about education today go beyond the bandwagon, piecemeal approaches of the past, promising a systemic overhaul badly needed by the American public school system. Often overlooked, however, is the fact that success in restructuring, outcome-based education, consensus-building, site management, team teaching and curriculum integration, project-based authentic learning and assessment, and job- and liferelevant curriculum ultimately rests upon individual teachers. There will be no such long-term restructuring of the system unless these efforts are matched by changes in the recruitment, screening, and training processes which produce teachers. This study focuses on the personal attributes of teacher candidates who did not pass, or perhaps should not have passed, the final screening-point in teacher training, the terminal field experience commonly called student teaching. It is the purpose of this study to identify attributes contributing to failure and failure to thrive in student teaching, as a window to enhanced understanding of what it takes to be and to train a successful teacher.

Many failures to complete and perhaps a majority of failures to thrive in student teaching may be more directly linked to deficiencies in personal attributes than to deficiencies in competence (i.e., instructional skills and content knowledge,) even when the cause reported is technical incompetence. It also appears that, when reported, such attributes or attribute deficits are 
typically ascribed by field supervisors to problems of personality, maturity and attitude.

Personal experience, informal reports from among approximately 30 field faculty acquaintances in Washington and Oregon, informal review of approximately 300 field-faculty evaluation documents over the past seven years, and preliminary review of the literature led the Investigator to initially identify the following broad, tentative categories of attributes, or Capacities, in which many unsuccessful student teachers are apparently deficient. These capacities were posed as an initial framework for the study to be described here. They include the capacity to

- reflect, grow, and participate in change processes;

- recognize the moral and ethical implications of the teacher role;

- nurture self-esteem, learning and acceptable values in students, and

- experience personal efficacy.

The Investigator has further identified, through experience and in the literature, the following phenomena of teacher field experience evaluation, which suggest that concerns over capacities such as those listed above, and the attributes associated with them, are not often addressed. These phenomena are:

- Failures to complete teacher training and attain certification are relatively rare, for many reasons that respondents in this study will suggest, including unclear standards for performance in the terminal field experience (Schalock, 1979;) and ill-defined boundaries for entry into a professional teacher education program (Goodlad, 1990.)

- Failures typically do not occur until the terminal stage of teacher training; i.e., field internship or student teaching, when the effects of failure are 
devastating for the candidate, cooperating teacher, principal, and students in the candidate's field placement classrooms.

- Supervisors and cooperating teachers typically assess success in field experience in terms of performance competencies; i.e., those skills we can reasonably measure and expect to at least partially remediate during the internship, which is to say instructional skills and content knowledge.

- Cooperating teachers are exceedingly reluctant to assess success in field experience in terms of personal attributes; in fact, they are slow to take responsibility for declaring a student teacher "unfit" on any count.

- Field supervisors are also reluctant to judge a student teacher unsuccessful on the basis of personal attributes, and are particularly so in the absence of corroboration of that judgment by the cooperating teacher.

What follows, then, is the assumption that many "marginal successes" in student teaching result from cooperating teachers' and field supervisors' tolerance of minimal standards of technical competence, coupled with a sense of pressure to advance even the marginal candidate, and reluctance to "judge" candidates on the basis of personal attributes, even when they are recognized as relevant or critical.

A second key assumption of this study is that this phenomenon, when it occurs, leaves field supervisors, cooperating teachers, and others with serious concern over who is teaching our children. If it occurs with significant frequency, it needs to be identified as an appropriate source of serious concern for the profession as a whole and the society at large.

Finally, and of greatest immediate concern, is the assumption that meaningful educational reform rests on the success of individual teachers. 
Systemic restructuring of the public school system will not proceed far if teachers are not personally equipped to keep pace.

There is limited empirical foundation for these assumptions offered in the literature. This study was undertaken to identify commonalities between the Investigator's experience and perceptions, and those of other field supervisors. The intent was to investigate both nature and extent of the problem, through interviews expected to corroborate previously identified Capacities, and to generate additional categories (Domains) of attributes warranting further investigation.

\section{Need for the Study}

When student teachers fail, all participants in the process agonize. If the student teacher fails to understand and take responsibility for his/her own failure, the agony for cooperating teacher (mentor) and/or university supervisor is particularly exquisite. No "reasonable person" wants to be responsible for delivering so harsh a blow so late in a student's career (Goodlad, 1990, p. 233.)

Magnifying the pain is the investigator's assumption, based upon extensive experience and subject to confirmation by university field supervisors who will be interviewed in the course of this study, that most student teachers do not fail for want of content area or technical expertise. They fail for reasons much harder to measure and define, and therefore much harder to screen-for, teach or remediate in teacher education programs. Explanations for failure and marginality are suggested in remarks below, each representing a different student teacher and, as a group, fairly representative of explanations solicited informally by the investigator over the past seven years. (Direct quotations from 
respondent interviews are in italics, to distinguish them from references and other kinds of quotations.)

She didn't have the skills. She didn't care about learning them. I'm not even sure she likes kids.

Clearly, she expected this to be a much easier job.

He never seemed quite sure why he was here. When I asked him, he told me he got to the end of his program, realized he wasn't going to be a pro athlete, and then found he couldn't live on the wages of a part-time health-club trainer.

Skill was never the problem. She was technically OK. No heart, that was the problem, I think.

He waited to be told what to do. I never felt he was ready for full charge, because he continued to follow me around. He kept asking for detailed instructions and stuff of mine to copy, and deferring to my authority in front of kids. They never recognized his authority, because he never showed any.

1

On her last day of student teaching, she was still as scared of kids as she was on the first. She spent lots of time working after school. Her lesson plans were OK. But I always had the feeling she wished she could teach them with no students in the room.

At first, I kind of fell for his act. Then I got smart. I started calling him on some of the b.s. He didn't know what to do. I must have been the first authority figure he couldn't charm.

I can teach skills. I can remediate skills. I can't remediate character. I can't even tell you what was wrong with her character, exactly, except that I know she lied to me a few times.

Because of its design, it was important to let assumptions arising out of the generative interview phase further establish the need for such a study. However, since the Capacities listed on page one and below are observed to be essential, and amply cited in the literature as essential to teacher success, it was hypothesized that interviews would produce some assumptions about personal attributes that enhance, or obstruct, these student teacher capacities. 
Need for Capacity to Reflect. Grow. Participate in Change. Most field supervisors do not expect a student teacher to be professionally mature and technically expert. Therefore, capacity for future growth and change becomes a critical dimension of assessment. In the Investigator's experience, phrases like ... open and responsive to feedback; eager to learn; quick to modify ineffective practices; committed to professional growth are a regular feature of summative evaluations of successful student teachers. They are absent from reports on students known to be marginal.

The need for teachers with capacity to reflect and to grow therefrom is also evident and amply documented in the literature on teacher education (Arbreton, 1992; Bowman, 1989; Bullough and Knowles, 1990; Clemson and McTighe, 1990; Duke, 1984; Garman, Fall 1986; Goodlad, 1990; Joyce and Showers, 1983; Knowles and Hoefler, 1989; Kriowles and Sudzina, 1992; Sarason, 1971; Skrobola and Knowles, 1992; Zeichner and Liston, 1987.) Such studies are cited in order to further define this Capacity and its associated attributes in Chapter II: Review of the Literature.

A compelling reason for concern with this attribute in preservice teachers is that it is key to professionalization for teachers in general. Those individuals who are given-to and value reflection will not seek entrance to a profession where reflection and personal growth is not the norm. By sustaining interest in growth, self-reflection is also the mechanism for avoiding burnout in the individual teacher. Ironically, real personal empowerment for teachers at the same time requires and is prerequisite to our attracting the brightest and best motivated individuals into the profession. It is also key to our keeping them.

One particularly important corollary of capacity to grow is willingness to participate in change processes and efforts toward reform. When even a well- 
motivated, reflective, veteran teacher attempts to implement change within the confines of a single classroom, extended periods of time and extensive reassurance and support are required to counter the effects of the disequilibrium that inevitably ensues (Joyce and Weil, 1986.) An orientation toward change and a capacity for tolerating this disequilibrium would seem a highly desirable attribute in a student teacher.

Respondents in this study shed light on these questions: Is it external conditions, primarily, which impinge upon capacity for reflection, growth, and change? Are there antecedent personal attributes that lead to failure to demonstrate this capacity? Corroboration was anticipated for the expected importance of this Capacity in respondents' consideration of attributes associated with student teacher marginality and failure.

Need for Capacity to Recognize Moral and Ethical Implications of the Teacher's Role. Reflection is effective only insofar as the reflector is cognizant of the moral and ethical implications of the teacher role. This requires some standard of what constitutes "bad" and "good"; in short, a moral standard. It is this notion of reflection as a moral activity that is essential to Argyris and Schon's "double-loop learning" (1974,) and to "moral imagination," defined by Green (1984) as the ability to assess things as they are and envision how they may be better.

Unfortunately, it is common for student teachers to be teased by veteran colleagues that their visionary idealism will only last until "practicalities" set in, and for student teachers to report that the classroom (the "real" world with its "real" kids) is a rude awakening quite unlike what college coursework led them to expect. 
Recognition of the moral and ethical implications of the teacher's role is imperative in a society where public education is compulsory, the audience captive, the door often closed, the parent not necessarily included, and conformity too often mandated, The charge to teachers is, in fact, nothing less than stewardship of human lives, requiring a profound recognition of and sensitivity to the myriad intellectual, spiritual and emotional needs of an increasingly diverse population.

It was anticipated that respondents would clarify for the investigator whether the capacity to take the moral high ground is recognized as an antecedent of success in student teaching. What personal attributes characterize those who persist in standing that ground in the face of conditions that work against it? What is it about some novice teachers that causes them to resist the lure of conformity, conservatism, and a priority on control?

Experience suggests that "moral imagination" is not frequently, or at least not explicitly, required of a student teacher. It does not figure in typical assessments of performance except in the rare cases where there appears to be potential for harm to children through abuse of power, denial of civil rights, indoctrination or negative modeling.

It was expected, therefore, that this Capacity might receive the least respondent attention in thinking about attributes related to marginality and failure. The Investigator anticipated that it might be found in this investigation under idiosyncratic labels and in unexpected guises.

Need for Capacity to Nurture Self-Esteem, Learning, and Appropriate Values in Students. Recognition of potential harm to children more commonly takes the form of concern over teacher-behaviors' effects on a student's selfesteem. In fact, many contend that capacity to nurture self-esteem, learning, 
and acceptable values is more important in a teacher than content area expertise or pedagogical skill (Purkey and Novak, 1984; Good and Brophy, 1984; Noddings and Shore, 1984; Weinstein and Fantini, 1975.) Attributes associated with this in the literature are ability to create a positive classroom climate, facilitate self-esteem and confidence, instill in students positive selffulfilling expectations, etc.

It was predicted that these conditions which facilitate learning, and the teacher attributes which facilitate these conditions, would be more important to respondents in this study than instructional styles and strategies. This is because the mechanics, rules and processes of teaching learned through a 12year apprenticeship in public-school classrooms are not, strictly speaking, attributes of the student teacher. Also not identified as attributes for purposes of this study are the styles and action strategies student teachers may learn and adopt to increase the likelihood that students will learn. More to the point here are the less conscious and deliberate features of a student teacher's philosophy, choices, perceptions and habits; along with those patterns of selfpresentation and interpersonal communication which readily yield neither to definition nor remediation. Such patterns may be closer to what we mean when we describe student teachers with phrases like born teacher, good instincts, the right stuff, and the gift.

Attributes which allow a teacher to nurture acceptable values in students are similarly tricky to define. Yet, without a clear understanding of the character and moral attributes we expect our teachers to model, we cannot hope to settle the tough questions around what values may appropriately be taught to students. (The converse is also true, of course, and complicates the problems of teacher screening, training and evaluation.) 
This Capacity has few concrete referents. It was considered most likely of the four to serve as temporany cover term for a wide variety of attribute descriptions associated with "personality," or the student teacher's style of selfpresentation. Therefore, due to recognized lack of precision in our language for features of personality, it was expected to garner many mentions and require the Investigator's careful attention during the categorization process.

Need for the Capacity to Experience Personal Efficacy. Finally, development of all these capacities -- to reflect, grow and participate in change processes; make choices from a viable moral perspective; and nurture selfesteem and learning in students while guiding them toward viable moral perspectives of their own -- may depend in the final analysis upon the teacher's own sense of self, or personal efficacy. Two of the four commonalities Jackson cites in his landmark 1968 study as identifiers of superior teachers are corollaries of efficacy: a strong sense of individuality, and an insistence upon personal autonomy. (Factors which impinge upon these attributes are also commonly cited as causes of burnout and departure from the profession.)

Conditions of public school teaching tend to militate against teachers' feeling personally powerful Powerlessness is not conducive to reflection. The beleagured do not commonly question their own behavior or spend time and energy on personal growth. Student teachers tend to be particularly powerless and beleagured by the conditions of the typical field placement. What attributes cause certain student teachers to assume postures of helplessness or yield to defeat? What attributes cause others to maintain personal efficacy, grow and thrive? Deficits in the capacity to experience personal efficacy were expected to figure prominently among attributes implicated by respondents in student teacher marginality and failure. 
This study of preservice teachers helps illuminate attributes essential to teacher efficacy and success as reflective practitioners, growing, nurturing growth in students, and participating in change processes; as moral agents, capable of distinguishing higher good, and serving as models and teachers of fundamental moral principles; and as socially responsible stewards of the public trust, who recognize the sober implications of the power-to-influence that is inherent in their role.

Intuitively viable, these four capacities were tested for empirical durability during the interview phase of the study. They constituted the beginning of an analysis process that would finally identify specific attribute constructs, group them into domains (a re-naming of attribute categories, to distinguish categories identified by respondents from those tentatively identified by Investigator and temporarily labeled Capacities,) and form the basis for a taxonomy of personal attributes associated with marginality and failure among student teachers.

\section{The Question}

Do student teachers in terminal field experience judged by their university supervisors to have been passed as marginal or to have failed have in common certain personal attributes and attribute deficits?

Scope. The Question was broad in scope, to be narrowed as initial interviews suggested appropriate and realistic parameters. It was viewed as temporary and tenuous, for as new information was provided by respondents and new levels of inquiry were suggested, the Question itself was expected to change or be expanded. 
The viability of so "provisional" a Question is suggested by statistician John Tukey: "Far better an approximate answer to the right question, which is often vague, than an exact answer to the wrong question, which can always be made precise. Data analysis must progress by approximate answers, at best, since its knowledge of what the problem really is will at best be approximate" (1981, p. 338.)

Ultimately, responsibility for defining the problem in this study lay with the respondents. Respondents were given opportunity to suggest alternate explanations, including to select the categories of technical competence and content-area expertise as explanations for marginality and failure. Repondents thereby determined the problem's parameters or scope. Tentative identification of certain categories of attributes labeled Capacities merely provided a framework and an organizer for the interview. Final definition would be left to the data analysis process.

Limitations. There were two components of the study which presented certain limitations: its respondent population, and its design. It could, for example, be argued that the Question may not be best answered by the chosen respondent population. They do not, for instance, have the steady daily contact with student teachers that cooperating teachers have. Cooperating teachers, however, tend to overprotect and idealize their charges, to blame themselves for student teachers' problems, or see them as reflections on themselves. They are also even less likely than supervisors to presume to assess personal attributes, and do not have supervisors' relative objectivity, or training in observation, data collection and conferencing. Failed and marginal student teachers themselves might have been promising sources of insight regarding impacts of field placement context, cooperating teacher selection, university 
program and supervision. They were not, however, judged best qualified to assess the impact of their own personal attributes.

The study was limited to precepts and domains generated or corroborated by the respondent group. This allowed for the possibility that issues of technical competence might become the operative focus, rather than the personal attributes which the investigator intended. The study also was not intended to measure a number of other variables which the Investigator guessed might be significant, unless they should arise during the interview phase with sufficient force to warrant their inclusion. Among those anticipated as additional possibilities were:

1) Contextual influences: Certain kinds of field experience environments may be more powerful determinants of marginality/failure than personal attributes.

2) Life circumstances: Attributes may be situational and transitory, with undisclosed personal problems, for example, causing the student teacher to be temporarily incapable of behaviors deemed critical to success.

3) Observation limitations: Behaviors "seen" by field supervisors may provide insufficient evidence of the attributes in question; observation does not, among other things, allow for measurement of intent.

4) Stress: Student teaching is noted for the stress it induces, which is only increased in most cases by the presence of a university supervisor, and which increases the likelihood that behaviors observed are not representative.

It was not the intent of this study to create a limiting or exclusive profile of the successful student teacher. It was undertaken in the hope, however, that its findings might begin to establish and contribute to a sound knowledge base with implications for teacher education program design, future studies exploring 
predictors of success in teaching, and development of effective screening instruments.

\section{Operational Definitions}

These definitions are original and apply to terms used in Chapters I-III, only. Some will be supplanted in succeeding chapters by better terms or definitions for similar concepts or constructs, as provided by respondents, or the concepts abandoned altogether as irrelevant in light of the data collected.

Capacity. A term used to identify categories of attributes thought likely to figure prominently in interviews with respondents, employed tentatively and temporarily by the Investigator. It served to distinguish the Investigator's own categories from those produced by Respondents in the course of interviews, and labeled Domains.

Domain. A category or sphere-of-influence of a particular set or class of items (i.e., attributes/attribute deficits identified by field supervisors) or incidents (i.e., field-supervisor stories) that identifies or gives a name to the nature of the relationship and commonalities among them. Also, a cover term or name for elements whose relationships are purely semantic. Elements within this cover are called included terms (Lincoln and Guba, 1985.)

Precept. A principle or maxim that serves to define and guide a particular set of behaviors and by which one person (i.e., field supervisors) sets the standard for conduct expected of another (i.e., student teachers.)

Construct. A label-in-use for describing (respondent construct) concepts, processes and behaviors, which are the materials for explaining (investigator constructs) those concepts, processes and behaviors, and assigning them to relevant categories (precepts and domains.) 
(For example: The domain of moral behavior and understanding is defined by some to include the precept responsiveness [Jarrett, 1991; Blum, 1987] which in turn defines such constructs as empathy, sensitivity to others' distress, and being able to understand what kind of help is needed [Jarrett, $p$. 38.])

Attribute. A feature of one's behavior and discourse that describes and defines it for others.

Deficit. A lack or shortage. Here, a lack or shortage of an attribute thought to be associated with success among student teachers.

Attribute/Deficit. A combining used in this text to indicate that both attribute and attribute-deficit together are meant. Synonymous with attribute and/or attribute-deficit.

Reflection. Here, used in the sense John Dewey (1933) intended, when he contrasted reflection with routine action (that action which is guided by impulse, tradition, and authority,) which takes for granted uncritically accepted definitions of reality, and of problems and the means for their solution. Reflection involves active, persistent and careful consideration of beliefs and practices, both as to the grounds for them and the consequences of acting on them. (Within the construct reflection are the attributes of, for example, openmindedness, responsibility, and wholeheartedness.)

Cooperating Teacher. Also called mentor teacher or master teacher, this is a veteran classroom practitioner who assumes responsibility for daily mentoring of the field intern or student teacher, shaping the experience, conferencing before observations, observing the student's teaching, and giving written and verbal feedback following those observations. This teacher's 
evaluation of the student teacher's performance typically becomes part of the student's career placement file.

Student Teacher. A preservice teacher who, having completed virtually all coursework, and all preliminary practica, required for certification to teach, is engaged in the terminal field experience.

Field Experience. Used here interchangeably with terminal field experience, field internship, internship, and student teaching, this is the final stage in most certification programs, and typically consists of nine weeks to a year of phasing into and then assuming full charge of a cooperating teacher's class, or full load of classes, for a period of no less than three weeks. It is not to be confused with other practica, such as September Experience or those practica associated, in some teacher-education programs, with methods courses, which are typically short-term, part-time, and characterized by more observation than participation.

Field Experience Supervisor. Also called University Field Faculty, Clinical Associated Faculty, etc., and (here) field supervisor, this is a professional teacher educator who provides occasional observation and feedback conferences to the student teacher, representing the standards of the university of origin in a final evaluation which typically becomes part of the student teacher's placement file. Level of contact varies widely. Some field supervisors visit only two or three times in the course of a term. (Field supervisors in Washington state are required to document a minimum of 12 hours one-to-one conference and direct observation time per student teacher, regardless of length of term.) 


\section{Method and Design}

Bationale. Ethnographic methods and the interactive interview, in particular, are philosophically compatible with the objectives of this study. That is, the study is intended to be an interpretive inquiry: generative rather than conclusive, inductive rather than deductive, constructivist vs. reductionist. Its aim is understanding, and its concern is as much with process as with product. It is therefore appropriate that in its design and in the analysis of its results, credibility be given to informants' subjective experience and idiosyncratic constructs and precepts.

Evaluation of preservice field experience is an inexact, unsystematic process, with which quantitative measures are incompatible. Investigation of that process has promise of informing practice only to the extent that the Investigator asks the expert respondent to, "Tell me the questions I ought to be asking, and then answer them for me." (Lincoln and Guba, 1985, p. 269)

in a similar context, Argyris and Schon (1974) claim that, in order for real, or "double-loop," learning to occur from research, investigators must involve respondents in defining which variables are to be important and what are the relationships between them, so that "research acts and learning acts serve to reinforce each other. Tightly-controlled subject-researcher relationships contrived to keep subjects in the dark won't provide the minimally-distorted information required to provide guideposts to effective practice" (p. 286.)

Further, it is important that this study model what it purports to enlighten: those methods with greatest promise of leading to substantive attempts to justify teacher decisions, test teacher assumptions, and discover empirical support for deeply-held beliefs about what constitutes success in teaching. Ethnographic methods have such promise. 
Finally, underlying assumptions, which Schein (1983) describes as being taken for granted by 'insiders,' are best studied through measures like interview. In interview, assumptions may be worked out jointly with those willing to bring to the surface their fundamental assumptions and beliefs about the nature of reality. Shared learnings can be created thereby, which can then serve to guide subsequent investigations.

Procedure. The study combines some of the elements of naturalistic inquiry (Guba and Lincoln 1983; Lincoln and Guba 1985; Goetz and LeCompte, 1984); ethnographic research (Spradley, 1979;) and modified analytic induction (Goetz and LeCompte, 1984; Bogdan and Biklan,1982,) as they apply to the collection and analysis of data, and to the development and testing of theory.

A series of interviews of teacher education program field faculty were conducted. The interview was of the "depth" type defined by Massarik as appropriate where investigator and respondent are peers (1981.) The object was to learn from respondents' subjective accounts of their experience with marginal and failed student teachers what they consider to be the key attributes/deficits of those teachers.

By a process of modified comparative analysis of interview transcripts, respondent precepts and constructs, recurring labelings of attributes, and/or emerging patterns of meaning that might be labeled as attributes, were identified. As repetition and clear patterns established "durability," domains of attributes/deficits were labeled.

These interviews were unstructured, open-ended, aimed at helping an elite informant reconstruct experience, and deriving a wide range of perspectives. Fundamental to the design of this study was the Investigator's commitment, throughout every interview, to avoid allowing personal 
assumptions to condition interaction with respondents. Thus could respondents themselves help to determine the variables to be considered in this investigation (Guba and Lincoln, 1983; Goetz and LeCompte, 1984; Bogdan and Biklan, 1982.) Care was taken to maximize responsiveness and flexibility in the interview format, so that the respondents continued to guide the direction and determine the shape of the study as it proceeded. (Bodgan and Biklan, 1982; Dexter, 1970.)

Instruments. In the interview, general opening questions were "funneled" in the direction of greater focus. The expectation was that asking the most general question first will gain the most comprehensive view of the respondent's experiences or feelings, and eliminate the need to ask a large number of specific questions. It also served to avoid "conditioning" the respondent by limiting him/her to a particular frame of reference. It is an appropriate approach where respondents are unlikely to feel reluctance or distrust (Guba and Lincoln, 1981).

A set of pre-scripted questions were prepared, for the investigator to draw upon. Warmup questions asked the respondent to consider the larger picture of his/her practice, in terms appropriate to that individual. For example, for a field supervisor relatively new in the role, the question might be "How would you assess the caliber of teacher candidates you are seeing?" whereas a veteran might be asked, "How has the picture of the typical teacher candidate in field experience changed since you began your career __ years ago?" The investigator relied upon nonverbal prompts and brief verbal questions and cues, to minimize interrupting the flow of respondents' accounts.

The tone of these interviews was deliberately casual, conversational, with the Investigator communicating empathy, encouragement and 
understanding while maintaining a measure of neutrality. It is generally agreed that this mode is most likely to yield elaborate, subtle and valid data (Denzin 1978, Schatzman and Strauss 1973, Lofland, 1971). As noted in Sample, the Investigator was alerted to possible difficulties with establishing certain kinds of reliability, arising out of the increased idiosyncracy of interview sessions that this degree of rapport can produce (Cicourel, 1964.)

Interviews were audio-taped, and transcripts keyboarded. The Interview Format is attached as Appendix A.

In the second phase, interview transcripts were returned to respondents, as agreed-upon in the Assurances, Explanation of Method and Followup form attached as Appendix C. It was hoped this phase would serve to verify accuracy and stimulate further respondent insights.

The Investigator kept a personal journal chronicling the study, recording demographic and professional data on respondents, and recording general impressions. This journal was held in the Investigator's personal files and comprise an audit trail along with original tapes, transcripts of interviews, and respondents' amendments to those transcripts, if any. As data analysis began, the journal was supplanted by a running account of Investigator thoughts and reactions in the data sets themselves.

Sample. Respondents in the interview stage were field faculty of three Washington, two Oregon, and two regional teacher education programs. The sampling was purposive, not random, per guidelines for analytic induction methods in Bogdan and Biklan (1982.) The respondents were invited to participate in expectation of their being able to facilitate development of theory. Their level of expertise and degree of philosophical compatibility with the intent 
of this study was carefully considered. Acceptance of an invitation to interview was voluntary.

These respondents fit Masserik's definition of the "insider," or Lincoln and Guba's "expert group" (1984.) As the investigator's peers, they improve the prospect of rapid progress toward depth and novelty of response. Their credibility is enhanced, say Lincoln and Guba, by the length of professional contact and mutual trust or "prolonged engagement" $(1984$, p. 18) established between respondents and investigator. (It is also a recognized potential confound. Any threat to validity which might arise out of the investigator's close associations with respondents will be addressed as the need arises.)

Recommendations for respondents were solicited from directors or coordinators of field placements. The following three criteria for selection applied:

1) Respondents are faculty of, or (in the case of regional program supervisors) have previous university experience or serve as adjunct faculty for, the six targeted teacher training institutions, with field supervision experience of no less than three years' duration.

2) Respondents are recognized by their peers and have a reputation among their students as expert "coaches" of practice teaching. (Those whose reputation suggests they do not maintain close contact and provide ample support to teacher candidates, or who see their role as one of wielding the "rubber stamp," were not invited to interview for this study.)

3) Respondents are known for their willingness to make hard choices about a candidate's suitability for certification, see themselves as gatekeepers to the profession, and have experience with failing, as necessary, or 
counseling-out as appropriate, those student teachers whose deficits cannot be remedied during the student teaching period.

Informed consent procedures included discussion and signing of the form attached as Appendix B. A thorough explanation was offered of the study and the respondents' part in it; i.e., that their stories will generate both the questions and a range of possible answers, and that the study is working toward naming the problem, as well as suggesting possible approaches to solution (see Appendix C. Assurances, Explanation of Method and Followup.) Any respondent question was answered freely and honestly. There was no covert Investigator agenda.

Data Analysis. A modified comparative analysis method, derived from the work of Goetz and LeCompte (1984), Bogdan and Biklan (1982), Lincoln and Guba (1985), and Glaser and Strauss (1967), was utilized in the examination of interview transcripts. It was the method of choice because it is specifically designed to provide a "grounding" for theory in the social sciences: comparing applicable incidents, integrating categories and their properties, delimiting and writing theory.

Spradley (1979) provides sources of categories into which interviewers' accounts and meanings (cover terms, names and semantic relationships) might be classified. Those expected to be particularly useful in this study included inclusion ( $X$ is a kind of $Y$;) sequence ( $X$ is a step or stage in $Y$;) and attribution ( $X$ is a characteristic of $Y$.) A fourth to be considered was Lincoln and Guba's reinterpretation of Spradley's "cause-effect" source; i.e., mutual shaping ( $X$ and $Y$ are shaped by each other.)

In the second phase, to further enhance credibility or "referential adequacy" (Lincoln and Guba, 1984, p. 301) each interview respondent 
received a written transcript of her interview. The respondent was invited to comment, make changes in the manuscript, suggest new interpretations, correct mistakes, and add any insights and second thoughts.

It was anticipated that data derived from this stage might verify the usefulness of the Investigator's tentative classifications, and the accuracy of selected examples. It might also call into question certain constructs or generate new themes, suggesting new lines of inquiry.

\section{Predictions}

It was appropriate, given the inquiry nature of this study and the parameters of naturalistic research, to avoid anticipating certain results, and thereby to avoid the conditioning of responses or interpretations that might arise out of such anticipation.

The study was undertaken in the hope, however,

- that respondents in the interview phase would produce useful attribute/deficit constructs to explain the student-teacher failures and marginalities in their experience;

- that from respondents' talk would emerge certain precepts (to be expressed as cover terms) about what constitutes success in teaching and a successful student teacher.

- that these constructs and precepts would produce patterns aligning themselves under certain categories or themes -- domains -- compatible with but not limited to the assumptions in Statement of the Problem. further detailed and categorized in Need for the Study;

- that these domains and their included terms would lend themselves to a taxonomic arrangement, or model, sufficiently cogent, definitive, and 
comprehensive to be incorporated into and further validated by subsequent studies; and

- that this taxonomy would have potential as a foundational knowledge base.

By asking respondents to tell their stories, the investigator also hoped to discover novel and evocative "languaging" of such attribute/deficit constructs, precepts and domains, which might prove useful in developing a common vocabulary for talking about student teacher failure and marginality.

\section{Eormat of the Dissertation}

The balance of the dissertation is organized as follows:

Chapter Il: Review of the Literature expands upon references to the literature, including citations appropriate to anticipated respondent-generated attribute constructs and construct domains. In later chapters, literature relevant to respondent concerns will be cited as part of the ongoing process of letting respondents determine parameters of this study. Chapter II addresses a dearth in the literature of studies such as this one, and cites studies foundational to this one on the topics of reflection and growth, moral and ethical perspectives, nurturing students' growth as learners and persons, and personal efficacy.

Chapter III: Research Methodology and Design elaborates upon the Design and Method section of Chapter I: Introduction, and tracks the evolution of the design over the course of this study, giving rationales for modifications and introduction of new elements as the need arose. Its main categories are Introduction, Sample, Criteria for Nomination of respondents by university field experience coordinators, description of Nominees, Sampling Concerns Addressed, Data Collection (including interview schedule, interview format, 
interviewer's stance, and interview followup;) and Data Analysis (stages one through five with tables presenting sample records from each stage.)

Chapter IV: Findings contains the results of respondent review of interview transcripts and selections from data accumulated through the interview phase, and considered in Stages I and II of the data analysis. These data are organized into new preliminary categories (domains) labeled Extrapersonal (containing references to conditions external to the student teacher such as logistical and contextual problems, and references clearly intended as judgments of the quality of the student teacher's training and therefore skills); Irremediable (including attributes not subject to the supervisor's or the student teacher's own intervention, such as limited intelligence and mental or character disorder); Intrapersonal (including stress tolerance, organization, energy, belief system, ego strength, locus of control commitment, passion, effort, reflection, defensiveness, and flexibility); and Interpersonal (including with-it-ness, empathy, ability to relate to students, people skills, authenticity, self-assertion, and articulateness). It concludes with a discussion of Data Analysis Stages III through V.

Chapter Five: Discussion offers an interpretation of findings in light of the original Question, assumptions and presuppositions. Comparisons are drawn between what the investigator anticipated and what actually emerged. Conclusions are presented. Implications and potential applications are examined. Farther-reaching inferences that might be drawn from the data are discussed, and directions for further investigation are suggested.

Chapter $\mathrm{V}$ is divided into sections labeled The Model (model-building process, tests applied to labels, concerns about parameters and focus, corroboration of findings, and redistribution of attributes based on findings;) 
New Domains: Process and Definitions (where rationale and definitions are provided for the final identification of attribute constructs;) The Attributes (the Efficacy Domain, including ego strength, locus of control, flexibility, and reflection; the Relatedness Domain, including ability to relate to students, empathy, self-assertion, and people skills; and the Heartfeltedness Domain, including belief system, commitment, effort, and passion.)

Chapter $\mathrm{V}$ proceeds to brief discussion of three Auxiliary Themes identified by respondents: failure to attract high-caliber candidates, weaknesses in the function of professional gatekeeping, and deficiencies in the teacher preparation curriculum; and a discussion of a preliminary hypothesis (Capacity) which this study does not support.

Chapter $V$ and this dissertation conclude with the Investigator's Recommendations for further research and for application of findings to teacher education in the areas of teaching to and mediating desired attributes, and to screening and gatekeeping at key points in preservice teacher training. 


\section{CHAPTER ॥}

\section{REVIEW OF THE LITERATURE}

\section{Introduction}

This study of personal attributes implicated in failure and marginality in student teaching must begin with a review of other studies which address or shed light upon the problem. This literature review begins with an investigation of the limited extent to which other studies give attention to such attributes, thereby establishing the need for this study. It proceeds to cite studies of preservice education in general that were foundational to this one.

Among such foundational studies are some that focus on adult developmental stages and strategies for mediating those stages; some that attempt to identify and label key personal attributes; some establishing the importance of such personal attributites to success in field internships or teaching in general; and some that recommend changes in teacher education to attract candidates who possess or are likely to develop desirable personal attributes.

Finally, this review cites studies specifically identifying particular attributes relevant to preservice teachers. These studies helped establish the preliminary parameters of this one, providing foundation for identification of the four Capacities which appear on page one; i.e., to reflect grow, and participate in change processes; to recognize the moral and ethical implications of the teacher role; to nurture self-esteem, learning and acceptable values in students; and to experience personal efficacy. 


\section{A Dearth in the Literature}

The fact that personal attributes are missing from much of the discussion of issues in preservice education was a motivating factor for this study. Only two of the papers presented at the American Educational Research Association conference for 1992 concerned themselves with this topic, and many of those prepared between 1988 and 1992 originated with the same group of researchers at the University of Michigan (Knowles and Hoefler, 1989; Bullough and Knowles, 1990; Knowles and Sudzina, 1992; Skrobola and Knowles, 1992.)

Many studies which ostensibly address personal attributes in preservice teachers tend to do so incidentally or tangentially. For example, Knowles and Sudzina in "Personal Characteristics and Contextual Conditions of Student Teachers Who Fail" (1992,) describe via narrative case studies the personalities of student teachers who failed (shy and reserved, a "drill sergeant," uncommitted to teaching, derogatory of students.) They do not, however, explicitly deal with these or any other "personal characteristics" in the final compilation of their results. Instead, they create a taxonomy of implicated circumstances, which in a list of 25 items includes a single item, "Patterns of social interaction," into which all 15 or more personal characteristics implicated in these student teachers' failures by supervisors' narrative accounts are lumped.

Like many recent studies in preservice education, Knowles and Sudzina focus instead on academic difficulties, personal hardship, and the particulars of placement (with emphasis on the latter.) Their conclusions have more applicability to deficiencies in field experience programs than to personal 
attributes of unsuccessful preservice teachers. Indeed, in another paper that same month and year, Knowles and Sudzina (April 17, 1992) offer recommendations for creating more humane and ethical preservice programs through effective screening, evaluation, and placements.

Skrobola and Knowles' (1992) address student teacher attributes from the same perspective as this study; i.e., university supervisors' perceptions, and through semi-structured interviews. They did not, however, directly invite university supervisors to focus on personal attributes that could be generalized, in their experience, across cases of failure, and did not address marginality. Their study focuses instead on philosophies and role identities, attitudes, content area knowledge and programmatic support mechanisms. It further paralleled this one in that another area of focus was student teachers' ability to address student needs. "Failure to create an environment to foster and encourage students' academic and social growth" (p. 17) was implicated in several accounts, accompanied by an unwillingness or inability to address their difficulties or engage in reflection. In general, student teachers in these supervisors' accounts were found to be unprepared to teach in terms of content, management, appreciation of the time and effort required, and planning.

With these studies Knowles et al. support the need for this one. They confirm the literature's inattention to student teacher failure in general. They also make a case and explicitly call for greater consideration of student teacher "predispositions" (Knowles and Sudzina, April 20, 1992, p. 8.)

Eight articies in the 1990 Handbook of Research on Teacher Education (Houston, ed.) are concerned in some measure with student teacher attributes. Fewer than one quarter of the total of 48 give any credence at all to the notion that personal attributes and the values, experiences and developmental stages 
that underlie them may be important to student teacher success. More typical is the unwavering focus on content area and pedagogical expertise, rigorous coursework preparation, and roles and processes of the terminal field experience in Guyton and McIntyre's review, "Student Teaching and School Experiences" (1990, pp. 514-529.)

Computer searches of the literature produced 25 relevant studies over the past ten-year period. Sixteen of these investigate personal attributes of veteran teachers as they impact teacher behavior. Most apply findings in specialized contexts; e.g., teacher effectiveness with Eskimo and Indian children in rural Alaska, teachers' ways of dealing with failing students, the relationship between teachers' personal attributes and their effectiveness with ethnically diverse populations; affective competencies needed by teachers of visually handicapped students.

Only nine of these studies pertain specifically to preservice teachers and/or to teacher education in general. One focuses on locus of control/attribution theory, and use of the Rutter External//nternal Locus of Control Scale to examine attribution of success and failure, and attitude toward authority; and to predict student teachers' problem-solving capabilities (Kremer and Kurtz, 1982.) Another relates student teacher performance as perceived by fourth and fifth grade students to student teachers' self-perceptions of adequacy as measured by the instrument Myself Now, and finds five personality dimensions to be significantly correlated with positive student perceptions: a sense of adequacy, preference for working with children, feeling of being loved, and self-labeled extroversion and emotionalism (Payne and Manning, 1988.)

This survey of literature dealing with attributes of successful teachers suggests that a study which helps to identify personal attributes associated with 
success in field experience could be extremely useful to teacher educators. Before substantive research can be conducted in this arena, a foundation must be laid by such exploratory studies as this one. Such an effort acquires particular urgency if, at some point in this study or subsequent ones, it can be established that critical personal attributes are amenable to intervention, to unlearning and relearning, in the time occupied by teacher training.

\section{Foundational Studies}

The remainder of the studies surfaced via computer search proved foundational to this study by helping to narrow the focus and ultimately to identify the Capacities expected to be instrumental. Four of them applied the Myers-Briggs self-report inventory which classifies people into dichotomous categories along four scales (extroversion/introversion, sensing/intuition, thinking/feeling, and judgment/perception.) Jeri Pfeifer (1983) finds success in student teaching, as measured by cooperating teachers' reports, to be related to the sensing, judgment and extroversion traits. Linda Pratt (1982) relates scores on the National Teachers' Examination to Myers-Briggs scores, finding that the majority of her predominantly black population are sensing types and score below intuitive types on a standardized test, and recommending that both selection and training take into account the interaction between academic qualifications and personality types. Rojewski and Holder (1990) assess personality types of vocational student teachers and find a high prevalence of sensing-judging and sensing-perceptive types.

Marso and Pigge (1990) investigate the relationship between changes over time in student teachers' concerns (from survival-type concerns to teaching-task concerns) and student teacher personality attributes as measured 
by the Myers-Briggs and Rutters scales. The findings are tentatively interpreted to support the argument that personal characteristics as well as environmental factors influence the nature of the impact of teacher training upon prospective teachers.

Hughes (1982) uses the Myers-Briggs, Rutters and Rehfish personality measures, and applies a statistically rigorous design to assess the relationship between an effective cooperating/student teacher match and personal characteristics of flexibility, empathy and self-esteem in the student teacher. He finds only flexibility (as measured by the Rehfish Rigidity Scale) to have adequate validity by the high standard he established, but emphasizes the need for further methodological studies in the examination of teacher characteristics.

The remaining studies yielded by computerized search provided support in the form of expert observation and theorization, rather than of research. For example, work by Sprinthall and Thies-Sprinthall (1987) applies adult developmental stage theory to student teaching. They urge teacher education institutions to create programs that affect, modify, and move teachers in training beyond their current developmental stages.

A similar perspective is under development by Arthur Costa and Robert Garmston, whose latest work in Cognitive Coaching (1993, in manuscript) describes strategies for pacing and leading teachers toward holonomy via the key attributes (labeled by Costa and Garmston states of mind) of efficacy, flexibility, craftsmanship, consciousness, and interdependence.

Sleeter (1990) and others working in the area of teacher sensitivity to cultural diversity recommend the application of Loevinger's model of ego development to teacher education curriculum, especially as levels of ego 
strength relate to moral and interpersonal development, in the form, particularly, of respect for diversity and ability to empathize.

Walter Doyle, introducing The Handbook of Research on Teacher Education (Houston, ed., 1990) notes that teacher education is moving away from an emphasis on the technical to embrace such concepts as teaching the prospective teacher how to "come to terms with the self" or achieve psychological maturity in order to better create supportive learning environments to promote students' growth; and to "inquire into teaching and think critically about their work," with a focus on inquiry processes, and the collecting of data (pp. 5-6).

This combination of desirable personal attributes with a capacity for reflection is echoed in the Handbook in articles by Pintrich (1990), who applies psychological research on teaching and learning to the training of teachers, in particular their locus of control, self-beliefs, and motivation; by Mary Kennedy (1990), whose emphasis is on giving independent thought priority over content in teacher education; and by Kenneth Zeichner (1990), who argues for the "critical approach" and a student teacher who is able to maintain independence and flexibility in the face of pressures to conform. Zeichner goes on to criticize the "functionalist" and "interpretive" approaches to novice teacher socialization, because they view the student teacher as passive or plastic, and the socialization process as moving that student inexorably toward a more bureaucratic orientation, toward dogmatism, and maintenance of the status quo.

Katz and Raths, discussing the mastery/coverage dilemma in teacher education come to a conclusion akin to the assumptions which drive this study; i.e., that specific content of teacher education changes over time, given a knowledge explosion in our field as in any other, so that "the greatest 
contribution teacher education programs (may be able to) make is to strengthen appropriate dispositions of candidates" (1985, p. 301.) They suggest such dispositions as "being accepting, patient, thoughtful, resourceful, experimental, cooperative, open-minded" (1992, p. 378.) Melnick (1989) cites $76 \%$ of his survey-respondent population of cooperating teachers as having placed special emphasis on the qualities of enthusiasm and self-confidence . . . sensitivity and respect concerning the needs and feelings of students . . . and effective communication with students.

Many investigations have focused on the effects of the student teaching experience, challenging popular acceptance of the folk wisdom that more field experience is good field experience (Zeichner, 1987; Tabachnick, Popkewitz, and Zeichner, 1979-80; Walberg, Metzner, Todd and Henry, 1968; Weinstock and Peccolo, 1970.) Silvernail and Costello (1983) investigate the progression of student teacher concerns through field experience, and find that while they tend early in the experience to move away from concern for self and task, and toward impact on students, this tendency begins to reverse itself during the second half of the internship program.

Studies in this arena identify as central to effective teaching many teacher attributes that fall within the categories (Capacities) tentatively set forth in Chapter l: to reflect, grow and participate in change processes; to recognize the moral and ethical implications of the teacher role; to nurture self-esteem, learning and acceptable values in students, and to experience personal efficacy. The following section categorizes additional studies under these Capacity labels.

Reflection and growth. Saphier and Gower (1987) tell us effective teachers are reflective; i.e., "aware, conscious, and deliberate ... doing what 
they do because they've thought about it and it seems like the best thing to do;" and Schon (1983) describes the reflective practitioner as a teacher who "tries to listen to her students: She asks herself, for example, How is he thinking about this? What is the meaning of his confusion? What is it that he already knows how to do? But if she really listens to a student, she entertains ideas for action that transcend the lesson plans ... it must become a rough ground plan for action, a skeleton around which the teacher develops variations according to her on-the-spot understanding of the problems of particular students.

Lortie (1975) maintains that growth is discouraged in teachers simply by the day-to-day pressures of the job. It is also a common experience for student teachers to encounter in the faculty lounge not only passive resistance to change but rampant cynicism over "reforms and band wagons." Zeichner (1987) notes that practice teaching often has the effect of inducing or reinforcing conservatism. Goodlad, Soder and Sirotnik (1991) claim practice teaching may merely "clone" cooperating teachers in the absence of solid instruction and practice in pedagogy prior to the final field experience. Knowles and Sudzina (1992) assert that field experience is as often miseducative as growthful in terms of a novice teacher's willingness to challenge the status quo.

Moral and ethical perspectives. Only one recent study focuses specifically on student teacher attributes related to moral and ethical values. Su (1990), summarizing research findings from a national project on teacher education, describes the moral and professional socialization of teacher trainees in 29 United States institutions, with special attention to educational beliefs, attitudes and values. He concludes that teacher education programs are providing inadequate foundation courses and failing to create a peer culture with shared moral vision. 
Walter Doyle, noting that some field experiences have negative, conservative impacts, suggests that this results in compromises in moral and ethical perspectives. Such compromises, he says, are reflected in increasing priority on control in student discipline, and decreasing priority on student active participation in learning (1990.) Fullan (1993) links participation in change processes with the moral dimensions of the teacher's role. Citing Stiegelbauer's 1992 survey examining why people enter teaching, Fullan notes that the most frequently mentioned theme among student teachers was "to make a difference in the lives of students." He calls this "a clear sense of moral purpose" (1993, p. 13.) Farber (1991) and many others note that such moral purpose is often undermined by the realities of teaching, replaced by "a growing sense of inconsequentiality."

The profound moral implications of teaching, and the need for teachers sensitive to them, have preoccupied many liberal thinkers (Fox, 1991; Illich, 1971; Kozol, 1990; Giroux, 1988; Green, 1984; Noddings, 1984; Jarrett, 1991; Purpel, 1976; Goodlad et al., 1991; Oser, 1986.) Many worry that without this sensitivity, teachers are ill-prepared to teach students those moral and ethical principles generally believed to be fundamental to a liberal education:

Theodore Sizer (1984), for example, maintains we need at the least to be teaching for "character" (which he calls synonymous with values,) and that the key values are "fairness, generosity and tolerance" which he groups under the category "decency:"

People who are in trouble or who for whatever reason are weak deserve a special hand; the big guys should not force their way on the little guys. It is difficult to imagine a citizen who would seriously quarrel with any school that tried to stand for these values (and) difficult to find many schools today that both formally articulate decency as an aim and precisely outline how students can achieve it (p. 121.) 
Sarason (1971) maintains we can safely teach "self-evident" moral truth (defined as any principle whose opposite is unthinkable;) Jarrett (1991) argues for "caring" and "appreciation;" Noddings (1984) for a "feminine" approach. Innocuous as such perspectives may be, the question of whose morals, values and ethics shall be taught -- and vis-a-vis whose culture -- remains so troublesome that many teacher-educators rely upon the doctrine of church/state separation, and their own need to remain impartial and objective, to absolve themselves of responsibility for assessing a student teacher's capacity or teaching a student teacher how to influence students in this arena.

Nurturing students' growth as learners and persons. Even more widespread than concerns about the moral and ethical dimensions of teacher education are those having to do with teachers' ability to nurture students' intellectual growth and psychological well-being. Carl Rogers, arguing for participative and experiential learning for students, says "It is obvious that if prospective teachers are to engage in this kind of stimulation of inquiry among their pupils, they must have experienced it themselves." The same must be said for teachers' affective development.

Many experts agree that the affective domain, and those personal attributes in teachers that serve to motivate, engage, challenge and reward students; create a warm classroom climate, facilitate self-esteem and confidence, and lead to positive self-fulfilling expectations are more important factors in student learning success than are teachers' content area competence or instructional skills. Good and Brophy's hundreds of classroom observations lead them to conclude teachers who do not model appropriate warmth, respect, and courtesy lack credibility with their students and create corresponding deficits in learner success (1984.). Glasser (1990) asserts that traditional 
teaching strategies do not succeed in classrooms where teachers insist on tight authoritarian control, but that a wide variety of teaching strategies can be successful in classrooms where students feel they share the power. Purkey and Novak's influential Inviting School Success (1984) places student self-concept first among prerequisites to learning efficacy. Weinstein and Fantini dismiss as "personally irrelevant" materials and methods that "ignore the learner's feelings" (1975, p. 21.)

However, in this Capacity as in the first two, studies of preservice teachers suggest that they lose rather than gain ground over the course of their field experience. Silvernail and Costello cite numerous studies showing that field experience tends to move preservice teachers toward less acceptance of pupil ideas and less pupil-centered, personal perspectives in general, and toward more rigid, negative attitudes toward both children and teaching. Fuller's 1971 study finds student teachers place self (e.g., getting a favorable evaluation) first among their concerns, the task (e.g., lesson planning) second, and students (e.g., guiding student learning) last.

Personal Efficacy. Finally, many blame failures of teachers to acquire or develop the first three Capacities on a failure in this fourth; i.e., on institutional and contextual factors that militate against teachers themselves having a sense of personal efficacy. For example, Doyle notes in his Introduction to the Handbook that

... process-product research has severe limitations as a knowledge base for teaching and teacher education. In part, the problem is that this research tradition is entangled with the technocratic mentality and external control mechanisms of schooling, so that the findings, despite the best intentions of researchers, are likely to be misappropriated in ways that undermine the professional status, autonomy and judgment of teachers $(1990$, p. 19.) 
Terence Deal:

(in public schools) where wave after wave of reform has weakened cultural values and beliefs, where constant criticism and ridicule have eroded professional confidence, where experience has been devalued in favor of youth, where main avenues for survival have been to hunker down, burn out, or leave, (what is fostered is) an attitude of looking outward and upward for direction and solutions. (1984, p. 135)

This study may help determine whether there are antecedent personal attributes in teacher candidates that reinforce attributes of context, to cause conservatism, burnout and flight. Many previous studies document the significant negative impact of powerlessness on teachers' performance and on their personal interpretations of their professional lives (Rutter, 1979; Lieberman, 1988; Lortie, 1975; Smith, 1988.)

Jackson (1968) cites as one of the four themes in identifying "outstanding" teachers the theme of personal autonomy, which he defines not as an attribute a teacher may simply possess, nor as a function of the "closed door" culture of schools, but rather as a right s/he must actively fight-for against considerable odds. He calls it "intent to strongly resist the possibility of an inflexible curriculum and undue impact on the classroom of administrative presence and standards of evaluation." By his estimate, only the top $5 \%$ of teachers persist at this level of personal efficacy.

By far the majority of teachers respond to low felt efficacy by resisting change and becoming preoccupied with maintenance. Payne and Manning (1989) remind us that the student teacher's sense of efficacy is even more fragile, and threatened by the fact that s/he is under close scrutiny, with a future professional career in the balance. Consequently, few dare to venture thought or behavior different from the cooperating teacher's, let alone from the perceived norms of the culture. Sarason (1971) suggests we take this 
observation one step farther, asking "How many young teachers left the classroom and teaching precisely because they had the relevant characteristics and could not tolerate the interferences or constraints they experienced?" Considering those who remain he adds, "the first two years of teaching are a baptism of fire in which many things can be consumed, including some of the ingredients that make for a good and even outstanding teacher" (pp. 170-71.) Among the qualities burned away: altruism, passion, and idealism.

A sense of powerless begets passivity, a survival mentality often expressed in terms of the very attributes that Daniel Duke (1993) says block professional growth -- especially disillusionment, pessimism, comfort with current practice and fear of failure $(1993$, p. 702.) It is a recognized impediment to teachers' developing critical "voice," to the possibility of educators' raising challenges to domination and oppression (Giroux, 1988). Even those whose traditional role is supervision and evaluation of teaching are recognizing the need for educational reform and accepting the logic that, for reform to happen, they must support teachers' efforts to think "efficaciously" and behave like reformers (Gitlin and Price, 1992; Sergiovanni, 1992; Nolan and Francis, 1992.)

Studies reviewed here merely established the Investigator's early provisional boundaries (the four Capacities and related issues) for a study whose final parameters are determined by the respondents, and presented in Chapters IV: Findings and V: Discussion. Literature relevant to respondentgenerated attribute constructs is cited as appropriate in those chapters. Literature support for methodological decisions is provided in Chapter III: Research Design and Methodology. 


\section{CHAPTER III}

\section{RESEARCH DESIGN AND METHODOLOGY}

\section{Introduction}

The purpose of this study is to examine how university field experience supervisors identify and describe personal attributes associated with marginality and failure of student teachers in the terminal field experience, or student teaching. This intent dictated selection of a qualitative, naturalistic design and method for this study.

In this chapter are the sample selection process, including criteria for nomination, description of nominees, and concerns addressed; data collection stage, including interview format, interview process, interviewer's stance, and interview followup; and the four stages of data analysis, including sample records from Stages I - III (data from Stage IV, complete, are included as Appendix D: Table IV) and presentation of a model (Figure) derived from Stage IV.

\section{Sample}

Respondents were selected from an accessible population of field experience supervisors in programs with which the Investigator is associated in Washington and Oregon Selection began with the Investigator soliciting reputational nominations from coordinators of educational field experience at three Washington and two Oregon university teacher-education programs, and 
two regional field experience programs (the latter drawing field interns from several universities and colleges.) This purposeful sampling as described by Bogdan (1982, p. 67) resulted in an expert group or elite sample designed to facilitate the expansion of developing theory.

Criteria for Nomination. The following criteria for nomination were developed and presented in person or by telephone to nominating coordinators of field experience:

- Minimum experience as a student teacher supervisor of three consecutive years in the current position;

- Minimum average caseload per term of five student teachers;

- Considered by coordinator to be expert in assessing teacher effectiveness;

- Considered by coordinator to be current and expert in matters of curriculum and instruction;

- Considered by coordinator to have established supportive coaching relationships and known to have maintained frequent, close contact with student teachers in their caseloads;

- Shown by their records to be willing to adopt a gatekeeper role as appropriate; i.e., to counsel out, require remediation for, or decline to recommend for certification student teachers whose performance in field experience was unsatisfactory.

The first four criteria were aimed at establishing subjects' credibility. They were easily met by most of a potential sample pool of 97 . However, the fifth criterion, a coaching stance with close supervision and frequent contact, is relatively rare, and reduced the sample size considerably. 
The ultimate size of the sample and the Investigator's experience confirm that the majority of university supervisors make relatively few visits and adopt an evaluator role. The sixth criterion, willingness to adopt a gatekeeper role, grew out of the Investigator's observation that many colleagues in field supervision see themselves and behave as if theirs is a "rubber stamp" function. This is reinforced, in the Investigator's experience, by widespread disinclination among employing principals and superintendents to accept as credible supervisors' evaluations of student teachers.

The request for nominations, therefore, asked field experience coordinators specifically to exclude rubber-stamp supervisors; i.e., those who tend to pass with a positive evaluation anyone who survives student teaching, even those whose performance and skill level are marginal. Combined, criteria five and six reduced the potential sample pool from 97 to 15 .

Nominees. All but two of the 15 nominees were female. Of the 15, one was later found not to have the requisite experience, one was judged to be too closely associated professionally with the Investigator, one was interviewed but the tape unusable due to a recording malfunction, and one declined for lack of time to meet. Eleven field experience supervisors accepted invitations to participate and were interviewed over a period of three months in 1992.

Length of experience of the eleven respondents ranged between three years and 23 years, for an average of nine years. Their average student teacher caseloads ranged from five to 15 per term, for a combined average of 12 student teachers per term. Seven had untenured lecturer or adjunct faculty status, two held untenured assistant professorships, two were tenured full professors. Three had attained the Ed.D. degree, four had Ed.D.'s in progress, and four had M.A. or M.Ed. degrees. 
Sampling Concerns Addressed. Sampling concerns which arose were associated with the Investigator's region-wide work in field experience program coordination and supervision; i.e., all respondents were professional peers. Careful consideration was given to potential confounding effects of the Investigator's prior acquaintance and/or reputation with the respondent group.

A major concern was that participation should be wholly voluntary, without pressure on respondents and creating as few reservations in the respondents as possible. This concern was addressed by the following conditions:

- No respondent was subordinate to the Investigator in any way;

- Coordinators who provided respondent names (and had some measure of authority over field experience supervisors) agreed not to discuss the invitation with potential participants;

- Informed consent procedures described in Chapter I: Introduction and Appendix B: Informed Consent were closely followed, questions invited and freely answered, so that respondents knew exactly the nature and method of the study, and how the results might be used;

- Assurances of confidentiality in matters of personal identity, identity of professional affiliation, and identity of subject student teachers were given and accepted before interviews could begin.

Confidence that this concern could be put aside was increased by the degree of enthusiasm and interest expressed by potential interviewees; clearly, those who agreed to the interview were intrigued by and eager to talk about issues of marginality and failure among student teachers.

Further, respondents clearly felt comfortable divulging experiences, some of which clearly did not make them proud, and sharing problems openly, 
as with a peer capable of appreciating their dilemmas. Respondents gave evidence of taking the questions very seriously, pausing to reflect; explicitly labeling a "good question;" asking for additional time, returning to issues raised to offer second thoughts, to elaborate upon or qualify previous answers.

Only two respondents expressed some concern over anonymity, one on her own behalf and one on her institution's. Both were apparently satisfied with the Investigator's assurances.

Membership of the Investigator in the respondent or expert group proved a further advantage in that the Investigator shared a common language and common experience with respondents, whereby

- rapport and trust were pre-established;

- dialogue could begin at an advanced level, subsuming informational details and contextual givens;

- both interviewer and interviewee could probe and elaborate at a high level of subtlety and complexity.

Membership in the expert group was a potential confound only with regard to the Investigator's maintaining the "studied naivete" needed to "view all responses as new and potentially significant" (Goetz and Lecompte, p. 168.) This stance is essential where the research objective is to surface and discover order and pattern in respondents' discourse, as opposed to creating it. The Investigator struggled, sometimes, to maintain it (see Investigator's Journal note, p. 96,) and found that careful adherence to the principles of active listening was helpful.

In summary, the sample population was derived by establishing criteria for and soliciting nominations from teacher education program field experience coordinators. Once identified, concerns related to the composition of the 
sample group and the Investigator's position within it were addressed. The study then proceeded to a data collection phase.

\section{Data Collection}

Interview Schedule. Interviews were scheduled by telephone and conducted at the respondents' locations over a five month period from August through December of 1992. Care was taken to pick a time convenient for the respondent that would not be cut short by other obligations. In two of the 11 interviews, the interview had to be terminated at 45 minutes or one hour. In the other nine cases, the tape ran as long as the respondent had something to say on the subject. Typical length was between 60 and 90 minutes.

Interview Format. Questions asked in the interview moved from very open-ended conversational questions to more specific requests for stories about marginal and failed student teachers, to specific probings for attributes associated with their marginality and failure. The purpose of the investigation having been previously established, respondents required little encouragement to move in the direction of such specificity. The number of specific questions asked was held to a minimum in order to avoid limiting a respondent's frame of reference. As Guba and Lincoln (1981) predict for interviews where respondents and investigator are already acquainted, respondents demonstrated a high level of trust and willingness to talk with minimal encouragement.

The interview was designed to yield an understanding of how subjects themselves structure the topic (Bogdan, 136). The goal was to let respondents identify both questions and answers. Therefore, it was important to avoid controlling content, by encouraging respondents to personalize their remarks. It 
was also important to phrase interview questions and comments in ways that invited respondents' own words. These strategies are compatible with a study whose objective is creation of a comprehensive taxonomy where any sort of activity is significant (Guba and Lincoln, p. 169,) and in which one hopes to "include as much information as (respondents)are using to organize their worlds" (Spradley, p. 221.) It is appropriate that this compromise be made, for this study should, as Bogdan suggests, provide a rationale for subsequent more structured data collection methods and studies yielding comparable data across subjects (1982, p. 136.)

Respondents tend to be most at ease and responses most complex when the questions invite storytelling. Therefore, the overriding objective in the interview format displayed as Appendix A was to keep the interview openended, gathering as much as possible of the respondent's own language and meanings, and doing nothing to discourage the stream-of-consciousness mode in which respondents were most creative.

Interviewer's Stance. In the interview stage, concern for the Investigator's maintaining an outsider's reflective perspective toward the data was addressed to a large extent by the respondents themselves. Having been made privy to the rationale behind naturalistic inquiry methods, and knowing themselves to be peers and equals, they felt free to correct deviations from the method. For example, there were several instances in which a respondent actively resisted the Investigator's 1) trying to put words in her mouth (No, that's not what I meant, at all), 2) drawing too quick a conclusion (Give me another minute here... I have to think about that), or 3) labeling an attribute in a way she could not relate-to (That's not what I'd call it . . .). Such resistance reminded the Investigator of the appropriate modality, "keeping her honest." It 
provided further assurance that data were unlikely to be tainted and quite likely to be made richer by the fact that Investigator and respondents were members of the same expert group.

The Investigator's primary task in interviewing was to listen as effectively as possible. Her style utilized the following processes:

- putting the respondent at ease,

- actively attending,

- asking for clarification,

- inviting explanations,

- probing for specificity,

- asking for examples,

- encouraging elaboration, and

- paraphrasing.

Regular paraphrasing served four important functions; 1) it helped the respondent review, re-orient and avoid redundancy; 2) it gave the respondent opportunity to correct misperceptions; 3 ) it validated the worth and importance of the respondent's perspective; and 4) it allowed the Investigator to check her own understanding of what was being said. The self-disciplined detachment required to employ these strategies was instrumental in creating and helping to sustain an attitude akin to Goetz and LeCompte's "studied naivete."

Interview Followup. After the taped interviews were keyboarded, transcripts were returned to the respondents for review. The Investigator thanked them again for their participation and invited them to add, delete, amend, and submit elaborations and second thoughts, per Appendix C: Assurances, Explanation of Method and Followup. 
Two respondents returned the transcripts with notes indicating they saw nothing that needed correcting. Five made numerous minor alterations in phrasing, and carefully corrected typographical errors. Three respondents did the same but in addition laboriously corrected what they saw as their own errors in grammar and syntax, and reworded areas where they thought their meaning had not been clear enough. With a few very minor exceptions, these clarifications were unenlightening. What was interesting was the intensity with which several respondents approached the task. They were very concerned lest their meanings be mistaken, and gave considerable time and thought to the review. The three respondents whose editings were most extensive called the Investigator to apologize for keeping the transcripts so long. Regardless, "meaning" was not significantly altered by any respondent's review feedback.

The results of the respondent review were disappointing, in that respondent-edited transcripts afforded no new attribute labels, attribute constructs, cover or included terms. They were, however, reassuring in that respondents found nothing substantive missing from the transcripts, and offered feedback that expressed both their satisfaction with the process and their personal investment in the product.

Verbatim transcripts of approximately fifteen hours of recorded interviews resulted from the data collection process described in this section. From this stage, the study progressed to data analysis using the naturalistic inquiry model described in the next section, Data Analysis.

\section{Data Analysis}

Goetz and Lecompte (1984,) Glaser and Strauss (1967,) Bogdan (1982) and Lincoln (1985) all speak to the need to let meanings arise from and be 
defined by the respondent group. Sample selection and interview processes previously described were designed to facilitate this process. In the dataanalysis stage, however, checks on the temptation to impose categories and create meaning had to be self-monitored and occasioned some anxiety. Excerpts from the Investigator's journal illustrate the problem:

.. I realized well into first examination of the fifth interview transcript that I didn't remember noting references to simple incompetence, to absence of skills in an otherwise "successful" candidate. Selective inattention? must revisit transcripts. (Later) (I find myself making leaps across logic that amount to deciding what I wish my respondents had said; e.g., Fullan and moral change agentry -- how l'd like it to apply! I have to slap my mental hand and be reminded that the data have not yet established this as a clear theme. I must resist the temptation to make it so.

Analysis proceeded through a series of stages suggested by the literature on ethnographic research. The stages represent different ways of manipulating and displaying the data that continue to serve the purpose of deriving units of meaning as opposed to contriving them. Each new stage allowed the Investigator to see with 'new eyes.' Each time the data were reformatted, the results led the Investigator back to the original interview transcripts, and each time, looked at from a fresh perspective, the transcripts yielded new insights and constructs overlooked before, to be entered into the data base.

This recycling did not, however, tend to discredit previous labels and constructs or categories; in fact, it repeatedly reinforced their durability. Taking seriously concepts expressed by the respondents, even when their importance or salience could not be immediately established, the study derived formulations that remained congruent when viewed from different perspectives, per Guba and Lincoln (1981, p. 93.) The recycling process continued through 
four stages, until the transcripts were no longer yielding new constructs and those in use had proven durable and sufficient.

Stage 1. First, conceding to Goetz and LeCompte's claim that for purposes of designing a taxonomy, an activity is important even if it occurs only once (p. 169), transcripts were simply scanned for all references to personal attributes. These were recorded on a Macintosh computer in a Filemaker Pro format that allowed for subsequent sorts by discrete categories. The computer program made it possible to conduct simple counts and measures, isolate specific responses and types of responses for further examination, and track linkages and patterns.

For a preliminary rough grouping used to organize the data input stage, attribute references were separated into two categories: 1) the attribute named (adjective or noun label,) and 2) the behavior described (participial and verb phrases.) It was expected that both categories would yield attribute constructs, somewhat independently of each other. This proved not to be the case. Interestingly, while respondents frequently described a behavior in colorful and provocative language, the descriptions were invariably offered in close association with an attribute label; i.e., behavior descriptions served as elaborations, examples, metaphors for attribute labels, rather than sources of new attributes. The result was fewer instances than anticipated of respondents having no label and relying on description. On the contrary, respondents both had labels and provided additional richly layered illustrations and elaborations to justify and enhance understanding of those labels.

What tended to complicate labeling was that respondents frequently identified attributes indirectly, either identifying an undesirable behavior by comparing it with its opposite, or describing in positive terms an attribute absent 
in the subject student teacher. It was noted that certain attributes had in common usage both negative and positive labels, and others had only one or the other. This helped account for the need to regularly describe attributes in behavioral terms. The categories attribute and attribute-deficit did not remain useful past the initial rough analysis, as the respondent would typically provide a label and/or a behavior description that rendered the distinction unnecessary. (For subsequent stages in the data analysis, it is assumed that an attribute stated in positive terms by a respondent implies a deficit of that attribute in the marginal or failed student teacher in question, or is offered by way of contrast.)

Attribute labels and behavioral descriptions were often accompanied by respondents' related editorial comment, comparisons, generalizations, and productive 'birdwalks.' Those with potential for contributing to the study were included in the database as a Filemaker Pro field labeled Respondent Comments, summarized or, more often, quoted verbatim. Direct quotes were filed for later retrieval to illustrate respondents' attribute constructs.

As the data were analyzed, thoughts would occur to the Investigator about areas of confusion, concepts needing further investigation, and what should be the next steps in data analysis. These were input as a field labeled Investigator Notes. As analysis proceeded, these notes replaced a separate personal journal that had been maintained by the Investigator during the interview process.

Finally, the initial data analysis included identification of the subjects of respondents' stories. So that attributes and behaviors ascribed to a particular individual could be separated from those ascribed to another, the Investigator took care in the interviews to identify subjects by asking questions like, Are we talking about the student teacher who ..., and Is this another or the same 
student teacher? This made it possible to roughly calculate the number of different subject student teachers mentioned, assign numbers to them, and include them in numerical codings of Filemaker records; e.g., Code $1 \mathrm{B1.1}$ is Respondent 1, Tape Side B, Transcript Page 1, talking about Student Teacher Number 1.

The categories in the initial data input were Respondent/Tape Code, Transcript Page Number, Student Teacher Number, Attribute Labels, Associated Behaviors, Respondent Comments and Investigator Notes. Approximately 120 different attribute labels were ascribed by respondents to approximately 70 different subject student teachers. Some of these student teachers were mentioned once; others described more fully. Some measure of a student teacher's "story" (as opposed to a simple description) was recounted in about 50 of these cases. Table I which follows is a sample of the file records from Stage 1.

Stage Il. The next step was to begin the collapsing of attribute labels into attribute constructs. This process of discovering categories of meaning and their included categories through semantic relationships is described by Spradley $(1979$, p. 107.) Categorization was begun by analyzing collections of data for terms that were inclusive. A number of simple names of attributes available in the plural (i.e., more than one kind, more than one way, having more than one part) were identified and listed in an initial scanning of the first interview transcript. The process for the second through eleventh transcripts, analyzed chronologically by date of interview, was to locate an attribute labeled or described by the respondent, and either add it to the existing list, or count it as included in an attribute already identified. 
Certain semantic relationships were more useful in this case than others. While Spradley describes nine such relationships and Lincoln and Guba 12 , only four were viable for purposes of this study. They were Spradley's

- strict inclusion ( $\mathrm{X}$ is a kind of, a way to, or a part of $\mathrm{Y}$,)

- attribution ( $X$ is a characteristic of $Y$, )

- sequence ( $\mathrm{X}$ is a step or stage in $\mathrm{Y}$, )

and Lincoln and Guba's (1985, p. 340)

- mutual shaping ( $\mathrm{X}$ happens when $\mathrm{Y}$ happens, or $\mathrm{X}$ tends to occur in concert with Y.)

Progress toward identifying cover terms was aided by the discovery that relatively few new candidates for cover-term status emerged after the fourth transcript; that is, certain clear patterns were already emerging.

On the other hand, it was at this point also that particular care needed to be taken to avoid force-fitting categories and drawing premature conclusions. Increasing attention to the data was required to avoid overlooking more interesting and idiosyncratic constructs as they emerged. In fact, many of the initial tentative cover terms later did become included terms under constructs capable of more layers of meaning.

An initial list of 41 attribute constructs were then further collapsed by means of the "tacit knowledge" test described by Glaser and Strauss. That is, the Investigator trusted personal judgment in assigning units to categories on a "feels right" or "looks right" basis (in Lincoln, 1985, p. 340.) The resulting categories conformed to additional 'tests' suggested by Guba and Lincoln (1981) to validate intuitive categorizing: recurring regularities; "internal homogeneity" of items (p. 93); meaningful dovetailings between categories; and a minimum of subjective, idiosyncratic observations that fit no category. It was 


\section{TABLE I}

\section{SAMPLE RECORDS FROM STAGE 1 DATA INPUT}

$\begin{aligned} \text { Respondent Code: } & 1 \text { B } 6 \\ \text { Subject Code: } & \text { ST } 4,5\end{aligned}$

Attribute: ego weakness

Behavior: lack of confidence coupled with lack of Respondent Comments:

don't stick out in my mind as two I tried very hard to save Investlgator Notes:

Relationship drawn here and in next record describing EM between confidence level and degree of focus on students. Does passion for kids lend one confidence? Does this notion appear elsewhere?

\section{Respondent Code: $1 \mathrm{~B} 7$ \\ Subject Code: ST 6}

Attribute: passion for kids, love of kids

Bohavior: high energy, positive, optimistic

Respondent Comments:

Investigator Notes:

describing here a ST who should have failed due to multiple strikes against him (include details of story); credits success (and optimism about prospects of success) to these and following attributes

\section{Respondent Code: $1 \mathrm{~B} 7$ \\ Subject Code: ST 6}

Attribute: belief in self

Behavior:

Respondent Comments:

Investigator Notes: 
thought premature at this point to establish another of their criteria, clear differences among categories or "external heterogeneity" (p. 93.) This test was not deliberately applied until Stage IV of the data analysis process.

These tests or criteria yielded 24 tentative attribute constructs which might (or might not) eventually serve as cover terms for purposes of developing a taxonomy. To ensure that these initial categories remained tentative pending further analysis, two fields were added to the data: possible alternate cover terms and possible other included terms. Displaying these allowed the Investigator to constantly cross-reference and compare categories, while proceeding to further analyze the data for semantic relationships.

. From the rough compilation of attribute labels into attribute constructs, analysis proceeded to sorting attribute constructs into three fairly self-evident organizing domains: Interpersonal (having to do with relationships among people), Intrapersonal (having to do with the person's relationship to Self), and Extrapersonal (having to do with conditions external to that person and his/her relationships). During this stage these domains appeared to suffice as temporary organizers, although the assignment to them of certain constructs was not intuitively satisfying.

Included in this stage and entered into the record as a new field was a simple count of apparent occurrences across transcripts of each attribute construct/potential cover term. Finally, respondents' behavioral descriptions and comments were reformatted into a single category and labeled Elaborations. Table II which follows displays sample records from the data set generated by Stage II.

Stage III. It was reasoned that if the findings were indeed to reflect respondents' thinking and not the Investigator's own, further steps needed to be 
TABLE ॥

SAMPLE RECORDS FROM STAGE II DATA SORT

ATTRIBUTE: RELATE TO KIDS

NO.: 12

POSSIBLE COVER: ", empathy, affect, interpersonal, people, social skills

OTHER INCLUDED: love of kids (1), comfortable with kids (2), warmth (w/kids-1)

ATTRIBUTE: EMPATHY (FOR STUDENTS)

NO.: 12

POSSIBLE COVER: ", affect

OTHER INCLUDED: flat affect (4), intuitive (1), responsiveness (to children 1)

ATTRIBUTE: SOCIAL/PEOPLE SKILLS

NO.: 18

POSSIBLE COVER: *interpersonal

competence,

interdependence

OTHER INCLUDED: outgoingness (1), pleasing personality (2), abrasive (1), insensitive (2), hypersensitive

(1), unprofessional (in the sense of too personal) (2), aloof (1), loner (2), responsive (to other adults) (1) 
taken to corroborate the existing 24 constructs and/or further collapse them. As the data were repeatedly scanned from beginning to end, certain constructs seemed clearly to belong together. However, while informed intuition -- the "feels right/looks right" test described by Spradley (1979) -- might have sufficed as a guide, the Investigator chose to delay reassigning and further collapsing constructs in favor of additional tests of viability.

Focus was shifted to two potentially "natural" organizers; i.e., patterns of use by respondents of these 24 and their included attribute labels (which might reveal which were more useful to more of the respondents;) and naturally occurring combinations or aggregates of these attributes in individual student teachers (which might provide corroboration of the intuition and semanticrelationship analysis used to justify current groupings.)

A field was added that removed the transcript page number from the respondent's identifying code, to show Respondent/Tape Side, and Student Teacher Number, for example, $5 \mathrm{~A} 1$. This allowed the Investigator the option of sorting and displaying records by Attribute, Respondent, and Student Teacher. Table III which follows displays samples of the data set generated in Stage III.

Stage IV. When these tests for "natural organizers" produced nothing of particular significance (see Chapter IV: Findings), two further tests of the Investigator's devising were applied. First, transcripts were scanned for instances of attribute labels being used together in the same clause, sentence, or subject-specific description. This "same breath" test helped decide how to modify category labels and which of them could be justifiably collapsed together or included.

Second, a standard of "richness" was applied to the constructs to test for viability as cover terms. Richness was interpreted to mean 1) numbers of 
TABLE III

SAMPLE RECORD FROM STAGE III DATA SORT

RESPONDENT/STUDENT TEACHER: 1B1; 2A2, 2A3; 2B1, 2B2, 2B3; 3B1, 3B2; 4A6, 4A7; 5A1; 7A2, 7A5, 7A6

ATTRIBUTE: EMPATHY (FOR STUDENTS)

RESPONDENT/STUDENT TEACHER: 1B1, 1B3, 1B6; 3A2, 4A2, 4A7; 6A1, $6 \mathrm{~A} 7 ; 6 \mathrm{~B} 1 ; 7 \mathrm{7A} 1,7 \mathrm{A4}, 7 \mathrm{~A} 5,7 \mathrm{A6}$

ATTRIBUTE: COMMITMENT

RESPONDENT/STUDENT TEACHER: 1B1, 1B2, 1B3; 3A2, 3A4; 4A2, 4A3, $4 A 7,4 A 8,4 A 10 ; 6 A 1,6 A 4,6 A 6 ; 6 B 2$, $6 B 3 ; 7 A 1,7 A 4 ; 8 A 2,8 A 3,8 A 4,8 A 7$

ATTRIBUTE: EFFORT

RESPONDENT/STUDENT TEACHER: 1B1, 1B3, 1B6; 2A2; 4A3, 4A5, 4A10;

$5 \mathrm{~A} 1 ; 6 \mathrm{~A} 2 ; 6 \mathrm{~B} 1 ; 7 \mathrm{~A} 2 ; 8 \mathrm{~A} 5$

ATTRIBUTE: FLEXIBILITY

RESPONDENT/STUDENT TEACHER: 1B1, 1B3; 2AG, 2A3; 6A5; 6B2; 7A2, 7A3, 7A4, 7A6

ATTRIBUTE: HOME/FAMILY/WORK ISSUES

RESPONDENT/STUDENT TEACHER: 1B1, 5A1;6A5; 8A1, 8A2, 8A4, 8A5, $8 A 6$;

ATTRIBUTE: RELATE TO KIDS 
mentions by the actual name label considered as a cover; 2) levels and layers of meaning the potential cover label allowed for; 3) preponderance of respondent-generated illustrations, analogies and metaphors related to that label; and 4) the number of included terms offered for that potential cover label by the respondents themselves.

Throughout this stage tests of semantic relationship and the intuitive "looks right/feels right" test continued to be applied. This resulted in some reordering and exchanging of included for cover terms, but no new constructs. Instead, with all labels and constructs readily assignable to existing categories, it was now appropriate to tackle the problem of overlapping data, which Guba and Lincoln call "good evidence that some basic fault exists in the category system" (1981, p. 93).

The task of clearly differentiating and clarifying construct categories, and settling on labels, could proceed at this point because the Investigator was finally confident that the data as organized were faithful to the original language and collective opinion of the respondent group. For purposes of organizing discussion of the findings and providing a graphic representation, a taxonomic model was devised. The objects were 1) to ensure external heterogeneity, or clear differences among, domains of constructs, and 2) to establish the nature of relationships between them. This involved further collapsing and, in some cases, renaming domains and constructs with labels derived from but not necessarily appearing in the interview transcripts.

The model resulting from this stage is presented as a Figure, p. 93. Construction of the model required that the Investigator proceed to final conclusions about the meaning of respondents' discourse as presented in Chapter IV: Findings. It represents interpretation rather than simple 
presentation of the findings. Therefore, the process by which the model was derived is not further detailed, and the model not displayed, until the beginning of Chapter V: Discussion.

All aspects of the method employed for this study and presented in this chapter -- sample, nominating process, data collection through interview, and the four-stage data analysis process -- were designed to facilitate a developmental, constructive process of drawing forth from a select respondent group the meanings they ascribe to their own experience in preservice field experience. Their perceptions of their experience as it pertains to the impact of personal attributes on student teacher failure and marginality are detailed in Chapter IV: Findings. 


\section{CHAPTER IV}

\section{FINDINGS}

\section{Introduction}

The task of reporting findings is complicated by the fact that what is "found" in a study of this nature is not some objective reality, but rather ways of getting "inside the language and thinking of informants" (Spradley, 1979, p. 205.) The data provided by expert respondents and analyzed via the stages described in the previous chapter are only as useful as their translation in this chapter. Presentation must be into terms meaningful to a general audience interested in the subject at hand: personal attributes associated with student teacher marginality and failure.

The challenge in this case is to keep the translation as near to the respondents' own intent, as faithful to their own apprehension of meaning, as possible. It was therefore important to return over and over again to interview transcripts to check the viability of domain and construct labels, and to avoid premature conclusions.

"Translation" in this case does not describe a product or outcome. It describes the process by which meaning was derived and conclusions were reached. To that end, findings will be reported here in the same sequence in which data analysis proceeded.

Stage I (data input) and Stage II (first data collapse and sort,) described in Chapter III, produced a list of 23 respondent-identified student teacher attribute constructs and their included terms, under three umbrella categories or 
domains: Extrapersonal, Intrapersonal and Interpersonal attributes. Although these initial domains were more functional than meaningful, and intended as temporary, they were useful as an early sorting mechanism.

The same labels will continue to serve that function in this chapter, providing headings for the three major categories of data results until they are replaced by labels provided or suggested by respondents. In fact, as analysis of findings proceeded data were further collapsed, new labels were recognized and added, and original labels were rendered obsolete and replaced or discarded. Because this process produced a model that represents the Investigator's conclusions regarding the final data set, it is detailed and the model presented as a Figure in Chapter V: Discussion.

\section{Extrapersonal Domain}

Extrapersonal as used here requires a specialized definition. Included in this domain are respondent-identified characteristics which are clearly beyond the student teacher's control and/or are not seen as subject to mediation within the teacher training context. Extrapersonal in this context also means "outside" the parameters of the personal attributes which are the subject of this study. It is a way of designating -- again, temporarily -- concerns which respondents generated that may not appear to pertain, but must be recognized, until it can be established that they do not outweigh in importance the personal attributes identified by the Investigator as this study's focus. (In fact, this domain was destined not to endure through Stage IV of the data analysis, as detailed in Chapter V.)

Included in this domain were four distinct categories: irremediable attributes (lack of intelligence, mental and character disorder;) problems 
associated with home, family, and work conditions; issues of placement (problems with grade level or difficulties inherent in the placement context;) and skill issues (deficiencies in technical skills required to teach.) The latter were most persistent in their challenge to the study's focus on personal attributes. Indeed, followup studies may be needed to determine the weight which should, in fact, be accorded them.

The distinction between conditions arising from within, and those external to, the student teacher was not arbitrarily or unilaterally made. Indeed, the Investigator at first resisted somewhat respondents' observations that deleterious student teacher behavior that might have been illustrative of negative personal attributes should be excused because of difficulties in one of more of these "external" areas: It really wasn't his fault; the commute was exhausting; or It was just a bad time for her personally; or She'll be OK once she gets rid of that boyfriend. Similarly, once a supervisor had concluded that an attribute revealed a deep psychological difficulty or intelligence deficit that couldn't be helped, she would often herself maintain that the attribute was irrelevant for purposes of this study in other words, these conditions rendered the student teacher's marginality or failure not really his fault, occasioning sympathy rather than further analysis on the supervisor's part.

The decision to reluctantly accord separate status to this domain is reflected in the Investigator's journal: If the respondent believes the attribute or condition associated with marginality or failure was beyond the student's control, then it was. That has to be good enough for me.

Irremediable Attributes. This small set is labeled irremediable because it consists of attributes seen by respondents as being beyond the supervisor's, the mentor teacher's, or the student teacher's own power to correct. This 
category attracted only three kinds of references: 1) mental illness (three references,) 2) character deficiency (two references, one respondent;) and 3) lack of cognitive capacity, or intelligence.

1) Mental illness. A veteran teacher, used by one respondent to illustrate the kind of pathologies she believes the system still allows into teaching, is described as. . wacko. Completely off the wall. Needed to have been told a long time ago to do something else with her life. Not remediation. Out. A student teacher with a flat affect ... unable to look at a group and sense their response and do something with it ... no sense of what they liked is later described as having been diagnosed bipolar depressive. (In the same interview the respondent further illustrates absence of empathy by describing two other unsuccessful student teachers with very similar symptoms, not so diagnosed, suggesting a severity continuum.)

2) Character deficiency. This irremediable attribute is cited with reference to two student teachers in one respondent's experience who were so manipulative and deceitful as to suggest a pathological character disorder.

3) Intelligence. Explicit references by name to the intelligence label were avoided by eight respondents, although some of them admitted to being hard-pressed to avoid it. Two who did address it editorialized:

Lately, it seems like we're getting more of those for whom this is the highest white-collar profession they can aspire to ... (especially) fewer and fewer bright females who have so many alternatives these days.

The marginal student teacher is often a poor student in general (like one who needed help with basic math skills at the elementary level) because ... we get the message "you're not professionals and you don't work very hard and you're not very smart." 
Issues of Placement. All but three respondents were silent regarding the impact on marginality and failure of inappropriate or unfortunate placements. Of these three, one noted that a student teacher might have done better at a higher level; one expressed mild disappointment with an apathetic cooperating teacher; and one said the student teacher had been unprepared for this much cultural diversity.

One explanation for the low number citing placement concerns is that eight of the eleven turned out to have much more involvement in decisions about where student teachers are to be placed than is typical in most university settings. Working as adjuncts for geographically isolated teacher education programs in Washington state, seven of the 11 supervise students placed in communities some distance from campus, and most serve as the university's contacts with the districts where placements are sought. They know building administrators and teachers and help select them. Those who did not have this luxury occasionally blamed in part the context -- a placement arranged by someone else -- for the student teacher's inadequacies, but never exclusive of contributing personal attributes. One, noting how certain attributes could compensate for a bad placement, used this context to illustrate the importance of locus of control with a student who took the setting and went beyond the setting... not letting anything be an excuse.

Home/Family/Work Issues. Problems in this category were cited with reference to thirteen student teachers, by five of the respondents. Most tended to be logistical in nature; e.g., the student . . . had to commute 140 miles each way on Friday night to get back home where he was going to have to put in a 10-hour Saturday and Sunday of work in order to keep his family fed; or was having trouble with child care, or lived with an ailing or needy older relative, etc. 
Two respondents merely wondered aloud if a student teacher's difficulty might have had to do with such problems in the personal life, and three knew their student teachers' situations well and considered the impact of such matters very significant. These three respondents accounted for 11 of the references to home/family/work issues. One of them told several such stories. She supervises in a relatively isolated geographical area where candidates tend to be older, career-changers or late-starters, many with families and complicated lives. She notes all my student teachers at "at risk."

Skill Issues. References to deficiencies in skills required to teach were included in the Extrapersonal Domain provided the respondent indicated that shortcomings in the teacher training program, or other circumstances beyond the student teacher's control, created the deficiency, and not personal attributes. (Where personal attributes were explicitly blamed for the skill deficiency, the reference was included under the relevant personal attribute cover term.)

The size of the category skill issues (arising in connection with 20 of the approximately 50 student teachers whose stories were told in some depth) is pertinent to the fundamental premise of this study; i.e., that student teachers are marginal or fail due more to personal attributes than to skill deficiencies. The category is relatively small in comparison with others identified in this study, but large enough to challenge that premise. Within this category nine of the 11 respondents addressed five areas of concern:

1) Instructional methods: Four of 11 respondents indicated this was a major deficiency in marginal and failed student teachers they had supervised.

2) Classroom management: Three of 11 respondents referenced this skill deficiency. 
3) General knowledge: One respondent cited this, with reference to general literacy and elementary content mastery.

4) Planning skills: Four respondents cited this skill deficiency.

5) General preparedness to teach: Six respondents cited this ias evidence of technical deficits ascribed to program deficiencies. In any case the size of the skills issues category probably cannot be interpreted to be significant. This is because of the way the interviews were set up. For example, in the Informed Consent form (Appendix B) respondents agree to participate in a project entitled "A Study of Personal Attributes Associated with Marginality and Failure of Preservice Teachers in the Terminal Field Internship." In the opening gambit of the interview, respondents were asked "Do you think marginality/failure in a student teacher has more to do with skills or with personal attributes?" While this invites respondents to defend the primacy of skill or any other category of issues if they choose, the combination of these two items in the opening gambit clearly conditioned their responses.

While results in this study should not be taken to mean that personal attributes are clearly more influential in marginality and failure than skill deficiencies, it is true that by far the majority of references to skill deficiencies were offered in close association with key personal attributes. In addition, most respondents clearly took the position that skills could be remediated and attributes could not. Several qualified their position by adding remarks like not remediable in the time we have in student teaching. One of two respondents who took exception to this viewpoint maintained at first that she did not pay particular attention to attributes, that she was primarily interested in and therefore took most notice of things I can do something about, i.e., of skills. It should be noted, however, that as the interview proceeded, and she began 
recounting her experience with marginal/failed student teachers, her position changed markedly.

The second respondent was fairly consistent about focusing on skill issues and giving considerably less weight to personal attributes, saying

There are specific teaching skills that we can talk about that we can teach people -- questioning skills or whatever they are. There are other skills that people need to work effectively in school and I'm more comfortable thinking of them as social skills, personal, interpersonal skills, organizational skills rather than as character and personal attributes that are absolutely unchangeable. I feel more comfortable in that. I'm a teacher and I believe in the power of teaching and learning and people's power to change themselves. And I'm comfortable with saying so and so does these behaviors (because) they haven't learned (for example) the skills of accepting feedback and the social skills, not to be defensive, and so on.

While this respondent insisted early in the interview that skill level might be just as powerful a predictor of marginality and success as personal attributes, there were no stories, either in her interview or in the other ten, of student teachers who failed due to skill incompetence alone. From this respondent's interview, for example:

She'd spell items wrong when kids were brainstorming, correct answers that were already right. She was deficient in all the subject areas. What can you remediate when there's such an enormous gap? How? Have her repeat 5th or 6th grade? Asked, "Was it lack of cognitive capacity, or a failure to apply?" she replied, I don't know. She'd say she had reading problems, I think. But then, come to think of it, she was also really negative: no willingness to admit and no effort to compensate for her knowledge gap (emphasis mine.)

In fact, there were no stories told in any of the interviews about failed student teachers who had had a strong will to improve technical shortcomings. 
On the other hand, stories were common of student teachers who had few skills entering field experience but made amazing progress, thanks to redeeming personal attributes: .

I've seen others whose affect is very high, they're dedicated to teaching, but their technical skills are very low. And l've seen those people change incredibly right up through the last week because they have the commitment and caring for the job and the students. They are willing to change and grow and develop the technical skills.

Another respondent makes a similar point in a different way:

I just don't get this skills thing. You can have two students from the same university, and one will say "I didn't learn a thing, "and she didn't ... and the other will say "I learned so much," and has taken that and used it and is a wonderfully skilled teacher.

A respondent who was asked to "sum up" the attributes that commonly contribute to failure observed that there are only two types who fail:

1) There are student teachers who don't communicate well ... are not confident ... have a lot of issues of their own to work out and don't feel good about themselves. These, she says, are likely failures or marginal passes regardless of skills.

2) There are student teachers who have these people skills, but don't have the (teaching)skills and who don't want to work to get the skills (emphasis mine.)

This domain does not endure as a separate entity through the modelbuilding process described in Chapter V. Attributes categorized as Extrapersonal were sufficiently weak to warrant discarding them or, in most cases, including them with closely associated construct labels. Rationale for such inclusions is provided in discussion of those constructs in Chapter V. Had the domain been more robust, the research Question would have had to be 
modified. As the domain stands, it neither addresses the Question as stated, nor constitutes a sufficiently weighted group to warrant such modification.

\section{Intrapersonal Domain}

This domain was problematical from the start, for while it was fairly easy to distinguish which student teacher attributes clearly impacted relationships, and could be classified as Interpersonal, it was more difficult to distinguish which student teacher attributes did not impact relationships. It contributed to the realization that clear differentiation was an important test of a domain's viability, and that an eventual restructuring of domains would be required. In the meantime, the test for differentiating the two categories was to ask whether the respondents indicated the attribute in question was reciprocal; i.e., dependent to some extent on others' presence and reaction to the student teacher. If it was, the attribute was categorized Interpersonal. If it tended not to be, the Intrapersonal Domain was selected.

Included in this domain are two attributes that might be classified intrapersonal or extrapersonal depending upon individual interpretation, but in any case provided relatively little weight and eventually fell logically under another cover term. These are stress tolerance, and organization. Also included and addressed in this order are energy, belief system, ego strength, locus of control, commitment, passion, effort, reflection, defensiveness, and flexibility.

Stress tolerance. This construct was labeled Intrapersonal with some misgiving. In one case, the respondent described a student teacher who quit when she discovered she enjoyed kids one-to-one but not in groups. This reference was, at the respondent's request, included with the category Relate to 
students; however, the respondent went on to suggest that stress tolerance was a pre-existing condition, and so powerful a player in student teacher success in general that we ought to screen for it. She notes that it can't be taught, and may be involved in many cases where student teachers just obviously aren't enjoying themselves.

Three other respondents noted stress appeared to play a large role in a case of marginality or failure, especially as it applied to intolerance for time limits, deadlines, student activity and noise, but ascribed more blame to such contributing attributes as lack of commitment and lack of empathy. For example, Respondent 7A describes a student teacher who drew her colleagues' unfavorable attention by leaving the building daily during the lunch break. Her supervisor learned that she was leaving to get in the car, just go drive, and collect herself. What appeared initially to be inability to deal with stress proved to be more accurately ascribed to lack of commitment:

She (student teacher) said, "You know what I just realized? This isn't like a college class. I can't decide at the last minute that I don't want to go, or that I'm going to get there when I get there." "That's right!" I said, and she told me she was really going to work on that, make a commitment. But she couldn't. She didn't think she ever could. She just quit.

Respondent $2 \mathrm{~B}$ suggests that student teaching puts an unreasonable premium on this attribute, regardless of both personal attributes and skills. Talking about a student teacher who failed the first time but is now highly successful at another grade level, she says. . it was a terrible thing to put him through. Student teaching is 'way too stressful. It's a stupid system that doesn't work and it's not . . . the longer I work in it the more I don't believe it is a proper training for teachers. 
Qrganization. Organization is another construct that respondents did not clearly identify as belonging to one domain or the other. Referenced surprisingly few times as an attribute in its own right, Organization, like Stress tolerance, tended to be strongly associated with other attributes in the Intrapersonal domain, particularly with Effort and Commitment. For that reason, it is included here. The three respondents who singled it out differed on the degree to which it was remediable. One, who claimed a student teacher of hers couldn't organize an answer, let alone a lesson; ask him what time it is, and he tells you how to make a clock, spoke of it as if it were a cognitive deficiency (which would render it, by the definition given here, "irremediable.") She went on to claim that this student and others "disorganized" in similar ways were unable to make concise, streamline, draw analogies and simplify content so students could understand.

By contrast, another respondent tied organizational deficiency to belief system and skill level or readiness to teach: ... sometimes poor organization reveals a lack of commitment, but (in this case) it was a matter of valuing and priority: He just didn't think it was important and so he wasn't good at it . . yet. (She also conceded that the attribute probably does not yield to remediation in the time available to us.)

Energy. An attribute that at first defied inclusion was energy. Is it an extrapersonal quality having to do with genetics, perhaps, or health? Is it ameliorable? The problem was resolved by noting that respondents mentioned it "in the same breath" with constructs of Commitment and Passion. One respondent, for example, when asked for a definition of energy, responded time-in, value-ing, commitment ... the giving of part of themselves. 
Another (rapping the table for emphasis) said, It (energy) is the fun part, the essence. (Those who have it) treat teaching as problem-solving, figuring out what will work, who you are, and what I can do to help you learn! Respondent 3B describes a pair of student teachers recently in her charge as. . . bubbly: they acted happy to be there, energetic, positive. Their kids were so responsive ... couldn't wait to see what was going to happen next. In this context, then, the attribute was clearly intended and therefore designated as Intrapersonal.

Belief System. The first unequivocally Intrapersonal attribute, belief system is also included later under a different cover. Never clearly defined in the interviews, it partakes of the concept of educational philosophy. It was offered as a cover for and was derived from frequent remarks in the nature of the following:

... couldn't tell me a good reason why he's in teaching. Didn't know how he could make a difference... or even why he would want to.

He (59-year-old candidate with military background) just couldn't take off that very old set of glasses and see teaching as more than telling.

You have to make all these decisions, every day. You have to be grounded philosophically to know where you're going with kids, what's appropriate for kids, what to teach and why.

Ego Strength. With included terms self-esteem and confidence, this attribute was suggested by respondent descriptions of student teachers who have no presence, no voice; who hang back, or physically shake. On the other end of the spectrum a few students were described as arrogant, or know-it-all. Respondents tended, however, not to address this attribute in isolation, but rather as a concomitant of Locus and Flexibility. (It was also associated with 
Defensiveness, but the case was stronger for including Defensiveness under the cover Reflection.)

One respondent blamed lack of ego strength on personal circumstances and inner work the student teacher needed to do before starting student teaching. Another suggested low ego strength could be associated with lack of Passion. Ultimately, it proved viable in its own right. While a few respondents seemed to suggest it was extrapersonal in the sense of pre-existing due to nature and nurture factors, it was retained as a cover in the Intrapersonal domain. This was because other respondents very often made an argument for its remediability, especially via the "confidence breeds confidence" concept; i.e., they asserted that the quality of the student teaching experience profoundly affected the student teacher's evident ego strength for good or ill.

Locus of control. This was another cover term that retained its viability throughout the analysis process, and was included in the final model. Its strength as a cover derived from the fact that respondents tended to identify the attribute in precisely these terms, specifically as external locus of control (nine cases reported;) or reported as such clearly related included terms as blaming and defensiveness. In addition, it was accompanied in the discussions by an impressive weight of verbiage, elaborate rephrasings, and colorful illustrations.

This collection of attributes was implicated about equally with Passion and People Skills in cases where student teachers had to be withdrawn:

When it's always somebody else's fault, there is an inabilty to connect with the child, inability to help the child grow, inability to communicate with parents . . . in other words, total failure as a teacher!

When it went wrong, it was everybody else's fault: students, bad advice from the cooperating teacher, etc. The interesting thing is, she also did not take credit when things went right. 
(Offered by way of contrast) I think of it as "optimism:" she believes in her own prospects to make it, given a little more time, a little more work.

"The blaming thing". . . when you aren't taking responsibility yourself to make changes that have to be made. (Asked, "Is that a quality that characterizes many marginal or failing student teachers?" this respondent answered, Absolutely. All of them.)

In fact, most respondents shared this sense that a pronounced external locus of control was an important factor in the majority, and three respondents implicate it in all cases of marginality and failure. Several respondents also note ironically that locus of control, like several other attributes, seems to be a continuum; i.e., certain student teachers internalize every mistake and failure, blaming themselves for everything. This end of the attribute's continuum was referenced several times as a complicating but not necessarily undesirable trait. It was not clearly implicated in any case reported of student teacher failure.

Commitment. Commitment was closely allied across the interviews with Passion. The decision to retain them as separate cover terms was based upon a clear difference between their included terms. Commitment drew included terms like grit, spunk, will, determination, drive, investment and purposefulness. It was lent strength as a cover by the richness of the stories associated with it:

He left a good job, has already turned down another offer, has a family, must drive 10 hours each way to go home and work 20 hours every weekend. . . and he's still trying really hard to get this right, still convinced he made the right decision. He's got the grit.

The case of the student teacher cited earlier, whose low stress tolerance caused her to leave the building at lunch every day, proved on closer examination to be a case of low commitment. Another respondent believes that, in some cases, attributes contributing to marginality and failure in otherwise capable-appearing student teachers are stress-induced, brought on by a kind of 
culture shock over the realities of teaching. She too goes on to note that in the absence of commitment, these "realities" produce growing uncertainty about teaching as a career choice, and precipitating the emotional trauma that naturally accompanies such uncertainty so late in a college career.

Passion. Passion might be seen as the affective component of Commitment, or as the internal state manifested in behaviors associated with Commitment. Its included terms are optimism, belief, idealism, positivity, enthusiasm, and heartfeltedness. Its presence was easier for respondents to describe than its absence; i.e., student teachers used to illustrate the importance of this attribute were usually success stories: . . she believes in her heart of hearts that she can make a difference; . . . he manages to maintain his idealism under duress; he overcame all the difficulties (of setting, relationship with cooperating teacher, culture barriers) with dedication plus discipline, because of certainty about what it is he intends to teach others.

Both Passion and Commitment were strongly related by the "same breath" test with the attribute Locus of control, and all three were closely associated with Effort.

Effort. Respondents tended to assume the Investigator knew what was meant by effort, and did not offer a great deal of elaboration when they implicated this attribute in marginality and failure. A few referred to weekend hours invested by student teachers, or how late they remained in the building at night. In contrast with Passion, however, Effort was more often illustrated by its absence than its presence in a student teacher:

For some, (teaching) is the path of least resistance . . they're looking for an easy job, summers off, compatible hours.

He'd used up all his energy trying to beat the system, trying to get by with a minimum amount of effort. 
Instead of going home and working, she'd cry. Saw me as a hurdle she couldn't jump, where she'd always been able to jump them before.

He'd gotten his way by whining all his life. Thought I should pass him just because he'd been at it for seven years already, and needed to start earning money.

He realized he wasn't cut out for the classroom when he saw how hard he'd have to work.

This attribute was mentioned in connection with 17 cases cited by seven of the eleven respondents. It was not cited as a single critical factor in marginality and failure; rather, it too was often mentioned in combination with Commitment and Passion. What gave it viability as a separate cover term was the frequency with which it was mentioned, the number of cases to which respondents believed it applied, and the diversity of included terms clearly belonging to it and not to the other covers: lazy, (lack of) rigor, diligence, selfdiscipline, hard work, initiative, follow-through. It was cited regularly both as a potentially ameliorating factor in other attribute deficiencies, or as the decisive negative element in combination with other deficiencies: . . . and he wasn't willing to work at it; or (it could have been) overcome with a little hard work; or s/he made no effort to. ...

This cover was expected to appear in the form of a continuum, with respondents noting that student teachers could work too hard and weaken their own experience and evaluation by becoming exhausted or distressed by less than perfection. In fact, however, no student teacher was faulted by these respondents for having worked too hard, and no marginal performance or failure was attributed to that cause.

Reflection. A significantly weighted construct cited in 19 cases was Reflection. Synonyms and included terms were honesty with self, self- 
analytical, self-assessment, self-critical, know-it-all, seek input, listen, motivated to improve:

... she was unwilling or incapable of looking critically at herself.

... adequate was good enough. I could never get him to look beyond adequate.

This construct clearly was perceived as a continuum: He was too hard on himself, frustrated all the time because he knew what he should do and when he wasn't doing it and just couldn't quite pull it off. It often appeared in the same context with Commitment, Passion, Locus, and Energy. It is a complex cover because it relies to some extent on ability and/or willingness to "receive" data and is therefore associated in the Investigator's mind with Empathy and With-it-ness, as well as implying adaptability, willingness to change, and ability to implement new learnings -- all included under Flexibility. In addition, it partakes of openness to feedback or non-Defensiveness.

Defensiveness. In respondents' discourse, this attribute clearly impacts the student teacher's ability to receive data from supervisors, and perhaps from children as well. It had a relatively weak showing as a cover in its own right, cited in eight cases by six respondents, and was later incorporated into Reflection. The decision to include it in Reflection was also based in part on the "same breath" test; i.e., respondent elaborations linked it with openness to input and feedback, motivation to grow, and capacity for self-criticism. It was cited as the attribute reflected both in helpless tears, and in the "know it all" syndrome; in other words, both were perceived as defense mechanisms against supervisor input.

While one respondent applied the term to a student teacher's relationship with children (. . . threatened by kids, suspicious of their motives 
toward him,) all the rest used it in reference to supervisor and/or cooperating teacher/student relationship: You know. . . the "yeah but" syndrome! orShe responded to feedback with antagonism, and saw the supervisor as hostile no matter what I did.

Until the final model with its more definitive domains was created, Defensiveness occupied an uneasy niche between the Intrapersonal and Interpersonal domains, an ostensibly internal state that does not find expression except in relationship.

Flexibility. This attribute is often cited in the same context as subsets of the attribute construct Reflection. The label is the only one contrived, rather than derived, from these findings. It is used here in the sense that it is used by Costa and Garmston, from whom it was borrowed: ability to see the larger picture, adopt the perspective of another, imagine a better state, consider 'breaking the mold' (Costa and Garmston, 1993.)

An important rationale for use of this contrived label is that it connotes cognitive as opposed to strictly affective processes. Respondents did not frequently refer to subject student teachers' intelligence or academic competence. This absence of explicit reference to cognitive function might appear to be a major gap in the data, but is more likely an issue of relative visibility. That is, certain attributes contain within them or presuppose a high level of cognitive functioning. Flexibility is one of them, as are creativity and empathy, for examples. (Nonetheless, respondents' choice not to clearly identify cognitive ability as an attribute pertinent to their consideration of student teacher marginality and failure is noteworthy.)

The introduction of language that did not occur as such in the interviews was justified by the need to account for a set of included terms for which 
respondents seemed not to have ready language, and which did not have clear relationships to other cover terms. They are adaptability, creativity, riskaversion, implementation (of supervisor/cooperating teacher input,) seeing growth possibilities and ability, in general, to envision.

The Investigator elected to include in this category certain physical behaviors that were often cited in the same breath with the preceding attributes. Respondents apparently perceived these as having the quality of physical manifestations of an internal state; e.g., frozen, physically constricted, rooted in one spot, stiff.

This attribute's subsets were referenced in 22 of the cases cited, by eight of the 11 respondents:

... defeatist. Wouldn't risk applying herself to something new.

... he could not think beyond the moment.

He was sitting at a table when class began, standing in one place while class was conducted, sitting at a table when class ended.

(offered by contrast)... not afraid to take chances.

Several respondents cited such cases to illustrate their conviction that deficiencies in this category led to "telling" as a teaching strategy, or to a style of teaching characterized by low interaction and low relationship.

As has been said, this domain was not satisfactorily inclusive nor clearly enough differentiated from the Interpersonal Domain, which follows. Clues to its lack of viability arose several times; for example, the need -- for want of a good alternative -- to somewhat arbitrarily include Defensiveness as a subset of Reflection. In the final sorting and relabeling that produced the model displayed on p. 93, included attribute constructs from this domain were redistributed 
between the domains Efficacy and Heartfeltedness. These new labels are defined and the processes that produced them described in Chapter $V$.

\section{Interpersonal Domain}

Attributes assigned to this domain were With-it-ness, Empathy, Relate to Students, People Skills, Authenticity, Self-Assertion, and Articulateness. The Interpersonal Domain was more clearly differentiated than the Intrapersonal, on the basis of a test described earlier; i.e., if an attribute impacted and was impacted by reciprocal relationship between the subject student teacher and the supervisor, adult colleague or student, it was included in this domain. Again, however, it is not entirely differentiated, for it contains at least one attribute, With-it-ness, that might argueably belong in either domain.

With-it-ness. This attribute straddles two domains. It is classified as Interpersonal because respondents described it by and large in the context of classroom interactions, using it as is suggested by Kounin (1977.) Respondents elaborate with remarks like the following:

... sometimes oblivious to the real concerns of teaching, what's happening in the here and now.

... incapable of seeing the effects of his teaching and making a mid-course correction. He just couldn't deal with more than one thing at a time.

She seemed not to even notice when her kids were totally lost.

It's that eyes-in-the-back-of-the-head quality.

The borderline quality of this attribute has to do with the fact that it partakes of the Intrapersonal attributes Reflection (because reflection requires that the student teacher step aside and observe self in action) and Flexibility (because flexibility requires that the student teacher step back in order to see 
the big picture;) as well as Empathy (because empathy requires that the student teacher first notice and then attend to the other's concerns.)

Empathy. Empathy and the attribute which follows, ability to Relate to Students, were cited in 12 cases each. Empathy or its included terms affect (flat or low), intuition, warmth, sensitivity and responsiveness were cited by seven respondents. Careful analysis suggested that respondents were using the terms relatively interchangeably, but the temptation was resisted to call them one cover (or integrate them with People Skills, another likely candidate) because most respondents seemed to intend by them different levels of affective and interpersonal depth or intensity.

In the category Empathy, respondents cited cases in the following words:

(S/he is) in tune with children.

Her own emotional needs came first; she was doing actual harm by 'hooking' children emotionally, manipulatively to meet her needs. She had no empathy.

He was unable to look at a group, sense their response, and do something with it. He had no sense of what they liked.

(Explicitly offered by the respondent as an illustration of lack of empathy) Failed to sense the right thing to do at critical times, had no "feel" for it.

A lack of ability to feel what students are feeling so often translates into anger at the students because they aren't doing what the teacher wants.

Relate to students. This attribute construct, with its included terms love of kids, comfortable with kids, warmth toward kids is referenced several times each by four respondents. As is true of Empathy, it is used by respondents exclusively with regard to children; that is, there was no instance cited of a student teacher who could relate well to or had empathy for adults, but not 
children. (Poor relatedness or lack of empathy between the student teacher and adult peers fell under the People Skills cover.)

In the category Relate to Students, respondents offered little variety, typically choosing these words or the term warmth, without elaborating. This was an attribute they expected the Investigator to be able to picture easily or find obvious. Illustrations were limited to variations of the following: She never got beyond the me stage to the kids stage; (and, asked what it means to be able to "relate to kids") . . . he visits with kids, greets kids, acts happy kids are there, seeks their company.

Respondents were typically emphatic, however, about their belief in the impact of this attribute: This, in combination with inadequate skills, can't be helped (remediated): it won't work.

People Skills. This label was selected as cover for a set of qualities respondents applied largely to student teachers' interactions with adults in authority and peers, and largely to interactions of a relatively superficial nature. It was nonetheless considered powerfully implicated in cases of marginality and failure, with several respondents suggesting that manners, friendliness and appropriate social interaction could often make or break a candidate.

Indeed, one respondent recounted being misled, along with a cooperating teacher, by "people skills" that masked other deficiencies (see Authenticity.) Another admitted that she personally found a student teacher hard to like because of attributes or attribute-deficits included under this cover term; i.e., outgoingness, pleasing personality, abrasive, insensitive, hypersensitive, unprofessional (here, in the sense of overly personal, or excessively self-disclosing,) aloof, a loner. 
She had zero social skills. Once during a critical appointment, she ate a bowl of chili and onions in front of her advisor and tried to talk through her food.

She was real needy; would call other student teachers and talk for hours, even though she should have known how busy they all were.

When other teachers passed her in the hall, she'd avert her eyes and never say "Hi." They even complained to me (her supervisor.)

She sat alone in the faculty room and never smiled. That's not good. The other teachers judge student teachers by this.

Authenticity. This label was reserved by respondents for cases of some level of interpersonal duplicity. Its included constructs were manipulative, lying, lack of consonance (says one thing, does another), a good act. These references occurred in eleven of the cases cited, contributed by five respondents.

He really tried to sell us all a bill of goods.

... lacks integrity. I really couldn't trust her.

... only says what he thinks you want to hear.

(re: his reason for teaching) One day it would be his heart's desire; the next, he's only doing it because his parents pressured him. It depended on what impression he was trying to make with me.

He's clever enough to be genuinely dangerous.

Asked, "Deliberately manipulative? the respondent replied:

I've seen that ... for example a student teacher with the COA (Children of Alcoholics) set of symptoms who got the cooperating teacher and myself to enable her to such an extent that ... we couldn't believe she had rooked us into that kind of thing. She had people skills, pleasant, manipulated her way in.

Self-Assertion. The connection between an intra- and an interpersonal attribute is illustrated by this construct: Self-Assertion appears as the interpersonal manifestation of the intrapersonal attribute Ego Strength. It and its 
subsets passivity, nonfrontational, docile, timid, shy, quiet, wishy-washy, and subdued were used to describe interaction with the supervisor (Just sits there and lets me do all the talking) or, more often, with students: Doesn't set -- or sets and then waivers about -- limits with students; and couldn't project at all; and She had no voice, no presence.

The construct also applied to the other end of an attribute continuum: pushy, in their face, arrogant, and was illustrated with accounts like, He said he was too old to have to conform like a kid to the rules that governed teachers in that building. Things like reporting on time and getting a substitute when you're sick. Little things like that.

This attribute construct as defined here was used 15 times by eight supervisors. When the cover Articulateness (see next attribute) was incorporated, the number rose to 19 references by nine supervisors.

Articulateness. Application of the "same breath" test removed early in the process the need for this small separate category. It was clearly linked by respondents to Self assertion and People skills, or was used to connote facile use of language. It did not have sufficient strength to endure as a personal attribute in its own right.

The entire data set resulting from Stages I and II and showing the attribute constructs discussed above, is displayed as Appendix D: Table IV. It is derived from analysis of the input set, including repeated returns to original transcripts. With the attribute constructs, it displays the initial domain designations, included terms, respondents' elaborations, investigator's comments, occurrences by respondent and by student teacher, and identification codes. 


\section{Subsequent Data Analysis Stages}

Stage III. Stage III was an attempt to validate the data set discussed above, demonstrating its utility or lack thereof with two new sorts: by Respondent and Attribute, and by Student Teacher and Attribute. The intent was to further test for clear differentiation, external heterogeneity, logical and "look alike" relationships, congruence from a variety of perspectives, and meaningful "dovetailing" of categories (Guba and Lincoin, 1981, p. 93.)

The first Stage III data sort, using the Claris brand Filemaker Pro program, was by Student Teacher and Attribute. It produced aggregates of attributes and made it seem as if all attributes implicated in that student teacher's marginality or failure had been identified and bunched, or that such aggregates might have some generalizability across student teachers. Upon reflection, this was clearly not the case. In fact, another survey of the transcripts showed that a given student teacher was often recalled specifically to illustrate a particular point, add to a "case" being made by the respondent for a particular attribute's importance, or just to add to a "count" intended to pile up evidence (and there was another one like that, who... ). Often the student teacher would be referred-to in this way and then never referred to again. Therefore, failure to produce by Filemaker Pro sorting an aggregate of attributes does not mean there was no such aggregate and, conversely, the identification of an aggregate cannot be taken to mean that it was in any way complete, even in that given case. A sample record from this unproductive step is displayed as Table III: Sample Record from Stage III Data Sort.

Similarly, while a subsequent sort by Respondent and Attribute was interesting, it merely suggested that certain respondents did not use certain constructs while, in general, the distribution was even enough across 
respondents, and the gaps small enough, to corroborate instead a relative homogeneity in respondents' use of the constructs.

Stage IV. In this stage respondent constructs were examined for durability via tests of "richness" and naturally occurring combinations (the "same breath test.") These tests were applied to validate the constructs, modify the labels, collapse similar cover terms into single sets, and re-label constructs and domains. This process is described in detail in Chapter III: Design and Method. The results are displayed as Appendix D: Table IV, and were used to construct a graphic advance organizer, or model, as a framework for Chapter V: Discussion.

The model which resulted is displayed as a Figure, p. 93. Details of the process by which it was derived are included in Chapter V. The decision to include them in the Discussion was based on the fact that Stage IV, subsequent model-building, and associated discussion introduce Investigator-devised domains and new domain cover terms, groupings and interpretations which are not in themselves findings. Rather, they represent the Investigator's own tentative conclusions about the meaning of her findings. They are appropriately detailed in Chapter V: Discussion because they 1) represent a process, rather than a product; 2) provide rationale for the Investigator's Conclusions and Recommendations, and 3) constitute a departure from absolute adherence to respondent-generated labels.

The questions which guided the writing of Chapter IV were tentative: 1) How do respondents explain the relationship between personal attributes and student teacher marginality and failure? and 2) Are there patterns apparent in the data that might guide the drawing of conclusions faithful to the intent of those respondents? The object was to present data in a way that maintained 
their integrity. Chapter $V$ will be an attempt to answer these questions more definitively, drawing conclusions. These will be presented in the form of a collapse of results into fewer, more logical or meaningful categories, with accompanying discussion that makes clear the patterns perceived and applied by the Investigator. 


\section{CHAPTER V}

\section{DISCUSSION}

\section{Introduction}

In this chapter the data analysis process is continued from a theoretical perspective. The process which led to a model, to redistribution of Attributes into renamed Domains, and to clear identification of specific attributes implicated by respondents in student teacher marginality and failure is discussed step-by-step. Domains and their included Attributes represent the Investigator's conclusions. Implications of those conclusions are addressed in the discussion of each attribute in turn, followed by Auxiliary Themes which emerged from respondents' discourse. These include concerns about the profession's failure to attract high-quality candidates, weakness of the gatekeeping function, and deficiencies in teacher education curriculum. Finally, an Unsupported 'Hypothesis,' or Capacity, is investigated, before the Discussion progresses to the Recommendations with which it concludes.

The theoretical framework for this Discussion is provided by a model displayed as a Figure on the following page, which was derived from the final stage of data analysis. In this stage, data collected about personal attributes associated with marginality and failure in student teaching were organized into a coherent whole. The resulting model represents the Investigator's own thinking about respondents' language and meanings, while remaining faithful as possible to their intent. It is presented here as an advance organizer for, and graphic conceptualization of, the Discussion. 


\section{FIGURE}

\section{A TAXONOMY OF TEACHER ATTRIBUTES/ATTRIBUTE-DEFICITS}

Bridge:

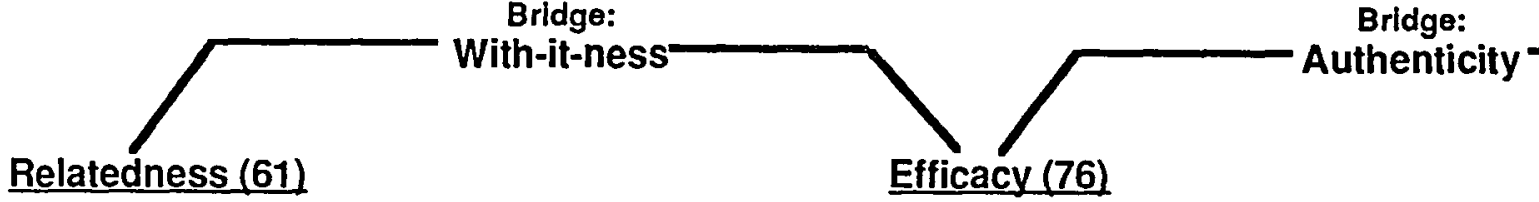

Bridge:

Efficacy (76)
Heartfeltedness (58)

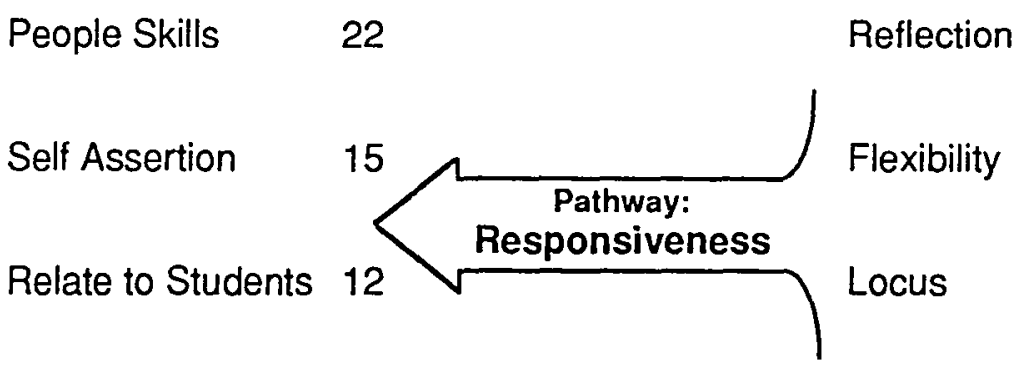

Empathy
Passion

22

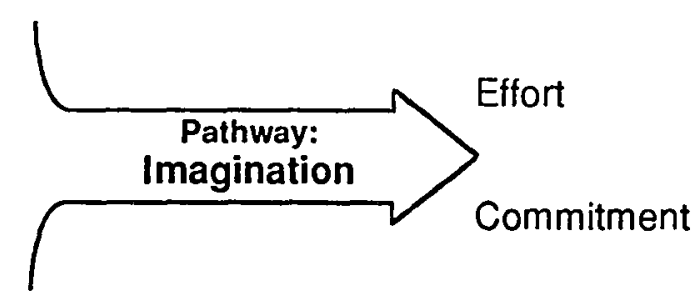

Belief System

\section{DEFINITIONS:}

Relatedness: Matured beyond egocentricism and motivated to disclose Self, actively seek meaningful productive engagement with other people, and effectively respond to other people's feelings and needs. A related person might be termed able to move bevond Self to Other.

Efflcacy: A state of engaged, enabled autonomy characterized by a sense of control of one's destiny, and belief in one's own power to perceive and act upon the need for growth and change. It implies an ability to envision an improved state and an improved self. By this definition, an efficacious person might be said to be empowered from within te grow.

Heartfeltedness: Belief in the importance of teaching that partakes of the qualities of calling and mission, and is demonstrated in degree of effort, commitment, apparent enthusiasm, and intensity of engagement with the client and the task. A person whose behavior can be described as heartfelt might be said to bo fueled from within to pursue a vision.

(The numbers above, indicating frequency of mention, are included as a point of interest. They should not be construed as a measure of relative weight or importance.) 
As explained in Chapter IV, attribute labels originally assigned to the domain labeled Extrapersonal no longer appear. If mentioned fewer than three times, they have been discarded or, as appropriate, have been incorporated into other constructs with which they were closely associated by respondents. That is not to say, however, that factors 'external' to the student teacher or to the student teacher's power to change within the given time are an inconsequential consideration in student teacher marginality and failure. It merely acknowledges the Investigator's purpose and the fact, also previously noted, that respondents' focus on personal attributes is the expected outcome of the Investigator's perspective as expressed, for example, in the wording of correspondence with respondents and interview questions.

The Model Building Process

Stage IV's final sorting and categorizing of student teacher attribute constructs resulted in the model displayed as a Figure on p. 93. New domain and construct labels were selected from respondents' language or borrowed from the literature on personal and teacher attributes. Decisions made in this stage included incorporating a few weak attribute labels into others that were stronger and sufficed.

\section{Tests applied to labels}

The domain and construct labels selected were deemed powerful by virtue of the following tests:

- frequency of mention as such (by the label in question,)

- clarity (avoiding multiple definitions,) 
- inclusiveness (providing an umbrella for a substantial number of attribute labels,)

- novelty (where a given term suffers from general overuse or triteness,)

- durability (remaining viable through trial redistributions,) and/or

- utility (for example, replacing terms Investigator and respondents had used for lack of better, but had agreed lacked referential adequacy.)

\section{Concerns about focus parameters}

The method of this inquiry requires that the Investigator remain in the "receiving mode" throughout, letting respondents dictate the shape of the question as well as potential answers. Consequently, the model-building process brought with it misgivings recorded in the Investigator's Journal.

I've had to return to the transcripts yet again, wondering if my respondents have given me clear authority to do what l intended to do from the beginning; i.e., focus on personal attributes. Did they voluntarily support this perspective, or did I engineer it? I'm satisfied l can proceed. Being "on my honor" made me especially scrupulous, I think. Still, I won't be completely satisfied until I see results of a subsequent large survey in which there is less "loading" in favor of personal attributes and skill/competence is clearly one of their choices.

The case for proceeding with confidence rests largely on the fact that all but two of the eleven respondents gave enthusiastic assent and considerable credence to the idea that personal attributes were more influential than content or pedagogical expertise in student teacher marginality and failure. Further, both respondents who did not support the Question explicitly provided narrative examples of marginality and failure that supported it implicitly; e.g., by 
implicating lack of commitment in failure to adequately plan, inflexibility in deficiencies in pedagogical repertoire, etc.

\section{Corroboration of findings}

Confidence to proceed with the categories which follow was further enhanced by corroboration from others who have ventured to name attributes critical to success in teaching. Knowles and Skrobola's (1992) supervisors implicate in student teacher failure characteristics of inflexibility, lack of with-itness, lack of empathy for students, absence of passion and effort, warmth and positivity; and ineffectiveness in social interaction. Daniel Duke (1993) identifies among his "personal barriers to professional growth" pessimism and high comfort level with current practice (shown by these respondents to be associated with deficits in internal locus of control, ego strength and flexibility.) Fullan's (1993) recommendations for restructuring teacher education include emphasis on cultivating in teachers elements of Relatedness (his are commitment to honoring diversity, and valuing collaboration;) Efficacy (his are listening to the "inner voice", openness to risk, and reflection "in, on and about action" [p. 17];) and Heartfeltedness (which he defines as commitment to lifelong active learning, belief in all students' right and ability to learn, and personal mission to serve the public good.)

Jackson's (1968) landmark study finds four themes in his respondents' descriptions of outstanding teachers: immediacy (sensitivity to the here and now, a state of constant vigilence;) informality (emphasizing freedom of movement and thought;) individuality, and autonomy. Finally, sixty years ago Dewey defined reflective action as partaking of three key "attitudes:" openmindedness (echoed in these respondents' Reflection and Flexibility 
constructs,) responsibility (found here as the construct Commitment,) and wholeheartedness (echoed in the domain Heartfeltedness) (1933, p. 17.)

\section{Redistribution of attributes based on findings}

Twelve of the attribute labels generated by respondents originally included under cover terms Intrapersonal and Interpersonal remained durable for the next sort of categories. The remaining eleven of the 23 attributes arrivedat in Stage IV were redistributed as follows:

1) Attribute labels in the Extrapersonal Domain and therefore abandoned at this point were Issues of Skill, Home/Work/Family, and Placement, along with the group called Irremediable Attributes (intelligence, and clinical-psychological or character disorder, etc.)

2) Organization, which respondents themselves ascribed variously to lack of college preparation, philosophical commitment to "flexibility," and lack of commitment to the profession, and which was mentioned in connection with only three cases, was discarded for lack of clear referent.

3) The following attribute labels became included terms under new labels:

a) Articulateness, which upon re-examination appeared to have connoted simple verbal facility, was incorporated with People Skills.

b) Defensiveness was almost exclusively associated with supervisor/student teacher conflict over perceptual differences, and in the context of inability to reflect on own practice; therefore, it was incorporated with Reflection 
c) Energy proved to be virtually synonymous with Passion as used by these respondents and was absorbed into that construct. d) Stress tolerance was an issue in only three instances and in each case seemed to the respondents to be a combination of culture shock and career-choice indecision; hence, it was incorporated with Commitment.

4) The attributes With-it-ness and Authenticity came to occupy positions of their own, as manifestations of attribute domains which span the boundaries between them. They are shown in the model as "bridges."

New Domains: Process and Definitions

Twelve remaining attribute labels survived the test of exclusivity; i.e., they were clearly differentiated, and corrected the problem of overlapping data mentioned in Chapter IV. These attributes sorted readily into three new construct domains that remained durable and intuitively viable through several subsequent trial configurations. Language in the affective and psychological domains being notoriously "slippery," the labels for these new domains were not immediately obvious. Since the object of re-labeling was to achieve clarity and elegance, many potential construct cover labels were rejected because of their multiple connotations. Several trial sets were tried, each requiring a return to the interview transcripts and/or the literature for corroboration.

In the final analysis, the intent of the original domains endured, although their labels did not: The Interpersonal Domain persisted as a construct in its own right re-labeled Relatedness; and the Intrapersonal Domain broke down into two new domains, labeled Efficacy and Heartfeltedness. 
Respondents tended to offer ample explanations and illustrations that served to define their own labels for attributes. Those that originate with the Investigator need similar elaboration. Therefore, working definitions are presented here, as is some reflection on the thought processes that produced them. This will include discussion of both the domain designations themselves, and an element newly introduced via the model; i.e., the bridges and pathways by which the domains are related to one another, and their boundaries spanned.

\section{Demain 1: Efficacy}

This domain was a candidate for the label Autonomy; however, the term is one example of the multiple connotations problem. It is commonly used to describe both the de facto isolation of the teacher's work, and the notion of selfgovernance. What the model needed was a domain label that combined autonomy, in the sense of self-directing and self-correcting behavior, with something like what Robert Garmston calls "autoplasticity: the capacity to mold themselves from experiences" (1993, p. 62). Also needed here was the action orientation suggested by respondent constructs like flexibility and locus of control; and the sense of empowerment suggested by respondents' use of the terms ego strength and reflection. This complex combination was provided by the domain label Efficacy.

Definition: A state of engaged, enabled autonomy characterized by a sense of control of one's destiny, and belief in one's own power to perceive and act upon the need for growth and change. It implies an ability to envision an improved state and an improved self. By this definition, an efficacious person might be said to be empowered from within to grow. 
The construct Efficacy occupies a central place among the three domains. As suggested by the model, it may even be interpreted as the set of capacities from which the other two sets derive. Also suggested by the model are the pathways of connection: with Relatedness via responsiveness, and with Heartfeltedness, via imagination.

Two respondent-generated attribute labels that represent boundaryspanning manifestations bridge the gaps between constructs: With-it-ness, a manifestation of Efficacy that bridges to Relatedness; and Authenticity, a manifestation of Efficacy that bridges to Heartfeltedness.

\section{Domain Il: Relatedness}

The next set of attributes echos another Costa and Garmston "state of mind," which they label "interdependence." It is intended to encompass that state. It is clear, however, that respondents' focus was at a more shallow level than Costa and Garmston's; i.e., on "outgoingness" in the sense of freedom from self-absorption, and on simple gregariousness. The label needed to partake of these qualities, as well as suggesting initiative and facility in relationship specifically with peers and children, a focus better suggested by the adopted term. Again, central to this construct is the respondents' strong intimation that Efficacy is what fuels responsiveness; responsiveness leads to people skills, empathy, ability to relate to students, and self-assertion; and the combination of efficacy and relatedness manifests in the "bridge" of With-it-ness.

Definition: Matured beyond egocentricism, and motivated to 1) disclose Self in appropriate ways, 2) actively seek meaningful, productive involvement with other people; and 3) effectively respond to others' feelings and needs. A related person might be termed able to move beyond Self to the Other. 


\section{Demain Ill: Heartfeltedness}

The third domain called for a construct label with "energy," reflecting the animation and emphasis with which Respondents focused attention on effort, passion, commitment, and belief. It is the attribute group least amenable to concrete definition, and yet clearly most powerful from the respondents' perspectives. It is not something we typically imagine being able to teach someone else. Garmston, for example, does not propose "coaching" strategies that might move a supervisee toward this state of mind. Words often failed respondents as they attempted illustrations of this construct: ... she just had that something. She was a natural. They radiated enthusiasm. ... a spark... fired-up. Indeed, it is probably safe to say that this domain would have attracted many more case references had there been more, and more precise, language available for it, and had respondents not been shy of venturing into the ineffable. The term engagement was considered and seemed apt, except that it is most often used specifically with reference to interactions among people, and it was important to select for the model terms that did not require immediate redefinition. Commitment lacked affective impact due to over-use. Heartfeltedness, while awkward, had both the dynamism and the self-definition that the construct warranted. Respondents appeared to associate it very strongly with optimism, connecting it with Efficacy via the pathway of imagination, and suggesting that its manifestation Authenticity provided a bridge.

Definition: Belief in the importance of teaching that partakes of the qualities of calling and mission, and is demonstrated in degree of effort, commitment, apparent enthusiasm, and intensity of engagement with the client 
and the task. A person whose behavior can be described as Heartfelt might be said to be fueled from within in pursuit of a clear vision.

The Attributes

\section{Efficacy Domain}

As previously noted, respondents tended to position attributes in this domain in fundamental, pivotal and causative roles; hence, its position in the center of the model. This domain is a combining of attributes that happened (without design) to contain internal states which the model reveals to be foundational to the observable behaviors in the other two domains, Heartfeltedness and Relatedness.

Costa and Garmston (1993) assert "(efficacy) may be the most catalytic of the five states of mind ... should teachers' efficacy be robust, they are likely to spend more energy at tasks, persevere longer, set more challenging goals and continue in the face of barriers and occasional failure" (pp. 6-7).

Fullan (1982) cites teachers' felt efficacy as a factor in successful implementation of curriculum change and staff development. A number of studies evaluating programs to enhance teachers' self-efficacy, specifically with regard to their sense of their own technical content mastery and ability to cope with change, report statistically significant gains in the academic performance of students of those teachers (Rosenholz, 1989; Berman and McLaughlin, 1977; Fuller, et al., 1982.)

Ego Strength. Respondents reference this construct by name (or as lack of self-esteem, absence of self-confidence) as material in marginality and failure. It is typically reported as part of a syndrome rather than as a cause in 
itself. One student teacher's ego weakness is described as lack of confidence coupled with lack of passion. Its opposite (that is, sufficient ego strength to decide against teaching as a career) is also noted by respondents, one of whom reports I just had a bright one quit after the first practicum. She noticed educators get no respect.

The social devaluation of teaching further leads young teachers to identify less than proudly with their occupation. They report that love of the work does not compensate for the profession's social status and members' low income and low self-esteem (Feiman-Nemser and Floden, 1986,) viewing it (with society at large) as ordinary work for ordinary women (Biklen, 1983.)

Corroborating the decision to include ego strength with other attributes in the Efficacy Domain is work in the stages of ego development, which are labeled by McNergney and Carrier (1981) citing Loevinger (1979,) as Presocial, Impulse, Self-Protective, Conformist, Conscientious, Autonomous and Integrated (an extremely high level of functioning rarely found in any population) In this scheme, the Conscientious and Autonomous individual has become self-aware and self-critical (here, reflection), internalized responsibility (here, locus of control), and learned to value and support the differences of others (here, flexibility) (pp. 140-141.)

Numerous measures of ego development are included in the work cited above; however, several respondents note that we should be careful not to prejudge on the basis of this quality. They tell stories suggesting that "weak ego" is a common condition for young teacher candidates facing what is often their first significant encounter with students from "the other side of the desk." They further suggest that a successful student teaching experience can be powerfully confidence-building. 
Locus of Control. This construct has been popularized in studies of peak human performance (Garfield, 1986) and resiliency in at-risk students (Garmeezy and Rutter, 1983.) It is cited in the interviews, typically by this name, as a very powerful determinant of marginality and failure, amply illustrated by a rich array of stories, some of which suggest that lack of internal locus of control is endemic in both the public school and teacher training systems:

I had one threaten to quit because he found school a depressing place to work. . complained of low morale and negativism in the teachers' lounge and teachers' conversations. "That won't work. These kids don't care. This kids comes from this . . or that . . kind of family."

She (a failing student teacher) wanted to know: "How did I make it this far?" The professors were at fault, you see. When I removed her from the placement she said to me, "I hope you have a good life; you've just destroyed mine."

The theme of "imagination" runs through the Efficacy Domain in general, and this attribute in particular, where respondents talk of student teachers' inability to picture herself ever succeeding, or to even imagine being happy teaching, or to share with me a vision of what it means to be a teacher. Their stories illustrate conditions exactly opposite to Garfield's "peak performers," described as having "virtually unassailable belief in the likelihood of their own success" $(1986$, p. 8.)

As noted in Chapter IV, this attribute was mentioned with such regularity that by the fifth interview the Investigator, exploring the concept, asked a respondent whether it was a factor in all cases of marginality and failure and got this answer: Absolutely. All of them. It also served as a reminder that whether a personal attribute receives scant or abundant attention may have much to do with whether there is available satisfying language with which to talk about it. 
There is ample "same-breath" evidence in the transcripts that respondents associate external locus of control with the pessimism and defensiveness that keep student teachers from responding positively to feedback and implementing suggestions for improvement. It is, as might be expected, closely associated with failure to reflect.

The literature on resiliency tells us that what makes the difference in the occasional child who survives all the socio-economic predictors of academic and social failure may be one grandmother, one coach, one teacher who instills in that child a belief in her/his ultimate power to alter destiny, who trains him/her to believe that success and failure are directly attributable to the individual's own choices. Respondents wanted to believe they could help candidates acquire this faith; however, even those who prided themselves on excellence as mentor-coaches decried the system's admitting so many whose attribution theory was already implacably other-oriented.

The link with resiliency in children merits further exploration. Can a teacher who does not model an internal locus of control assist a student at risk to rise above his/her fate? Sadowski and Woodward (1983) demonstrate a relationship between teachers' locus of control and students' origin climate perceptions (that is, students' feeling they have freedom to choose or originate classroom activities, set their own goals, feel confident, and take responsibility for their own performance.) They build on other studies showing teachers with internal locus of control to be more democratic toward students in both attitude and practice, more encouraging of self-directed behavior, more likely to maintain organized learning environments (Brophy and Evertson, 1976,) and to utilize techniques demonstrated to positively affect student motivation (Berman and McLaughlin, 1977.) 
From the Investigator's Journal: "Externalizing" might not interfere with the performance of a bricklayer or bartender, or even a brain surgeon. It might even be an asset to a criminal attorney. But it's disaster in a teacher, and my respondents and sources are telling me why.

Flexibility. As used here, flexibility is a term derived from Costa and Garmston's unpublished work and training workshops (1993) in mediating "States of Mind." As noted in Chapter IV, it provides a cover term for a collection of attributes both psychic and physical that fit intuitively together: inadaptability, lack of creativity, aversion to risk, failure to implement input, absence of growthorientation. They view this capacity as prerequisite to the ability to monitor and adjust in the classroom, or with-it-ness; and to empathically take another's perspective (shown in the model as the responsiveness pathway between Efficacy and Relatedness.)

The term flexibility gives a framework to a concept respondents had trouble expressing, but which they suggested was manifested physically, with terms like constricted, frozen, stiff, and rooted in one spot. It took the form of stories about student teachers' failures to respond appropriately to classroom situations and to children, and was illustrated with descriptions of behaviors suggesting lack of empathy. A case in point:

The cooperating teacher and I were working very hard to provide her with concrete data to show she did not give positive attention when students were doing the right thing but put out a lot of fires: "turn around," "look here," "Shhhh," "stop that." I would take frequency counts on numbers of positive and negatives, give her all kinds of suggestions for reminding herself that she needed to give attention to the behaviors she expected of them. For example, she responded to a lot to talkouts with "Yes, that's right, but you have to raise your hand." So we provided her with some strategies, things she could say that would allow more students time to raise their hand: "When you see a child's hand raised, let that be a cue to you that you need to do something to get more hands raised, and to feel free to call on students who don't have 
their hands raised." There happened to be one student who never raised his hand. Ever. They'd had him for four months, and he had not participated in any group activities. Well, he raised his hand. And she did not call on him. Her reason was that she was working on calling on non-volunteers...

She continued,

There are students who kind of have a feel for it, who can see to do the right thing. And (those who can't), who lack ability to feel what students are feeling, (and) commonly end up feeling anger at the students because they are not doing what the student teacher wants!

Flexibility is, with locus, closely tied to imagination, the pathway to Heartfeltedness. It is the attribute which allows the subject student teacher to step back from present circumstances and conditions of duress to see the larger picture of total impact, long-range goals and over-all patterns. It is this capacity that allows one to tolerate ambiguity, to break out of a given paradigm, to create innovative solutions to immediate small or systemic large problems. It is what Piaget meant by the capacity to deal simultaneously with multiple frames.

Reflection. The same respondent goes on to compare the reflective and the nonreflective student teacher in these terms: There are some who just automatically look at a lesson that has failed and say, "Oh, did l ever blow it here ... and when I was doing this, I should have been doing that." And then there are those who say, "Well, these kids are just out of control and I don't know what their problem is." The juxtaposition of elements in this respondent's stories makes obvious a logical progression (although she does not explicitly articulate it as such): from ego strength to locus to flexibility to reflection.

Respondents describe the behaviors they associate with reflection quite differently from those associated with flexibility: honesty with self, selfanalytical, self-critical, seeks input, motivated to improve. However, the distinction between flexibility and reflection becomes less necessary, more a 
temporal than a meaning difference, when one notes that it is flexibility which moves reflection beyond analysis of history, to on-the-spot apprehension of effects of one's own behavior on others, the reflection-in-action described by Schon (1983.) It is also flexibility that permits the "with-it-ness" which Kounin describes, which respondents favored as a term, and which arose from the data to provide a natural bridge between this domain (Efficacy) and the next (Relatedness).

There is also an obvious etymological connection between flexibility and reflection (also spelled reflexion, according to Webster [1983]), both deriving from the Latin flectere: flexible being "that which may be bent or curved, capable of adaptation, accommodation, change;" and reflection being "a casting of light back upon, allowing for mediation, contemplation, serious thought, consideration."

A respondent tells the story of a student teacher with a difficult class whose habit of reflection, obvious caring, sense of mission, determination to make school work for children, openness to input and eagerness to implement changes had endeared her to everyone: supervisor, cooperating teacher, principal, and colleagues in the building. Everyone was delighted to help. The respondent confided that of all the student teachers she had had, this one seemed most clearly destined to make a success of the experience, and to be a very effective teacher: She had it all. And she quit. She thanked all of us for our efforts, but basically the message was, "Forget it. I'm outta here." She wasn't stupid.

Those whose ego strength, locus of control and flexibility support a habit of reflective practice are less likely to opt for a profession in which such qualities are not rewarded, and in which reflective practice is the exception rather than 
the norm. The irony is that the more given an individual is to reflection, the more likely $s / h e$ is to care too much, and to need the support of the system as a whole to sustain the reflective habit through the crucial early days and years of teaching. The system is rarely equal to the task. Student teaching is not, as traditionally structured, a pathway for reflection or a portal to efficacy.

A profession whose expectations are low can expect its aspirants' abilities to decline over time to that level. Indeed, many warn about the profession in general that conditions which reduce teachers' sense of efficacy, such as lack of autonomy, decision-making power and free exchange of ideas (Lieberman, 1988) and top-down reform that discourages individual intellectual risk-taking and encourages protection of turf (Doyle, 1985) are root causes of teacher militance, burnout and a corresponding decline in numbers of talented people entering the profession. Theodore Sizer (1984):

Being trusted is the elixir of commitment. Unless we trust teachers ... we will only get more semicompetent people in the profession. Eventually, hierarchical bureaucracy will be totally self-validating: virtually all teachers will be semicompetent, and thus nothing but top-down control will be tolerable (p. 219.)

\section{Relatedness Domain}

The natural bridging function of With-it-ness is alluded-to above. It is important to begin discussion of this new domain by focusing on this bridge, for it is a quality respondents find very remarkable in a novice teacher. It is both an internal state of awareness or consciousness, and an external response mode. It also requires further elucidation; for example, a teacher who is aware of and reacts to every instance of student misbehavior is not necessarily perceived as "with-it." Investigator's Journal: 
Why not just absorb "with-it-ness" into another category, as l've felt at liberty to do with "defensiveness," for example? I have no explanation except my own intuition registering as "cognitive dissonance." I'm comfortable with its fit in either Efficacy or Relatedness. I guess that's the problem. The respondents seem to be making an argument for both, uncertain where it fits, and I can't argue with them.

With-it-ness as used by these respondents is not a cognitive function, and it is not value-neutral. It partakes of the qualities of intuition and of reflection-in-action, which Schon clearly identifies as a moral activity. It is the ability to take action in positive, creative, and responsible ways. It is childcentered. It is also an openness to new data, a 'receiving' mode and it is this, perhaps, that makes it so remarkable in a student teacher. Popular psychology tells us that human receptors tend to shut down under stress to avoid sensory overload, and by anyone's estimation, student teaching is a stressful experience.

Where else except in medicine do we ask the learner to practice the trade while learning it, and to practice it on human subjects whose survival -psychic and intellectual if not physical -- may depend on the outcome? Insensitivity to teachers' affective impact has serious repercussions for individual students, for this "hidden curriculum" significantly influences "how the student sees himself, his competencies, his worth and his prospects as a human being" (Mosher and Purpel, 1972,) not to mention his ability to learn. "With-it" student teachers demonstrate an ability to sense and assess their own affective impact.

Relate to students. There is some indication in the relatively infrequent mention of this attribute (12 times by five respondents) that respondents tend to 
minimize the effects of deficits in this attribute. This may be true of field faculty In general. We allow student teachers to practice on real children, in virtually any setting that will take them, and we try not to worry too much about the consequences for students. We do not, as a group, model appropriate levels of concern. We do not urge the newcomer to acquire the habits of relatedness. Respondents suggest we are shy about coaching a student teacher who fails to "connect" with students. What am I supposed to say to him? "Act like you care? Fake a little warmth? Show a little interest?' I try, but I always feel uncomfortable, like l'm asking the student to go against his nature. Another judged failure to relate to students to be a problem of self-absorption: She never got beyond the me stage to the kids stage.

Asked what "relatedness with students" looks like, respondents were able to provide descriptors: love of kids; comfort with kids; warm with kids. It means he visits with kids, greets kids, acts happy kids are there, seeks their company.

Issues of relatedness with students are of concern to other researchers, as well. Knowles and Suzina touch on it by noting that a "common characteristic" of the 19 individuals in their study was "an inability to evaluate and respond adequately to students' diverse needs." One of their subjects is described as proceeding with lessons "without ever assessing childrens' response to the material" and, as a group, they are typified by preoccupation with subject matter, lesson plan, performance: "classroom students were not the focal point of their teaching" (April 20, 1992, pp. 16-17.) Knowles and Skrobola (1992) are told by a supervisor that there are a substantial number of student teachers in his caseloads who have no genuine concern for kids, but expect help with learning how to act in warm and positive ways with students. 
In their studies as in this one, there is little comment on whether relatedness with students works both ways. A few respondents mention in passing and without particular emphasis that a student teacher was "liked" by students, but it is not always clear that this is seen as a positive.

Empathy. Many of the features of this construct have been discussed in its close counterparts With-it-ness and Relate to students. Respondents reserved this label and its included terms flat affect, intuitive, warmth and responsiveness for serious breaches of connectedness with children. Student teachers without it are described as not in tune with children, unable to sense the right thing to do at critical times, or as having no feel for it. Respondents use the word love sparingly, but love it seems, is often what is meant. One of them says this lack of ability to feel what students are feeling often translates into anger with students because they are not doing what the student teacher wants them to do.

By contrast, students in an empathic teacher's class feel supported in their differences, honored for their unique perspectives and given credibility for their own truths. Real listening on the teacher's part, and students feeling heard, confirms for them that what they feel is acceptable and valid (Belenky, Clinchy, Goldberg, and Larule, 1986.) This is the essence of a positive climate or hidden curriculum.

However, it may in fact be too much to expect from pre-service novice teachers concentrating on surviving the terminal field experience. Empathy is a very advanced interpersonal skill, and very fragile. Perhaps lack of empathy in a student teacher should not, of itself, cause major concern. In fact, the way we structure educational field experience may militate against student teachers' demonstrating empathy. Too much rests on the student teacher's performance 
there. Students can become just one more hurdle to jump. She may therefore be inclined to view them only as they relate to her and her chances for success, a "crowd" as opposed to a collection of individuals.

Self-Assertion. Respondents' references in this category included docile, timid, shy, quiet, subdued and hangs back. Nine of Knowles and Suzina's 19 failed student teachers are likewise described as shy, timid, retiring, withdrawn or inarticulate. They further note that all four of the cases of failure they draw from one private parochial university were at risk precisely because of what they call "inability to assert themselves" (April 20, 1992, p. 19). Eight of eleven respondents in this study cite similar cases. They do not, notably, associate lack of self-assertion with lack of passion and or commitment to children; in fact, they often indicate that student teachers lacking in self-assertion were "wellintentioned."

They do note two less benign effects: that student teachers characterized as passive, non-confrontational, wishy-washy may fail to provide structure for kids (He doesn't set, or sets and then waivers about, limits for students;) and fail to engage actively or take initiative in their own learning (She just sits there [in conference]and lets me do all the talking.)

Two student teachers in the Knowles and Suzina study are described as having "small voices." Respondents in this study used similar language, but more often metaphorically: lacking voice, having no voice, lacking presence. The construct is mentioned in connection with 15 cases, often in the same breath with ego strength, and may be seen as the external acting out in Relatedness of that internal state in Efficacy.

There is an "other extreme" in this attribute, as in several others: There is the student teacher so "self-assertive" (aggressive would be a better word) that 
her supervisor says everyone who had taught one of her classes or heard the stories that circulated about her could have predicted her "failure." At this writing, she is in her third attempt. She and others are variously described as pushy, overbearing, in-your-face, condescending, and know-it-all. Repeatedly, respondents assert or imply that they knew, that the student's other professors knew, that everyone knew long before the student attempted field experience, that this person was not going to be a successful teacher.

Such stories suggest that respondents feel helpless to intervene. Are faculty in a teacher education program proscribed from steering candidates to alternate careers or blowing the whistle on students destined to do harm? The Investigator's work with student teachers and field faculty from eleven different programs supports the influence of this sense of helplessness. Can teacher education faculty intervene in any way likely to remediate such negative interpersonal patterns? Many experts answer in the affirmative. Chris Argyris (1974) has produced an impressive body of work in group strategies for confronting the validity of goals and beliefs, building and maintaining consistency of behavior with a constant, unified purpose. His design for professional education, for example, includes a systematic series of laboratory experiences in group interaction, with ample opportunity to conceptualize and internalize operating principles, and to practice applying them so that later, under the conditions of stress that characterize the everyday classroom, they may be reproduced in concrete action.

Teacher education programs can, if nothing else, create a culture for teacher preparation so caring, committed, responsible and self-monitoring (Noddings, 1984) that persons seriously deficient in key personal attributes 
cannot be comfortable in the culture, or help but conclude that they do not belong.

People Skills. This attribute is at the "shallow" end of the Relatedness Domain. It is referenced often by this name and/or with labels like (lack of) outgoingness, pleasing personality; or as abrasiveness, zero social skills, insensitivity, hypersensitivity, unprofessional, a loner, aloof, unfriendly, cold. Despite its superficiality, this attribute garners 22 mentions (as opposed to 12 each for relate to students and empathy, and 15 for self-assertion.) This suggests respondents took advantage of readily accessible common language, willing to overlook the label's imprecision. References to this construct were reserved almost exclusively for student teachers' relationships with adult parties to the field experience, although there was no instance of ability to relate well to adults in the absence of ability to relate to students.

Corroboration is offered by Knowles and Sudzina, whose single construct of personal characteristics, "Patterns of social interaction," includes similar attributes. Twelve of the 19 subjects in their study are said to have deficiencies in "personal interaction skills with professors and others," and/or in "social habits and acceptance by peers" (April 20, 1992, p. 30.)

Some of the behaviors respondents describe are simple rudeness, which they agree can have long-range consequences by alienating colleagues at the placement site: She'd look away and not respond when other teachers greeted her in the hall; and She called other student teachers and talked for hours about her personal problems, without regard for their needs or schedules.

As Knowles' study and this study both suggest, many a placement falls apart for lack of "people skills" and other attributes in this domain; however, experience confirms that it is rarely reported as such. Cooperating teachers 
and supervisors are loathe to engage in what might be construed as "character assassination" in an oral feedback conference or written evaluation report. They are slow to blame failure on any quality that would be unlikely to yield readily to remediation.

Final evaluations may indicate instead that the failure was due to technical incompetence (and people-skill deficits do often manifest as technical difficulties), laying the foundation for prescribing a nominal remedial course or two. Occasionally, counseling or a course in interpersonal communication is recommended. These respondents report that some minimal remediation is very likely to be followed by the student teacher's returning to try again.

Knowles and Sudzina's studies (April 17 and April 20, 1992) corroborate this effect as a significant feature in common of several programs they studied which were otherwise quite different from each other, and from the ones represented in this study. All have informal policies that allow theoretically unlimited attempts to pass student teaching, virtually assuring that any candidate whose deficit in "people skills" is matched by his tenacity can eventually slip through the system.

Finally, respondents provide evidence that people skills can masquerade as concern for children and openness to feedback, or motive to improve, and be neither. One respondent describes her chagrin when she discovers that she has been conned into passing approval: The cooperating teacher and I had to reassure each other about it. We couldn't believe we'd let her get away with that. Several others also describe having been "charmed" and then disappointed by student teachers whose "people skills" proved a facade. 


\section{Domain III: Heartfeltedness}

Discussion of this domain begins, again, with a bridge. Authenticity would not readily be fitted into a domain. "Cognitive dissonance" and absence of any overlapping in the data were the Investigator's signal to question its inclusion under another label. It finally "fit" as an attribute that breaks the boundaries of both Efficacy and Heartfeltedness: Efficacy is a state of mind that mitigates the need to dissemble, to rely on artifice, to be concerned with other people's perceptions. An efficacious person is freed to be more authentic. Heartfeltedness is a state of mind in which other considerations pale beside powerful emotive forces. Preoccupation with devising an image or protecting an ego is not possible in the presence of concerted, wholehearted pursuit of a vision.

The pathway from Efficacy to Heartfeltedness, imagination has been examined in another context. It is important to note, however, that in this context it partakes of what Sergiovanni (1987) calls moral imagination, which implies not merely the capacity to envision but rather to envision a better state of affairs according to deeply held standards of what is good.

Belief System. There are relatively few explicit mentions of this attribute construct, but they are compelling. Respondents seem to mean by it and its included terms philosophy, mission, vision, and motive for teaching, a set of guiding principles.

One respondent, who interviews every student she supervises and personally matches each to a placement, routinely asks her charges "Why do you want to teach?" She finds it is getting harder and harder for them to answer. He couldn't give me one good reason why he's in teaching. Didn't 
know how he could make a difference in students' lives. Wasn't sure why he'd even want to.

By way of contrast, another respondent cites a sense of mission -- in this case an Hispanic student teacher's dream of returning to her home to promote education to children in poverty -- as the redeeming feature in what began as a lackluster student teaching performance. (Made aware of supervisor and cooperating teacher concerns about her performance, she was able to quickly and dramatically implement suggestions for improvement.)

A third respondent maintains a philosophical foundation is the key to a teacher's minute-by-minute decisions: You have to know where you're going with kids, what's appropriate, what to teach and why.

There many thinkers today urging us to formulate superordinate goals and examine purposes of our enterprise. Sergiovanni (1985) points educators toward new mindscapes and visions that allow us to stand for something and articulate it to others. Thomas Green (1984) focuses on the moral and ethical dilemmas we must address. James March (1978) challenges us to develop new forms of understanding and Yvonne Lincoln calls for new rules of discourse and the exploration of new languages for sharing those understandings (1986.) All imply that, while what those visions should look like and the content of those understandings are not something a teacher-training program can dictate, universities clearly are equipped to expose students to ideas, and train them in the analytic skills to turn ideas into coherent world views.

Commitment. Respondents' included terms for this construct are determination, drive, personal investment, purposefulness, will, grit, and spunk. They express confidence that they can "spot" its absence, in symptoms ranging 
from lack of physical animation in a student teacher to exaggerated concern about how long the field experience will last and what his grade will be. On the other hand, preoccupation with self-interest is commonly accepted in the young and in those who are "under siege." Student teachers are usually both. Respondents cite lack of commitment as a powerful force in marginality and failure; however, in the high-stakes context of terminal field experience, it is hard to get an accurate measure of this attribute.

In the context of the coursework which precedes field experience, on the other hand, it is imperative that we both measure commitment and intervene when it is lacking. Goodlad's (1990) ninth postulate asserts that ". . programs for the education of educators must ... (help) candidates transcend their selforiented student preoccupations to become more other-oriented" (p. 59) in their commitment to teaching. Katz and Raths (1992) assert that case method and training in reflectivity can focus attention on uncovering beliefs and preconceptions and working to reinforce or change them, as opposed to "blithely ignoring candidates concerns . . . and providing answers for questions not yet posed" (p. 380.) The test of such programs would be the student teacher's ability to sustain commitment and a coherent belief system through the crucible of student teaching.

Edgar Schein (1985) notes that examining one's own commitment requires a willingness to admit that things are not right and enlist the aid of others, a great ability to transcend self and dedicate one's effort to the good of the enterprise. It requires disconfirmation, a painful process (p. 323.) Again, it is not a quality that can easily be nurtured after student teaching has begun.

Nor should the power of commitment be underestimated. The Investigator's own case files offer an illustration: 
The student teacher was 51 , a victim of childhood polio who wore a heavy brace on one leg and had one arm that ended at the elbow due to a congenital defect. He was overweight, and in need of a new denture. He had a large family of young children supported by his social security and his wife's clerical job. Professors in his coursework had worried over his literacy skills and he admitted he had a serious problem with spelling. His student teaching had to be delayed for more extensive than usual background checks, due to his having spent five years in prison, 15 years prior, for embezzlement from the accounting firm where he had once worked. He claimed to be rehabilitated. His aspiration was to teach at the middle school level.

A principal and building staff willing to let him try was located, but the placement was arranged largely in the interest of due process; that is, no one really expected him to succeed. On his first day in charge of a class he asked students to help him with spelling and showed them the pocket dictionary he carried with him everywhere. He established, with their input, systems for management and discipline and was perceived by colleagues as having a high degree of natural authority. His tenure with them was marked by relative freedom from challenges by hisstudents. He proved to have a particular talent for making mathematics clear to confused adolescents. He appeared not to suffer from any lack of respect or confidence among the students, and colleagues marveled at his ability to (his principal:) connect, get through to the hardcore cases. He just seems to come to life with kids. He even looks different in a class full of kids. Happier.

Trying to isolate the qualities that made for success in the face of such odds, his cooperating teacher and principal identified these: commitment, positivity, optimism, feeling for children, belief in his mission, and love. 
Effort. Included terms are rigor, diligence, hard work, self-discipline, initiative and follow-through. For respondents, this attribute seems to be the visible manifestation of commitment. The connection is a somewhat dubious one. How hard a student teacher works tends to be measured in degree of urgency in his demeanor, number of new wrinkles on his brow, time clocked in the building. One of the Investigator's supervisees, an extremely capable and "committed" individual, recently admitted that she had taken care to park her car where her field-site colleagues and administrators would be sure to notice it when they left for home in the afternoon. There was no doubt about this student teacher's commitment, but she demonstrated that it is possible for a less-thancommitted individual to engineer an impression of hard work.

Still, because teaching is hard work and does often require long hours, respondents place a premium on effort. They indicate a desire to be able to say in an evaluation that a student teacher has gone beyond the call of duty. They scorn candidates like the one who thought I should pass him because he'd been at this for seven years and needed to start earning some money; or the one who refuses to get concerned about his evaluation, certain he'd be able in Alaska to find a teaching position for the months when he's not fishing. (After a few weeks in a high school, amazed at the hours and effort other teachers put in, this student teacher was no longer sure he wanted to teach at all: None of these people has a life! he said.)

One respondent quotes a student teacher expressing a similar attitude, then notes that most in her experience get jobs anyway, and reflects her dismay: If they are willing to look this bad when they're under scrutiny and on trial, what do you suppose happens after they're hired, and they close the classroom door? 
More to the point, perhaps, is a subtle distinction for which respondents have few words, that seems more in the nature of joy. They are not talking here about students who merely kept nose to grindstone. They talk about students who were absorbed in the business of teaching and learning, and sometimes failed to notice that it was time to eat or rest or go home. They talk about students who enjoyed what they were doing. And they admit that such cases are rare.

Also clear in the interviews is the respondents' linking of this attribute not so much with commitment, for which the language is relatively objective and cold, but with the "warmer" construct, passion.

Passion. For respondents, it appears that this attribute connotes nothing less than a giving-over of oneself to the enterprise of teaching. It was clearly passion by that definition that drove the student teacher described on pp. 121 122 to surmount a formidable panoply of negative odds, passion of the type that partakes of love of learning and love of students. A commitment to overcome his history, reform his life, make more money simply would not in itself have had the power to sustain this extraordinary degree of effort. He has a passion for teaching and for children.

Respondents include under this attribute cover terms like optimism, idealism, wholeheartedness, positivity and enthusiasm. (Its absence is represented by variations on lack of energy: heart not in it, running on empty.) Respondents indicate passionate student teachers believe they can make a positive difference in the lives of children. They are undaunted -- so far. Respondents reserve for this category the fired-up, fueled-from-within student teacher. Their own eyes light up and their voices become animated, visualizing how these candidates looked in front of a classroom or in a conference. There 
is nonverbal evidence that these were times when they really enjoyed their work as supervisors. The attribute represents the highest of an apparently "graded" set of characteristics, from belief system to commitment to effort, to passion. It is a kind of ultimate compliment for these respondents to be able to say of a student teacher, He was passionate about teaching.

But often the tone of comments that follow descriptions of such candidates takes on a wistful quality. It becomes clear that respondents also believe passion rarely survives the realities of teaching. They are not alone in that belief, and passion is not the only positive attribute which does not survive.

Sarason (1971), for example, concludes that the early days of a teaching career are "a baptism of fire in which many things can be consumed, including some of the ingredients that make for a good and even outstanding teacher." He identifies "culture shock" as one culprit, precipitating a desperate search for "some kind of acceptable compromise between the realities of the classroom and their fantasies about being able to help all children" (p. 171.)

Many others, as noted previously, describe student teaching as inducing a conformist, authoritarian, conservative mindset. These respondents confirm that they often watch apparently well-motivated novices abandon ideals, succumbing to the tyranny of bell schedules, a curriculum guide, a need to preserve time for paper-grading, the lure of "quiet work;" to constant interruptions to their work and bureaucratic invasions into the life of their classrooms. Terrence Deal (1984) says the nature of teaching offers only three choices to all but the most extraordinarily gifted, capable, and passionate: "hunker down, burn out, or leave" (p. 134.)

Tabachnik et al. (1979-80) write that while university program faculty like to think they offer philosophical counterbalance for the pragmatism of the 
workplace, they too encourage acquiescence and conformity over responsibility and reflection, urging student teachers to find ways to "get along and get good recommendations." In effect, they say, teacher education programs collaborate with public schools "to create a powerful conservative force for defending existing institutional arrangements from close scrutiny and challenge." They argue for teaching as a problem of knowing (as opposed to doing,) for the university's role as helping aspiring teachers "learn to live with and use the uncertainty that is a part of the excitement of life in a classroom," and for university teaching that nurtures facility in problem-solving (p. 22.)

Beyond such adjurations, there is no one setting a clear course for interventions that lead to the attributes of Heartfeltedness. Costa and Garmston, in their claims for Cognitive Coaching, do not venture here. Most professors, supervisors and administrators, and with them most theorists, have learned to be satisfied with technical competence.

In summary, analysis of respondent discourse isolated three domains of attributes and attribute-deficits strongly associated with student teacher marginality and failure. These are Relatedness, including the attributes People Skills, Self-Assertion, ability to Relate to Students and Empathy; Efficacy, including the attributes Reflection, Flexibility, Locus of Control and Ego Strength; and Heartfeltedness, including the attributes Passion, Effort, Commitment and Belief System. Among the three domains, Efficacy appears to occupy a fulcrum or pivotal position, connected to Relatedness by With-it-ness and Responsiveness; and connected to Heartfeltedness by Authenticity and Imagination. 


\section{Auxiliary Themes}

As the Investigator reviewed transcripts, "listening" again to respondents' attempts to name the attributes associated with student teacher marginality and failure, she noted that most of them also wanted to explore reasons why candidates with such attributes were common in our profession. They were not discouraged from doing so. From their attempts to explain emerged three distinct themes, amounting to indictments of the system at three levels: 1) failure of the profession to attract a caliber of candidate qualified to meet its requirements, 2) weakness of the gatekeeping function at several key stages in the candidate's training, and 3) certain deficiencies in the teacher education curriculum.

\section{Failure to attract high-caliber candidates}

Investigator: In your many years of practice, how have the candidates you supervise changed? Respondent: They're every bit as nice as they ever were. I get a lot of nice people here. Investigator: Smart people? Competent people? Respondent (after a thoughtful pause): Nice people. Really nice, wellintentioned people.

Another respondent already quoted calls teaching the highest whitecollar profession most of them (candidates she has seen in recent years) can aspire to. Several others note that the profession no longer attracts the brightest females, who have far more options than they used to. One notes that most of the males she supervises are in teaching because they aspire to coach, or because it is a prerequisite to a career in educational administration. 
Respondents report that they are seeing more candidates with poor academic records (although none is convinced there is a correlation between low grades and marginality in student teaching.) There is evidence in their stories of some concern that teaching has become attractive for the wrong reasons: I tell every one of my groups, "If you got into this business because you thought it would be easy and you like summers off, get out now before it's too late." Several fear that candidates may be selecting "the path of least resistance."

Their stories echo those of supervisors interviewed by Knowles and Skrobola (1992,) who note low levels of reflection and conviction in increasing numbers of student teachers who may not really want to be teachers but who see it as anybody's option. Such candidates may have no particular guiding philosophy of education nor sense of mission, nor realistic sense of the task, but feel confident they can do the authoritative "transmission mode" of teaching as well as it was done to them.

One respondent says she sees more people who are career-changers, and more of them changing because they failed: Marginal people who couldn't make it in other areas, thought teaching would be a piece of cake, summers free. They'll say they want hours compatible with their children's, but not why teaching is important to them.

As noted, one very strong theme, present in approximately 20 stories, was that tenacity is all it takes to get a chance to teach. One group described were students whom others had tried to discourage, who may have failed some coursework or gotten a poor preliminary practicum report, who simply persisted until they were allowed to student teach (many respondents noted that their universities yield fairly readily to entreaty.) Another group were students who 
were counseled-out and returned, or who failed at the student-teaching stage, whose tenacity combined with the university's concern over legal action earned them second and, in some cases, third tries. Respondents indicated that most of these students eventually succeed in "getting through" a student teaching experience and being certified.

Respondent $3 A$ describes behavior in their pre-internship coursework of candidates likely to fail: . . . they don't ask questions about content, only requirements; don't volunteer answers, sit back, go through the motions, ask ... not "How can I get something out of this?" but rather, "How can I pass this course?" And these people are probably all going to be teachers.

\section{Weakness at the Gates}

Respondents indicate many points in the marginal student teacher's career where the gatekeeping function failed.

At entrance. Required grade point average was below 3.0 for all but one of the institutions represented, and that one had only recently raised it in light of an overabundance of applicants. Several respondents told stories of students who did not qualify on that basis, but succeeded in entering the program by petitioning for admittance, a process one respondent called casual.

Early in teacher education courses. Above, a respondent claims to be able to see the marginal ones in the classroom. Many others talk of failed efforts to counsel candidates out early. One says,

I think the pressure (to pass student teachers) is a lack of support from the university. .. supervisors just say, "well, I got no support, so I just left it alone." It's hard to get a coordinator of field experience or a dean to say, "Yes, let's do it." They'll say, "You let them get this far -- you should have stopped them before."

Because it's true, we really know the problems before they go (to 
student teaching,) and that's the truth. It doesn't take long to figure out who will have trouble. . . there are very few surprises.

Judging from these respondents' reports, the student teacher who blamed her failure on the professors who had let her "get this far" may have had a point.

At the field experience level. One respondent describes her first term as a university supervisor: I had one who wasn't making it. I went to (her supervisor, who was head of the department and director of field experience) for advice. All he wanted to know was "Does this person have potential?" Later, growing more concerned, she asked her supervisor to observe the student teacher and give her a second opinion. All he would say was, "I've passed worse."

A respondent says of the student teacher in one of her stories that, because she had her in a class, she knew 18 months before that this one wouldn't work, but my hands were tied. The story illustrates another common theme: a reluctance, or a lack of administrative support, to fail anyone on the grounds of attributes whose remediability is in question. Often respondents admit that their recommendations not to certify may have cited matters of skill but were actually motivated by their assessments of personal attributes.

In the Investigator's own experience over the past five years, failed students allowed by their universities to repeat the experience have included the following: one who was caught venting his volatile temper on students, unaware that he was being watched (now working as a teacher;) a woman with a history of pathological dishonesty who had insinuated herself into a student teaching placement without having passed a state qualifying test or even been admitted to a school of education (currently finishing certification requirements in another state;) a charming, manipulative young man who was halfway through field internship before it was discovered that he had never planned a 
lesson on his own; instead, he was staying just a day behind his girlfriend, student teaching in another building and giving him all her lesson plans and materials (just passed his third attempt at student teaching.)

Such student teachers will gather the lion's share of a supervisor's time and attention to themselves in a given term, create significantly increased workload and stress for the cooperating teacher, tax the patience of principals (who after such a one often refuse to take another,) and threaten the learning and well-being of students. Failure to stop them at the gates probably reflects the difficulty of defending personal attributes as grounds in a legal action, a concern which is carried in some cases to extreme lengths by university policy.

A respondent whose university requires a comprehensive plan of remediation for any student teacher she elects not to certify says,

You see, her problems were so comprehensive that when we talked about "Should she be out?" we couldn't figure out how to remediate what was wrong because of the complexity of what was wrong. It would have involved her somehow gaining a huge amount of information about basic things (fifth-grade content) as well as changing her personality to make her appear as though she cared about other people, wasn't angry all the time. How do you remediate that? There are no courses in that. That's why we decided to pass her. After that she was going on to do her Special Education student teaching (emphasis mine.)

These findings suggest that when student teachers are grossly inadequate in terms of content preparation and pedagogical skill, they may withdraw or allow themselves to be counseled out. However, those whose inadequacies are more in the realm of personal attributes tend also to be tenacious; i.e., to insist on multiple chances to pass. Like Knowles and Sudzina's respondents, these respondents indicate students get those multiple chances. Several corroborated the Investigator's experience by noting that marginal student teaching performances are frequently allowed to continue for 
want of agreement on whether to terminate, with cooperating teachers in particular tending to hold out hope, or fearing the student's failure will reflect on them, or being unwilling to take a stand in a conference or written evaluation (Knowles and Sudzina also identify this as a common tendency and call it "euphemistic evaluation by cooperating teachers" [April 20, 1992, p. 24].) Respondent 7B describes such a cooperating teacher: She'd say, "Let's give her another week. . . let's see what happens in the next two weeks. . now that you've talked to her. . . now that we've written this contract . . now that she knows she's in trouble ... let's wait and see what happens."

In the Investigator's recent experience, a student teacher whose many shortcomings included his having used two previous placements as forums for fundamentalist Christian evangelizing was removed from a third placement. It did not happen until his sixth week on site, when cooperating teachers, administrators, and several faculty tangentially associated with the student teacher rose up and demanded of the university supervisor not only that the student teacher be removed from this placement, but that he be proscribed from attempting a fourth ... anywhere. In other words, when a student teacher fails it is likely to be because all parties to the placement have given up and, this example being a rare exception, the student teacher will usually still get another chance.

At the level of application for employment. There may not be a teacher shortage here, but most of these people (marginal student teachers) are mobile, says one respondent. Another notes that there is a critical shortage of special education student teachers and that anyone with that in their background gets hired, no matter what. (As the respondent noted, the "irremediable" student teacher cited on p. 131 went on from a marginal pass in 
the regular education placement to begin a placement in special education elsewhere.) One respondent says of prospective employers of marginal candidates, If they called me, l'd tell them not to hire her. They never call me.

There is pressure to pass and therefore weak gatekeeping due to concerns about legal action and due process. There is pressure because a university's reputation is at stake, and so too faculty appointments (one respondent notes that the Investigator is . . lucky. You don't have to protect a particular university's turf.) There is pressure in cases where all parties to the placement cannot agree not to pass. Finally, there is pressure to pass because too many suppose -- teacher educators among them -- that the attributes we strongly suspect are required for success in teaching cannot be taught, and therefore cannot be required.

The ripple effect from reluctance to draw boundaries and exclude people seriously deficient in the personal attributes critical to successful teaching is quietly devastating in terms of the first Theme as well; i.e., the caliber of those whom the profession attracts.

\section{Deficiencies in the teacher preparation curriculum}

There are few problems with teacher education identified by these respondents that have not been amply documented elsewhere. Most agree teacher education programs tend to lack rigor. Most agree that boundaries to teaching are too permeable, and that someone (else) should be doing a better job of gatekeeping as candidates move through on-campus coursework and related preliminary practica.

These respondents are unanimous about the importance of early, frequent, relevant and active participation in classroom experiences with 
children. All of them wish it were possible to be selective about cooperating teachers. Some wish all cooperating teachers were trained to mentor. All of these respondents struggle daily with unreasonable expectations regarding the time and energy it takes to do their jobs right, and every one longs for opportunity to really coach student teachers. All those respondents whose students are on site only nine or ten weeks expressed the opinion that universities need to require longer periods of student teaching. Five wished for a year-long internship model. None feels adequately appreciated or remunerated.

\section{Unsupported 'Hypothesis'}

As previously noted, three of the four original 'hypotheses' (i.e., the four "Capacities" for which the Investigator expected respondents would produce evidence) were amply represented in the interviews: The capacity to reflect, grow and participate in change processes; to experience personal efficacy; to nurture self-esteem, learning, and acceptable behaviors in students. Looking in the transcripts for the fourth, "capacity to recognize the moral and ethical implications of the teacher's role," she encounters a resounding silence.

Purpel (1989) and Giroux (1988) help explain it, as symptomatic of a general avoidance in our culture of confronting moral dilemmas, a "structured silence ... a conspiracy of silence ... a tacit recognition of and discomfort with the intense relationships between moral/social concerns and the concerns of public education," coupled with a tendency to "trivialize moral discourse by reducing it to technical or partisan debates" (Purpel, p. 9.) The Investigator should not have been surprised that supervisors, even of the exemplary caliber represented in this study, gave little explicit attention to this domain. 
Several explanations for this lack of explicit attention are possible.

\section{Respondents may}

- sense that considering attributes in this domain could be construed as violating church/state separation;

- understand that in a pluralistic society, moral and ethical questions are rendered all the more abstract and relative by considerations of diversity;

- be wary of subjectivity, reluctant to set themselves up as judges in this domain or to imply that such subjective judgments might in any way enter into a student teacher's evaluation;

- recognize that candidates are not receiving in preparatory coursework much if any exposure to the moral and ethical considerations of a teacher's role in their coursework;

- be concerned that to recognize moral and ethical issues would require addressing head-on certain risks inherent in doing so: There are no rewards attached to these topics in our culture, and many potential hazards presented by the radical fundamentalist and politically conservative right.

For whatever reason, respondents suggest that the focus in student teaching is on technical matters. Some maintain that it should be. Questions of the teacher's power to influence other people's children, stewardship of the public trust, and role in shaping the society are not foremost. Indeed, many student teachers never get beyond survival mode, or become comfortable enough with protocol and process to consider such issues. More to the point, perhaps, few supervisors and cooperating teachers are asking, and challenging student teachers to ask, why as well as how questions of themselves. 
Finally, it is not fair to say that such issues do not arise at all in the interviews -- only that, when they do, they are not labeled as moral issues. For example, much of what might be called "moral considerations" in other contexts appears here as attributes in the Relatedness Domain (whose attributes no doubt derive from certain elements of the Heartfeltedness Domain, especially belief system.) Donald Schon and Thomas Sergiovanni both focus attention on the moral implications of reflection-in-action ; i.e., on-the-spot decisions about how to respond to, treat, and interact with students, decisions which are made on the basis of an epistemology of some sort, a standard of good. Whether at a conscious level or not, teachers do in fact model and influence others in the direction of particular moral/ethical positions. To put it Purpel's way, moral education "comes with the territory" (1976.) William Greenfield explicitly recognizes this, too, labeling "moral socialization" the process by which school administrator dispositions are cultivated (1985,) a label that can certainly be applied as well to preservice field experience and teacher induction.

At the very least, teaching is a practical activity with profoundly moral consequences. By such a definition, all teacher behavior might be called moral behavior, and all education moral education. The issue, then, is not whether we do it; the key is in the wording of the unsupported "hypothesis": "capacity to recognize the moral and ethical implications of the teacher's role."

Recommendations for Application of Findings to Teacher Education

Studies like the present one, attempting to identify attributes linked to student teacher marginality and failure, have potential for application in teacher 
education. That usefulness is predicated, however, on the following presuppositions:

- that many personal attributes are transient and malleable, tied to circumstances and context, and/or to developmental stages;

- that certain personal attributes can, in fact, be taught or inculturated, and that we can create conditions that help reinforce, extinguish or otherwise mediate the attributes preservice teachers bring with them to their training program;

- that there may be a) good reasons and b) reasonable means to screen applicants to and participants in teacher education programs for certain intractable negative attributes; and

- that additional research is needed into these and related matters, and that that research should be of a particular kind.

\section{For Teaching-to and Mediating Attributes}

If the first presupposition is valid, as these respondents' claim, the second follows: that teacher education programs could develop curricula designed to "teach to" desired personal attributes, to inculcate or draw them out. Perhaps more to the point would be conditions and cultures created in which those who do not possess or aspire to such attributes would weed themselves out. In the best interests of student teachers, their students, their host faculties, universities and their reputations, and in consideration of due process, these objectives should be accomplished prior to preservice teachers being tested in the crucible of student teaching.

Are attributes malleable and transient? Much recent work in psychology, sociology, and organizational management accepts as given their malleability. 
Tabachnik et al. (1979-80) propose further study of the teacher sentiments that support classroom acts, because focusing on them can help student teachers surface their beliefs and strive for alignment between those beliefs and their behaviors. Sprinthall and Thies-Sprinthall (1981) write of their experience with creating programs to affect and modify an existing adult stage of psychological development. Costa and Garmston's (1993) workshops on coaching and current book (in press) prescribe carefully crafted strategies for assisting supervisees to move out of dysfunctional frames of mind in which they may have become "stuck." In particular, they focus on teaching supervisors to adapt their listening, their language and their style to help the subject teacher move from "external locus" to Efficacy (pp. 9-11, unpublished draft manuscript.) Sergiovanni's (1985) extensive work in theoretical and practical "mindscapes" and their power in determining practice is widely referenced in a variety of fields of human endeavor. Of particular interest here is his commitment to the belief that, where student teacher and supervisor are working together, not to establish truth but rather to accomplish meaningful change, they create and construct their own dynamic, volatile reality out of actual classroom events as they and students perceive them. He would have us look critically at the language used to frame problems, and consider how it has locked us -- and our student teachers -- into obsolete, dysfunctional mindscapes about teaching practice.

Can teacher training realistically be expected to address attribute deficits? Only if we abandon our current priority on "coverage," technical rationality, practicality and control. Carole Edelsky (1988) blames this priority for a trend toward the "deskilling, reskilling, and proletarianization of teaching" which works to atomize, behaviorally describe and appropriate teaching acts, 
thereby relieving them of judgment, intuition and control (p. 197.) Walter Doyle (1990) writes, "Practical knowledge is that which empowers outsiders (administrators, state officials or legislators) to control teaching, and effectiveness is assumed by prescribing uniform practice in the classroom and monitoring indicators to enforce compliance (p. 19). (Reassuringly, he claims to be witnessing just such a shift from status quo maintenance and quality control to knowledge and empowerment.)

Teacher training programs can certainly be expected to address issues of teacher socialization. The knowledge base exists to do so via research review and case study methods. Such a teacher education curriculum would draw heavily on the work of Jackson (1968), Good and Brophy (1984), Lortie (1975), Goodlad (1984) and others.

Teacher training can even, some would argue, address deficits in moral/ethical perspectives. There is a distinction between the "professional ethics" that we attend-to now with character checks and searches of police records; and the "ethics of teaching," which has to do with how the teacher perceives his/her role. Nord (in Dill, 1990) maintains we need teachers who see themselves as the moral agents that they are by virtue of position, and who are taught to confront the less "ideologically loaded" dimensions of moral and ethical learnings: principles of democracy, standards of decency, compassion, honesty, hope, courage:

It (the knowledge most worthy having) is a sense of what makes life meaningful, which would most certainly include love; having a place in, and an identity as a member of, various communities; moral purpose in one's life; work that draws on one's abilities and contributes to the good of others; art; and the life of the mind (pp. 187-88.) 
What this suggests is that teacher education might be a kind of conversion experience. At the least it suggests we ask candidates to envision and engage in a kind of teaching they might never have experienced. We also may well be asking each to be a different kind of person than s/he has ever been.

Respondents are asking that $\mathrm{s} / \mathrm{he}$ reflect deeply about self, and task, and consequences for kids. They are in good company. Indeed, intractability in this dimension may be a key to what we could legitimately screen-for, if a measure were available. It is in the very nature of lack of flexibility, a correlate of reflection, to resist change, to be "stable" in a negative sense, to see no growth possibilities.

By implication, respondents also ask that the candidate eventually subscribe to an identifiable set of sound moral/ethical precepts about teaching. Reflection, which they place at the heart of success in teaching, is a moral activity. Countless reformers urge that it be taught as such in teacher education programs. Argyris and Schon (1974) have developed widely-respected programs for altering people's theories-in-use, and a body of research that supports the efficacy of reflection for reducing defensiveness and for increasing exploration of different and risky ideas, sharing, cooperation, authenticity, autonomy, and internal commitment. Bowman and Hall (1989) offer insights into the uses of the journal as an instrument of reflection, research, and socialization; and Bowman and O'Brien (1989) explore peer coaching techniques as vehicles for student teacher reflection. Anzul and Ely offer this encouragement: "Once the reflective mode is introduced, this impulse toward examination and impetus to change is inevitable and inexorable" (1988, p. 685.) 
Weick (1982) suggests we be concentrating in teacher education on "symbol management." Our task is to do what this study itself attempts to do: to find a common language of important underlying themes and values, in terms of which people can "explain their own actions in a meaningful way and communicate with one another in similar terms" (p. 676.)

Tabachnick et al. examine "the university as an institutional context within which the perspectives of student teachers are either challenged or legitimated" (p. 13.) Like these respondents, they see student teaching as calling for reflection, autonomy, responsibility, self-fulfillment and active involvement -- as an enterprise in which success is measured in terms, not of knowing, but of acting and being. Understanding this, they and others submit, is fundamental to teacher education, for it calls us to focus on beliefs and theories which will support student teachers' matching of their teaching behaviors to their rhetoric, even when the heat is on.

If we accept as given that most of the attributes we value in teacher candidates can be inculcated or drawn out, then students in Knowles and Skrobola's (1992) study, who wanted their supervisor to teach them the behaviors associated with warmth and responsiveness to students, may have been on to something. In fact, Glasser (1990) and others maintain that to correct typically immutable internal states like beliefs and attitudes, it is most effective to intervene at the level of behavior. Most respondents express belief that qualities like warmth, caring and concern for students cannot be taught, but at least one feels perfectly justified in asking her supervisees to display these behaviors, regardless. I believe in that adage, this supervisor said, "Go through the motions and the motive will follow." 
Teacher candidates also need to be taught and shown the gambits of effective interaction with students. Many of us have few positive and many negative models of teaching in our personal histories. Teacher education needs to provide preservice teachers not only with models of pedagogical expertise, but with exemplars of interpersonal sensitivity and skill, with faculty who act out in their classrooms qualities of fairness, respect for diversity, commitment to democratic values, and stewardship of the public trust.

Finally, teacher educators need to help student teachers understand how their personal biographies interact with circumstances to affect their teaching personae for good or ill (Knowles in Goodson [ed.,] 1992.) A premium must be placed on self-knowledge, and resources provided for the odyssey of selfdiscovery, the early identification of problem areas, and the counseling and practice that might ameliorate them.

The following are minimum expectations for teacher education that respondents in this study urge:

1) That it create a culture in which no one unwilling to change would want to remain (the cohort program recommended by Goodlad [1990] is promising;) and

2) that it help to build in candidates a sustainable habit of morally responsible reflection on practice through

a) early, frequent, multiple and active practica in classrooms with children;

b) opportunities to gain self-knowledge through such means as journaling, peer coaching, and counseling;

c) confrontation of the moral and ethical dilemmas of education, with particular attention to issues of equity; 
d) study and practice of the principles of interpersonal competence and group process;

e) a practiced repertoire of pedagogical methods, and the action research strategies required to assess their impacts.

These should lead, then to a final field experience that can reasonably be expected to be a triumphant application of such learnings.

\section{For Screening and Gatekeeping}

Is such a vision possible without our using expanded knowledge of attributes implicated in marginality and failure to screen applicants for admission to this profession? The Investigator embarked on the present study in the first place because of concerns about the kinds of candidates she was seeing. One unfortunate side-effect of a reputation for low standards and lack of rigor is that education of teachers is not appealing to career-seekers nor credible to the tax-paying public. More rigorous screening than is typical may be not only appropriate, but necessary to support professionalization of teaching.

Screening is not, however, a course of action well-supported by these respondents, and will be left to others to consider. What is supported is the position that student teaching is too late a point in the candidate's career for us to be screening people out. The cost is too high.

The stories here strongly suggest that many student teachers are still at the self-protective and conformist levels of ego development when they enter student teaching. If so, under stress they may experience "arrested" ego development. What can a school of education do to move student teachers beyond current levels of ego development toward the conscientious, 
individualistic, and autonomous levels? Teacher educators need to study the literature and even consider applying the tests available in this domain, if not as screening then certainly as teaching devices, and as indicators of ways to individualize their instruction. (These might include such measures as ego- and moral-development scales, Myers-Briggs-type personality inventories, the Tennessee Self-Concept Scale, Rutter's Locus of Control Scale, the Rehfish Rigidity Scale, etc.)

If a way could be found to "screen for it," most teacher educators would also not hesitate to apply a test of viability to candidates' motives for teaching. Could we then say, "Sorry. Wrong answer. You're not our type?" This is dangerous territory. Still, the Investigator's Journal reveals a longing for just such discretion.

My perspective really is different from Knowles, et al. I admit I don't feel entirely comfortable with it. I wish I could find it already in the literature. I wish others in the field did consider it (as Sherwin suggested) "commonsense." I need the validation. Without it, I wonder again whether we all shouldn't confine our attention to conditions we can change, deficiencies we can remediate. . . But then I think. . .

What could possibly be more important than teaching our children how to learn and how to live? I find specious any argument against those priorities -- both of them, together. After parent, I believe the most sacred responsibility of all to be that of teacher. Consequently, I find myself concluding that we have a right and obligation to consider how to attract, mentor, train and empower good persons for this role. That begins, of course, with setting some sort of standard. I'm not so arrogant as to put forth my own criteria. But I believe the collective opinion of my very special respondents will yield insight into what those criteria ought to be. It's time we admit that certain kinds of people, however well intentioned, may not be teacher material. It's time we stand up and say, "Here's who you need to be in order to teach," (just as in the counseling professions, for example, the expectation is that those without empathy and compassion are censured; those too 
wounded to remain objective are themselves counseled; and those who got into the business only for the money are found out.)

Respondents did not resolve the Investigator's dilemma. In fact, not one suggested there was a "wrong kind of person" for teaching. And while not everyone said it outright, it appears most would have agreed with their colleague who repeatedly reminded the Investigator: I don't mean to suggest this person couldn't grow into this area ... they're just not valuing it, not good at it yet.

In any case, we could use screening tests as teaching tools. McNergny and Carrier (1981) identify a menu of instruments for assessing ability and cognitive style, as well as ego, affect and moral development. If we want such tests, they are available. But these experts further suggest that teacher educators need to decide what characteristics can really tell us what we need to know about prospective teachers, based on the following criteria (pp.129-30, abbreviated):

1) Does the particular concept of the person have a substantial knowledge base?

2) Is the characteristic pervasive and salient, a prominent and lasting part and influencing a wide range of personal behavior?

3) Is there reason to believe that the characteristic is modifiable?

4) Has the characteristic been investigated specifically in terms of its ability to explain teacher behavior?

\section{Eor Further Research}

Other research is certainly called-for by the findings of this study. How can we explain the dearth of attention in the literature to success and failure in 
student teaching? Respondents suggest some reasons that should be examined in depth:

1) the remediability of attributes is, for most, open to question;

2) there is imprecision in the language and in the thinking about personal attributes in general;

3) there is reluctance to set oneself up as judge and "assess" attributes;

4) there is currently no demonstrable or felt need to screen anyone out, even on the basis of grades and test scores, because there is need and projected need for teachers in most locations.

Another fruitful area of investigation would be the preconditions and attributes that lead some student teachers to successfully resist, in the sense of resistance meant by Zeichner (1980), the conservatizing and rigidifying forces of the student teaching experience. We need to look carefully at the attributes of these candidates, in order to better understand how we can support that kind of resistance through our teacher training programs.

We need new research that asks, as did Sarason (1971) "How do we account for the fact that so few teachers are considered outstanding? Is it that outstanding teachers were outstanding in the relevant characteristics before they became teachers; that is, are they a special breed of person who is always in short supply? . . . How many 'average teachers' had the potential to be much better teachers but because of lacks in training . . . this potential could not be developed?"

Whatever its specific focus, further research into these matters requires a mode of research that is still struggling for acceptance. Zeichner: "A central purpose of critical approaches is to bring to consciousness the ability to criticize what is taken for granted . . . a vital concern of those operating within the critical 
paradigm is social transformation aimed at increasing justice, equality, freedom, and human dignity. Reality is viewed as socially created and sustained.

Research professing to be critical must ideally be participatory and collaborative" (1990, p. 331.)

American dialogue on education, says Purpel (1989) has been "narrow in scope, technical in nature, and naive in quality." Such dialogue has not centered on "the relationship between education and meaning," has not been conducted widely (pp. 4-5,) and is not sufficient to address the concerns raised here. This study was and studies which follow it should be concerned with meaning, with languages in use. It should focus on existing mindscapes and, where appropriate, be concerned with discovering and testing alternatives to them.

The model on p. 93 should be the basis for a followup study by written survey. This survey must somehow motivate respondents to contribute detailed narrative accounts. The purpose is not so much to corroborate results here as to produce a body of data that might be persuasive to others by virtue of its weight and generalizability, as defined by Guba and Lincoln:

Some investigators think that generalizability is a chimera and that it is impossible to generalize in the scientific sense at all ... if the term 'generalization' is to have any meaning at all, it must be with reference to particular audiences. It is up to each audience to determine what, if anything, the information means and to determine for itself the information's applicability" (1983, pp. 1167.)

Finally, respondents in this study would subscribe to pre-internship measures to give students a realistic picture of what it is to teach; to require others' assessments of a candidate's character and likelihood of succeeding; to a new willingness to confront negative attributes directly and early; to journaling; to coursework in and statements of educational philosophy; to 
elevated entrance requirements not driven by availability of applicants to the teaching profession or the university's self-interest; to systems for selecting and training cooperating teachers; to status and recognition for supervisors commensurate with the demands and responsibilities of their role . . to any measures, in fact, that assured quality in the profession.

Investigator's Journal, May 17, 1992: The effort to establish high standards for entrance to teaching is meaningless, of course, if we don't also work to change people's estimation of the value of the task. That's a daunting proposition, but it's all of a piece, part of a continuum: we agree to certain personal (along with professional) attributes required to do the job well; we recruit and we screen for much more than GPA and standardized content knowledge test scores; we modify our programs so that potential teachers are 1) educated in the midst of children, and 2) given ample resources for personal growth and transformation (because in this business we believe in transformation;) we empower them, and remunerate them appropriately, and recover pride and standing in our society, because...

As we do, the kind of people who consider law because they love justice, or medicine because they hope to heal hurts, or the arts because they believe creative transcendence expresses the essence of what it means to be human, will add public education to their lists of options because they love children and learning and teaching. They're the kind we need. 


\section{REFERENCES}

Adler, M. J. (1982) The Paideia Proposal: An educational manifesto. New York: MacMillan.

Anzul, M. \& Ely, M.(1987, December). Halls of mirrors: The introduction of the reflective mode. Language Arts, 65, 675-687.

Arbreton, B. J. T. M. (1992, April). Challenging failure: How persistence, reflection and circumstances of placement affected my teaching career. Paper presented at the annual meeting of the American Educational Research Association, San Francisco, CA.

Argyris, C. \& Schon, D. (1974). Theory in practice: Increasing professional effectiveness. London: Josey-Bass.

Ary, D., Jacobs, L..C., \& Razavieh, A. (1985). Introduction to research in education. New York: Holt, Rinehart \& Winston.

Belenky, M. F., Clinchy, B., Goldberg, N. \& Larule, J. (1986). Women's ways of knowing. New York: Basic Books.

Berman, P. \& McLaughlin, M.W. (1977). Federal programs supporting educational change: factors affecting implementation and continuation. Santa Monica, CA: Rand Corporation.

Biklen, S. K. (1983). Teaching as an occupation for women: A case study of an elementary school. Syracuse, NY: Education Designs Group.

Blum, L. (1987). Particularity and responsiveness. In S. Kagan (ed.) The emergence of morality in young children ( $p .315)$. Chicago: University of Chicago Press.

Bogdan, R. C. \& Biklen, S. K. (1982). Qualitative research for education . Boston: Allyn and Bacon.

Bowman, A. C. \& Hall, J. L. (1989). The journal as a research tool: Preservice teacher socialization. Paper presented to the Association of Teacher Educators, St. Louis, MO. 
Bowman, A. C. \& O'Brien, S. (1989). Reflective collegiality: A model for student teachers. Paper presented to the Association of Teacher Educators, St. Louis, MO.

Bowman, A., Hall, J., \& Johnson, B. (1990). The journal as a research tool: Added dimensions. Paper presented to the Association of Teacher Educators, Las Vegas, NV.

Brophy, J. \& Everson, C. M. (1976). Learning from teaching: A developmental perspective. Boston: Allyn and Bacon.

Bullough, R. V. \& Knowles, J. G. (1990). Becoming a teacher: Struggles of a second-career beginning teacher. Qualitative studies in education $3(2)$, 101-112.

Burlingame, M. (1979). Some neglected dimensions in the study of educational administration. Educational Administration Quarterly, 15, 1-18.

Cicourel, A.V. (1964). Method and measurement in sociology. New York: Free Press.

Clemson, R. \& McTighe, J. (1990). Teaching teachers to make connections: A challenge for teacher educators. Action in teacher education, 12, 55-62.

Costa, A. L., Garmston, R. J., \& Lambert, L. (1988). Evaluations of teaching: The cognitive development view. In Stanley, S. J. \& Popham, W. J. (eds.) Teacher evaluation: Six prescriptions for success (pp. 145-172). Alexandria, VA: Association for Supervision and Curriculum Development.

Deal, T. (1984). Educational change: Revival tent, tinkertoys, jungle, or carnival? Teachers College Record, 86 (1), 124-137.

Denzin, N. K. (1978). The research act: A theoretical introduction to sociological methods. New York: McGraw-Hill.

Dewey, J. (1933). How we think: A restatement of the relation of reflective thinking to the educative process. Chicago: Henry Regnery \& Co.

Dexter, L. A. (1970). Elite and specialized interviewing. Evanston, IL: Northwestern University Press.

Doyle, D. P. \& Hartle, T. W. (1985, September). Leadership in education: Governors, legislators and teachers. Phi Delta Kappan, 21-27.

Doyle, W. (1990). Themes in teacher education research. In Houston, W. R. (ed.) Handbook of research on teacher education. New York: MacMillan. 
Duke, D. L. (1993, May). Removing barriers to professional growth. Phi Delta Kappan, 702-712.

Duke, D. L. (1985, June). What is the nature of educational excellence and should we try to measure it? Phi Delta Kappan, 671-675.

Duke, D. L. (1984). Teaching: The imperiled profession. Albany, NY: State University of New York.

Edelsky, C. (1988). Research currents: Resisting (professional) arrest. Language Arts, 65, 314-321.

Erickson, D. A. (1978) Research on educational administration: The state of the art. Paper presented to the American Educational Research Association, Toronto, Canada.

Farber, B. (1991). Crisis in education. San Francisco: Josey-Bass.

Fetterman, D. M. (1988, November). Qualitative approaches to evaluating education. Educational Researcher, 17, 17-23.

Fieman-Nemser, S. \& Floden, R. E. (1986). The cultures of teaching. In Wittrock, M. C. (ed.), Handbook of research on teaching. New York: American Educational Research Association.

Firestone, W. A. \& Corbett, H. D. (198,j). Planned organizational change. In Boyan, N. J. (ed.), Handbook of research and development in educational administration. New York: Longman.

Fox, M. (1991). Creation spirituality. New York: HarperCollins.

Fullan, M. G. (1982). The meaning of educational change. New York: Teachers College Press.

Fullan, M. G. (1993). Why teachers must become change agents. Educational Leadership, 50, (6), 12-17.

Fuller, F. F. (1971). Relevance for teacher education: A teacher concerns model. Austin, TX: Research and Development Center for Teacher Education, University of Texas.

Fuller, B., Wood, K., Rapport, T., \& Dornbusch, S. (1982). The organizational context of individual efficacy. Review of educational press, 52, (Spring), 7-30.

Garfield, C. (1986). Peak performers: The new heroes of American business. New York: Morrow \& Company, Inc. 
Garman, N. B. (1986) Clinical supervision: Quackery or remedy for professional development? Journal of curriculum and supervision, 1 (2), 148-157.

Garman, N. B. (1986). Reflection, the heart of clinical supervision: A modern rationale for professional practice. Journal of curriculum and supervision, 2 (1), 1-24.

Garman, N. B., Glickman, C. D., Hunter, M. \& Haggeson, N. (1986). Conflicting conceptions of clinical supervision and the enhancement of professional growth and renewal: Point and counterpoint. Journal of curriculum and supervision, 2 (1), 152-177.

Garmeezy, N. \& Rutter, M. (1983). Stress, coping and development in children. New York: McGraw-Hill.

Garmston, R. \& Costa, A. (1993). Cognitive coaching: Leadership for renaissance schools. Norwood, Massachusetts: Christopher Gordon. In press.

Giroux, H. A. (1988). Teachers as intellectuals: Toward a critical pedagogy of learning. Granby, Massachusetts: Bergin and Garvey.

Gitlin, A. \& Price, Karen (1992). Teacher empowerment and the development of voice. In Glickman, C. D. (ed.). Supervision in transition (pp. 61-76). Alexandria, VA: Association for Supervision and Curriculum Development.

Glaser, B. G. \& Strauss, A. L. (1967). The discovery of grounded theory: Strategies for qualitative research. Chicago: Aldine.

Glasser, W. (1990). The quality school. New York: Harper and Row.

Glatthorn, A. A. (1984). Differentiated supervision. Alexandria, Virginia: Association for Supervision and Curriculum Development.

Glickman, C. D. (1992). Supervision in transition. Alexandria, Virginia: Association for Supervision and Curriculum Development.

Goetz, J. P. \& LeCompte, M. D. (1984). Ethnography and qualitative design in educational research. Orlando: Academic Press, Inc.

Goffman, E. (1959). The presentation of self in everyday life. New York: Doubleday Anchor.

Good, T. L. \& Brophy, J. E. (1984). Looking in classrooms. New York: Harper and Row. 
Goodlad, J. I. (1984). A Place called school. New York: McGraw Hill.

Goodlad, J. I. (1990). Teachers for our nation's schools. San Francisco: Josey-Bass.

Goodlad, J. I. (1987). Toward a healthy ecosystem. In The ecology of school renewal: Eighty-sixth yearbook of the national society for the study of education (210-221). Chicago: University of Chicago Press.

Goodlad, J. I., Soder, R., \& Sirotnik, K. A. (1991). The moral dimensions of teaching. San Francisco: Josey-Bass.

Goodson, I. (1992). Studying teachers' Llves. New York: Teachers College Press.

Grant, C. A. (1984). Preparing for reflective teaching. Boston: Allyn and Bacon.

Green, T. F. (1989). The conscience of leadership. In Leadership: Examiring the elusive. Alexandria, VA: Association for Supervision and Curriculum Development.

Greenfield, W. (1985). The moral socialization of public school administrators: Informal role learning outcomes. Educational Administration Quarterly $21(4), 99-119$.

Guba, E. G. \& Lincoln, Y. S. (1983). Effective evaluation: Improving the usefulness of evaluation results through responsive and naturalistic approaches. San Francisco: Josey-Bass.

Gustafson, J. M., Peters, R. S., Kohlberg, L., Bettleheim, B. \& Keniston, K. (1970). Moral education: Five lectures. Cambridge: Harvard University Press.

Guyton, E. \& McIntyre, J. D. (1990). Student teaching and school experiences. In Houston, W. (ed.) Handbook of research on teacher education. New York: MacMillan.

Hallinger, P. (1987). Organizational and social context and the instructional leadership role of the school principal. Paper presented to the American Educational Research Association, Washington, D. C.

Hoffman, J. V., Edwards, S. A., O'Neal, S., Barnes, S. \& Paulissen, M. (1986, February). A Study of state-mandated beginning teacher programs. Journal of Teacher Education, 16-21. 
Hord, S. M., Rutherford, W. L., Huling-Austin, L. \& Hall, G. E. (1987). Taking charge of change. Alexandria, VA: Association for Supervision and Curriculum Development.

Houston, W. (1990). Handbook of research on teacher education. New York: MacMillan Publishing Company.

Hughes, R. (1982, March). Personality factors in the student teaching triad. Paper presented to the American Educational Research Association. New York, NY.

Illich, I. (1971). The Deschooling of Society. New York: Harper and Row.

Jackson, P. W. (1968). Life in Classrooms. New York: Holt, Rinehart \& Winston.

Jarrett, J. J. (1991). The teaching of values: Caring and appreciation. London: Routledge.

Joyce, B. \& Showers, B. (1983). The coaching of teaching. Educational leadership $40(1), 4-10$.

Joyce, B. \& Weil, M. (1986). Models of teaching. Englewood Cliffs, New Jersey: Prentice Hall.

Kagan, D. M. (1990). Research as art: Reclaiming educational research for teachers and other speakers of standard English. Action in teacher education $12,7-12$.

Katz, L. G. \& Raths, J. (1985). Dispositions as goals for teacher education. Teaching and teacher education, 1, 301-307.

Katz, L. G. \& Raths, J. (1992). Six dilemmas in teacher education. Journal of teacher education, 43 (5), 376-385.

Kennedy, M. M. (1990). Choosing a goal for professional education. In Houston, W. (ed.), Handbook of research on teacher education. New York: MacMillan.

Knowles, J. G. (1992). Models for understanding pre-service and beginning teachers' biographies. In Goodson, I. F. (ed.), Studying teachers' lives. New York: Teachers College Press.

Knowles, J. G. \& Hoefler, V. B. (1989, Summer). The student teacher who wouldn't go away: Learning from failure. The Journal of Experiential Education, 14-21. 
Knowles, J. G. \& Sudzina, M. R. (1992). Addressing 'failure' in student teaching: Some practical and ethical issues. Paper presented to the American Educational Research Association, San Francisco, CA.

Knowles, J. G. \& Sudzina, M. R. (1992). Personal characteristics and contextual conditions of student teachers who 'fail:' Setting a course for understanding failure in teacher education. Paper presented to the American Educational Research Association, San Francisco, CA.

Kounin, J. S. (1977). Discipline and group management in the classroom. Huntington, New York: R. E. Krieger Publishing Company.

Kozol, J. (1975). The night is dark and I am far from home. New York: Simon and Schuster.

Kremer, L. \& Kurtz, C. (1982). Locus of control: Perceptions and attributions of student teachers in educational situations. Tel Aviv, Israel: unpublished research report.

Krimerman, L. I. (1972). Autonomy: A new paradigm for research. InPhilosophical redirection of educational research: Seventy-first yearbook of the National Society for the Study of Education (327-355). Chicago: University of Chicago Press.

Lemlech, J. K. \& Kaplan, S. N. (1990). Learning to talk about teaching: Collegiality in clinical teacher education. Action in teacher education, 12 (1), 13-20

Lieberman, A. (1988). Expanding the leadership team in schools: From ${ }^{*}$ isolation to participation. Unpublished address to the national conference of The Association for Supervision and Curriculum Development, Orlando, FL.

Liebert, D. (1986, Fall/Winter). Partnership in teacher education: Mentor teacher, student teacher. Curriculum in context, 26-28.

Lincoln, Y. S.(1986). A future-oriented comment on the state of the profession. The review of higher education, $10(2), 135-142$.

Lincoln, Y. S., \& Guba, E. G. (1985). Naturalistic inquiry. London: Sage.

Lofland, J. (1971). Analyzing social settings: A guide to qualitative observation and analysis. Belmont, CA: Wadsworth.

Lortie, D.C. (1975). Schoolteacher: A sociological analysis. Chicago: University of Chicago Press. 
McKechnie, J. L. (ed.) (1983). Webster's new universal unabridged dictionary. Cleveland, Ohio: Simon and Shuster.

McNergney, R. F. \& Carrier, C. A. (1981). Teacher development. New York: Macmillan Publishing Co., Inc.

March, J. G. (1978, February). American public school administration: A short analysis. School review, 217-250.

Marso, R. N. \& Pigge, F L. (1990, October). Relationships between prospective teachers' personality attributes and changes in concerns about teaching during training. Paper presented to the Mid-Western Educational Research Association, Chicago, IL.

Massarik, F. (1981). The interviewing process re-examined. In Reason, P. \& Rowan, J. (eds.), Human inquiry: A sourcebook of new paradigm research. New York: John Wiley.

Melnick, S. A. (1989). Cooperating teachers: What do they see in the classroom? Paper presented to the American Educational Research Association, San Francisco, CA.

Mosher, R. L. \& Purpel, D. E. (1972). Supervision: The reluctant profession. Boston: Houghton Mifflin.

Noddings, N. (1984). Caring: A feminine approach to ethics and moral education. Berkeley: University of California Press.

Noddings, N. \& Shore, P. J. (1984). Awakening the inner eye: Intuition in education. New York: Teachers College Press.

Nolan, J. \& Francis, P. (1992). Changing perspectives in curriculum and instruction. In Glickman, C. D. (ed.) Supervision in transition (44-59). Alexandria, VA: Association for Supervision and Curriculum Development.

Nord, W.A. (1990). Teaching and morality: The knowledge most worth having. In Dill, D. D. (ed.) What teachers need to know. San Francisco: JoseyBass.

Oser, F. K. (1986). Moral education and values education: The discourse perspective. In Wittrock, M., Handbook of research on teaching (917936). New York: MacMillan.

Payne, B. D. \& Manning, B. H. (1988). Student teacher performance as related to self-perceptions of adequacy. College student journal, 78, 176-178. 
Peters, T. \& Waterman, R. (1982). In search of excellence. New York: Harper and Row.

Pfeifer, J. (1993). The effects of personality on success in student teaching. Paper presented at the National Field Directors Forum of the annual meeting of the Association of Teacher Educators, Orlando, FL.

Pintrich, P. R. (1990). Implications of psychological research on student learning and college teaching for teacher education. In Houston, W. (ed.) Handbook of research on teacher education. New York: MacMillan.

Poplin, M. (1989, May). Education and the revitalization of America. President's Forum, Claremont Graduate School, Claremont, CA.

Pratt, L. K. (1981). The relationship of the Myers-Briggs Type Indicator to scores on the National Teachers' Examination. Paper presented at the Annual Forum of the Association for Institutional Research, Minneapolis, MN.

Pugach, M.C. (1984). The role of selective admissions policies in the teachereducation process. In Katz, L. G. \& Raths, J. D. (eds.), Advances in teacher education (145-169). Norwood, NJ: Ablex.

Purkey, W. W. \& Novak, J. M. (1984). Inviting school success. Belmont, California: Wadsworth.

Purpel, D. E. (1989). The moral and spiritual crisis in education. Granby, Massachusetts: Bergin and Garvey.

Purpel, D. E. \& Ryan, K. (1976). Moral education ... it comes with the territory. Berkeley: McCutcheon.

Rogers, C. (undated reprint). The facilitation of significant learning. Paper presented to the Western Behavioral Sciences Institute, LaJolla, CA.

Rojewski, J. W. \& Holder, B. H. (1990). Personality type profiles of students in vocational education teacher preparation programs. Journal of vocational education research, 15 (2), 77-91.

Rosenholtz, S. (1989). Teachers' workplace: The social organization of schools. New York: Longman, Inc.

Rutter, M. (1979). Fifteen thousand hours. Cambridge, MA: Harvard University Press.

Sadowski, C. J. \& Woodward, H. R. (1983, October). Teacher locus of control and classroom climate: A cross-lagged correlational study. Psychology in the schools, 506-509. 
Saphier, J. \& Gower, R. (1987). The skillful teacher. Carlisle, MA: Research for Better Teaching.

Sarason, S. (1971). The culture of the school and the problem of change. Boston: Allyn and Bacon.

Schalock, D. (1979). Research on teacher selection. In Berliner, D. C. (ed.), Review of research in education. Washington, D.C.: American Educational Research Association.

Schatzman, L. \& Strauss, A. L. (1972). Field research: Strategies for a natural sociology. Englewood Cliffs, NJ: Prentice-Hall.

Schein, E. (1985). Organizational culture and leadership. San Francisco: Josey-Bass.

Schon, D. A. (1983). The reflective practioner: How professionals think in action. New York: Basic Books.

Sergiovanni, T. J. (1985). Landscapes, mindscapes, and reflective practice in supervision. Journal of curriculum and supervision (1), 5-17.

Sergiovanni, T. J. (1987). The theoretical basis for cultural leadership. In Leadership: Examining the elusive. Alexandria, VA: Association for Supervision and Curriculum Development.

Sergiovanni, T. (1992). Moral authority and the regeneration of supervision. In Glickman, C: D. (ed.) Supervision in transition. Alexandria, VA: Association for Supervision and Curriculum Development.

Silvernail, D. L. \& Costello, M. H. (1983). The impact of student teaching and internship programs on preservice teachers' pupil control perspectives, anxiety levels and teaching concerns. Journal of teacher education, 34 (4), 32-36.

Sizer, T. R. (1984). Horace's compromise. Boston: Houghton Mifflin.

Skrobola, N. L. M. \& Knowles, J. G. (1992, April). We watched them fail: University supervisors' perceptions of preservice teachers who 'failed' student teaching. Paper presented to the American Educational Research Association, San Francisco, CA.

Sleeter, C. (1990). Empowerment through multicultural education. New York: State University of New York Press.

Smith, F. (1988). Insult to intelligence: The bureaucratic invasion of our classrooms. Portsmouth, NH: Heinemann Educational Books, Inc. 
Smith, N. L. (1981). Metaphors for evaluation: Sources of new methods. London: Sage Publications.

Smythe, W. J. (1986). Clinical supervision: Technocratic mindedness, or emancipatory kearning. Journal of curriculum and supervision, 1, (4), 331-340.

Soar, R.S., \& Soar, R.M. (1978). Emotional climate and management. In Peterson, K. \& Walberg, H. (eds.) Research on teaching: Concepts, findings, and implications. Berkeley: McCutcheon.

Spradley, J. P. (1979). The ethnographic interview. New York: Holt, Rinehart and Winston.

Sprinthall, N. \& Thies-Sprinthall, L. (1981). Educating for teacher growth: A cognitive-developmental perspective. In Griffin, G. A. \& Hukil, R. (eds.) Alternative perspectives for program development and research in teacher education. Summary of proceedings of an invited symposium for the annual meeting of the American Educational Research Association, Los Angeles, CA.

Steigelbauer, S. (1992). Why we want to be teachers. Paper presented to the American Educational Research Association, San Francisco, CA.

Su, Z. (1990). Exploring the moral socialization of teacher candidates. Oxford review of education, $16,(3), 367-91$.

Tabachnik, B. R., Popkewitz, T. A. \& Zeichnier, K. M. (1979-80). Teacher education and the professional perspectives of student teachers. Interchange, 10, (4), 12-29.

Toffler, A. (1974). Learning for tomorrow: The role of the future in education. New York: Vintage Books.

Tukey, J. (1985). In Lincoln, Y. \& Guba, E., Naturalistic Inquiry (p. 338). London: Sage.

Walberg, H., Metzner, S., Todd, R., \& Henry, P. (1968). Effects of tutoring and practice teaching on self-concepts and attitudes in education students. Journal of teacher education 19: 283-291.

Weick, K. E. (1982, June). Administering education in loosely coupled schools. Phi Delta Kappan, 673-676.

Weinstein, G. \& Fantini, M. (1975). Toward humanistic education: A curriculum of affect. New York: Praeger. 
Weinstock, H.R., \& Peccolo, C. M. (1970). Do students' ideas and attitudes survive practice teaching? Elementary school journal, 70, 210-218.

Willower, D. J. \& Smith, J. P. (1986). Organizational culture in schools: Myth and creation. Paper presented to the American Educational Research Association, San Francisco, CA.

Wittrock, M. C. (ed.) (1986). Handbook of research on teaching. New York: MacMillan Publishing Company.

Zeichner, K. M. \& Gore, J. M.(1990). Teacher socialization. In Houston, W. (ed.) Handbook of research on teacher education (329-348). New York: MacMillan.

Zeichner, K. M., \& Liston, D. P. (1987). Teaching student teachers to reflect. Harvard educational review, $57,23-48$.

Zeichner, K. M. (1987). The ecology of field experience: Toward an understanding of the role of field experiences in teacher development. In Haberman, M. \& Backus, J. M. (eds.) Advances in teacher education (94-117). Norwood, NJ: Ablex. 
APPENDIX A

INTERVIEW FORMAT 


\section{Appendix A}

\section{INTERVIEW FORMAT}

(Demographic information in Journal: faculty/agency employment status, years of experience as field supervisor, average caseload per term. Opening warmup questions as needed.)

In Teachers for Our Nation's Schools, John Goodlad says By this point in his/her training, no reasonable person wants to consider taking responsibility for failing a prospective teacher." In fact, however, I -- and I presume you, too -have taken responsibility for exactly that. But there are more times, in my experience, when I pass a student about whom I am uncomfortable -- who doesn't pass my test; i.e., I wouldn't be comfortable if s/he were teaching my children.

Have you felt, on occasion, that kind of pressure to advance the marginal student? Please talk to me about that.

Do you think marginality/failure in (this student) (students you've supervised) had more to do with skills or with personal attributes? What attributes have made you willing to resist the pressure to advance? or What are the attributes that seem to lead certainly to failure, in your experience.

Probes:

I'm particularly interested in Can you tell me more?

Will you elaborate on that point?

What happened when you tried to remediate these deficiencies?

You use the word ___ in describing understand your use of that word. . Let me make sure I

You seem to be blaming ___ 's failure/marginality on Was that the primary cause? Were there other causes, in your opinion?

In your experience, have other marginal/failed student teachers commonly been characterized by this/these attribute(s)?

Are you having trouble naming that attribute? Let 's try some possibilities. or Feel free to invent a word if you need one. 
APPENDIX B

INFORMED CONSENT 
Appendix B

\section{INFORMED CONSENT}

I, the undersigned, freely agree to participate as an interview respondent in the dissertation project entitled

\section{A Study of Personal Attributes Associated with Marginality and Failure of Preservice Teachers in Field Internships.}

I agree to participate in the hope that my contribution will contribute to knowledge of potential benefit in the area of teacher education.

I have been assured that my responses will be kept confidential. Neither I nor my student supervisees will be identified by name. The written reports of this interview will contain no references to geographic location, agency or university.

It is my understanding that, beyond the time and inconvenience associated with giving this interview, my participation carries with it no risks or discomforts, physical, psychological, social or economic.

The extent of my contribution is agreed to be the time required to give this interview, except as I freely offer to make myself available for followup studies, if any. I understand that the interview will be tape-recorded and later transcribed for analysis, with audio tapes and transcripts remaining in the possession of the investigator. I have been assured that should I ask to be withdrawn from the study, all record of my responses will be destroyed.

Sharon Bancroft, Investigator, has offered to answer any questions I may have about the study, what is expected of me, the purpose of any question I am asked and how the results may be used. I have been assured that the investigator has no covert agenda.

I have read the foregoing and agree to participate in this study.

Date:

Signature

Please provide me with a report of results from this study.

Problems resulting from participation in this study should be reported to Chair, Human Subjects Research Review Committee, Office of Grants and Contracts, 345 Cramer Hall, Portland State University, (503) 725-3417. 


\section{APPENDIX C}

ASSURANCES

EXPLANATION OF METHOD

FOLLOWUP 


\section{Appendix C}

\section{ASSURANCES}

The demographic information I just asked you for will be kept in my personal files, only. Your interview will be identified everywhere else only by its number. Neither you nor any of your student teachers will be identified by name in the report of results from this project. First names which may be used casually in the course of this taped interview will be removed from the written transcript, along with any reference to geographical location, agency, or university.

\section{EXPLANATION OF METHOD}

(Abbreviate as appropriate. Some respondents are familiar with the method.)

The research method used here is an unstructured interactive interview, part of an ethnographic research design called modified analytic induction. Data collected this way will be interpreted through constant comparative analysis. One of the features of this method is that the researcher and the respondent cooperate instead of the former acting upon or "doing something to" the latter.

In effect, you and I will be working together both to delineate what are the appropriate questions to be asking, and to suggest how they might be answered. The goal is the surfacing of language, beliefs and assumptions that may contribute to theory-building in the area of student teacher success and failure.

\section{FOLLOWUP}

After the tape of our interview is transcribed, a copy of that transcript will be returned to you. You will be invited to add, delete, or amend remarks, and to submit any elaborations or second thoughts that may occur to you then or in the interim. 
APPENDIX D

\section{TABLE IV}




\section{Appendix D}

TABLE IV

DATA SORT BY ATTRIBUTE/DOMAIN AND RESPONDENT/STUDENT TEACHER

\begin{tabular}{|c|c|c|c|c|}
\hline ATTRIBUTE & RESPONDENT ELABORATIONS & OTHER INCLUDED & INVESTIGATOR NOTES & R/ST \\
\hline $\begin{array}{l}\text { SKILL ISSUES } \\
\text { Extrapersonal } \\
(20)\end{array}$ & $\begin{array}{l}\text { Iget stuck with the skills thing ... how } \\
\text { can it be, two students from the same } \\
\text { university with the same program, same } \\
\text { classes, and one will say "I didn't learn } \\
\text { a thing "... and she didn't . . and the } \\
\text { other will say "llearned so much," and } \\
\text { has taken that and used it and is a } \\
\text { wonderfully skilled teacher. } \\
\text { (same R., speaking of veteran } \\
\text { unsuccessful teachers she works with): } \\
\text {... people who've been certified but } \\
\text { clearly never had any kind of technical } \\
\text { training... of whom l can say, "This } \\
\text { person has no business teaching at all. } \\
\text { Shouldn't be with kids. There's nothing } \\
\text { to remediate. Should be doing } \\
\text { something else with their lives." }\end{array}$ & $\begin{array}{l}\text { content (1) } \\
\text { management (5) } \\
\text { pedagogy (4) } \\
\text { planning (4) } \\
\text { general preparedness } \\
(6)\end{array}$ & $\begin{array}{l}\text { In most cases, a personal attribute is reported } \\
\text { as contributing to deficits in these areas, and } \\
\text { recorded elsewhere; here, are "extrapersonal" } \\
\text { as reported; i.e., with fault assigned by and } \\
\text { large to teacher training programs and } \\
\text { practices) } \\
\text { See } 8 \text { A's telling "summary" } \\
\text { Cf Katz \& Raths, p. } 378, \text { warm fuzzy CT's }\end{array}$ & $\begin{array}{l}2 B 2, \\
2 B 3 ; \\
3 B 1 \\
3 B 3 ; \\
4 A 6 \\
4 A 7 \\
5 A 1 ; \\
6 A 4 ; \\
6 A 6 ; \\
6 B 3 ; \\
7 A 3 ; \\
8 A 1 ; \\
8 A 2, \\
8 A 5\end{array}$ \\
\hline $\begin{array}{l}\text { PLACEMENT } \\
\text { ISSUES } \\
\text { Extrapersonal } \\
\text { (3) }\end{array}$ & $\begin{array}{l}\text { It turned out to be the wrong grade } \\
\text { level. } \\
\text { The culture was too diverse, too } \\
\text { different from his own. } \\
\text { She overcame problems with setting, } \\
\text { context, CT... she just went 'way } \\
\text { beyond. }\end{array}$ & & $\begin{array}{l}\text { Surprised to find no one blaming } \\
\text { marginality/failure on CT/ST match (one } \\
\text { expressed disappointment with weak CT) }\end{array}$ & \\
\hline
\end{tabular}


TABLE IV

DATA SORT BY ATTRIBUTE/DOMAIN AND RESPONDENT/STUDENT TEACHER (continued)

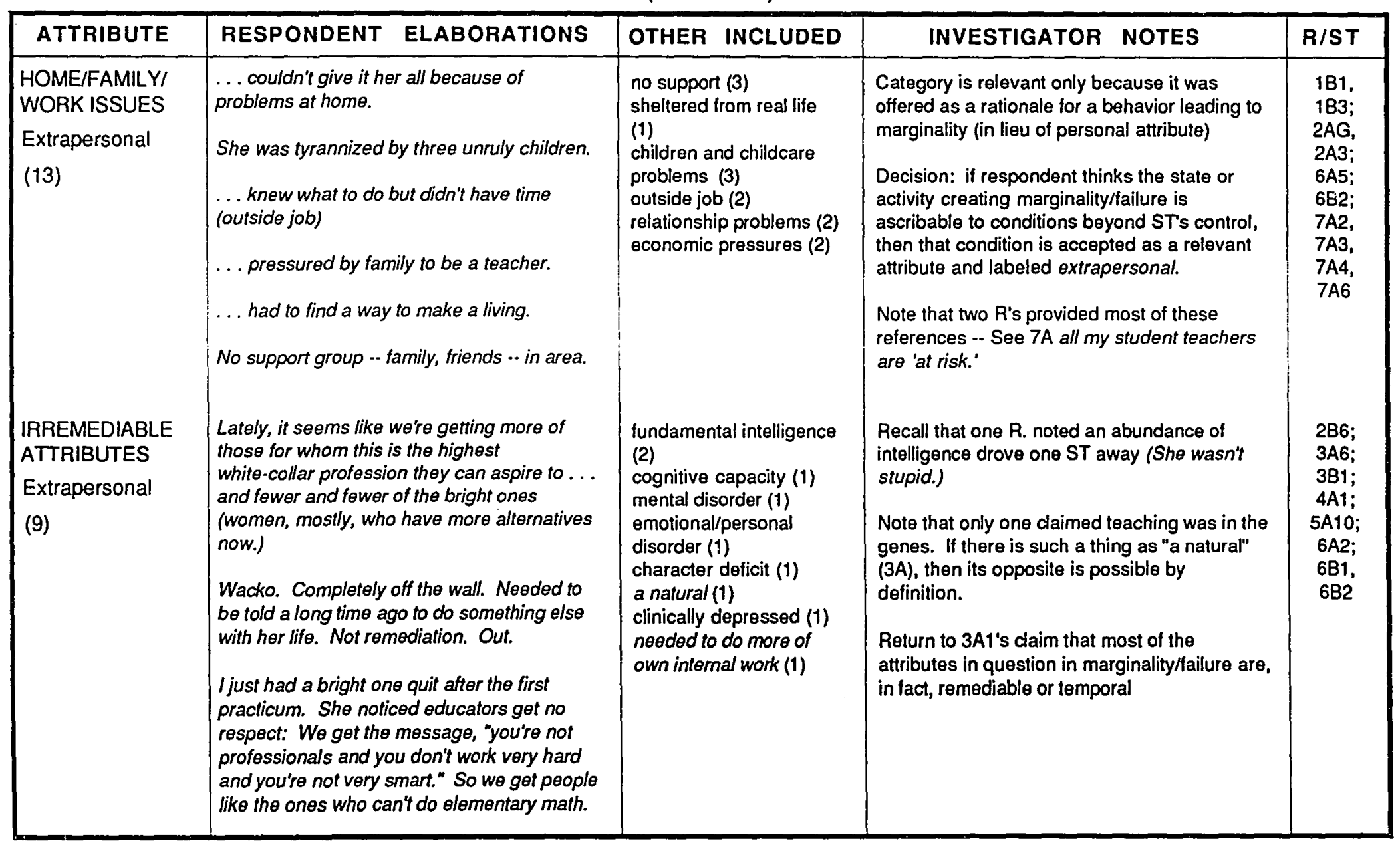


TABLE IV

DATA SORT BY ATTRIBUTE/DOMAIN AND RESPONDENT/STUDENT TEACHER

(continued)

\begin{tabular}{|c|c|c|c|c|}
\hline ATTRIBUTE & RESPONDENT ELABORATIONS & OTHER INCLUDED & INVESTIGATOR NOTES & R/ST \\
\hline $\begin{array}{l}\text { STRESS } \\
\text { TOLERANCE } \\
\text { Intrapersonal? } \\
\text { (6) }\end{array}$ & $\begin{array}{l}\text { 3A9... hated having to watch the clock, } \\
\text { bothered by constant changes of activity } \\
\text { and the activity level of the kids, not making } \\
\text { good decisions because she was } \\
\text { exhausted. } \\
\text { She was surprised and stressed out by the } \\
\text { demands of the job... if the reason for } \\
\text { teaching is right, these can be saved with } \\
\text { the right nurturing. }\end{array}$ & $\begin{array}{l}\text { stressed (2) } \\
\text { shocked (2) }\end{array}$ & $\begin{array}{l}3 \mathrm{~A} \text { admits here some attributes can't be } \\
\text { taught, wonders about ST's who obviously } \\
\text { aren't enjoying themselves, how much this is } \\
\text { the reason } \\
\text { IS it an irremediable? }\end{array}$ & $\begin{array}{l}3 A 9 \\
6 A 1\end{array}$ \\
\hline $\begin{array}{l}\text { ORGANIZATION } \\
\text { Intrapersonal? } \\
(6)\end{array}$ & $\begin{array}{l}\text { Sometimes reveals lack of commitment, and } \\
\text { sometimes (in this case) a matter of valuing } \\
\text { and priority: he just didn't think it was } \\
\text { important and wasn't good at it ... yet. } \\
\text { 5A7... unable to make concise, streamline, } \\
\text { draw simple analogies, simplify content so } \\
\text { students could understand. } \\
\text {... couldn't organize an answer, let alone a } \\
\text { lesson; e.g. Ask him what time it is, and he } \\
\text { tells you how to make a clock. }\end{array}$ & $\begin{array}{l}\text { absent-mindedness (1) } \\
\text { poor planning not } \\
\text { ascribed to lack of skill } \\
\text { (1) }\end{array}$ & $\begin{array}{l}\text { Establish relevance } \\
\text { For DISCUSSION, see } 3 A .1 \text { (p. 7) } \\
\text { Is this an irremediable attribute? a skill issue? } \\
\text { Note R. distinction: irremediable within the } \\
\text { time we have }\end{array}$ & $\begin{array}{l}3 A 2 ; \\
5 A 2\end{array}$ \\
\hline
\end{tabular}




\section{TABLE IV}

\section{DATA SORT BY ATTRIBUTE/DOMAIN AND RESPONDENT/STUDENT TEACHER}

(continued)

\begin{tabular}{|c|c|c|c|c|}
\hline ATTRIBUTE & RESPONDENT ELABORATIONS & OTHER INCLUDED & INVESTIGATOR NOTES & R/ST \\
\hline $\begin{array}{l}\text { FLEXIBILITY } \\
\text { Intrapersonal } \\
(22)\end{array}$ & 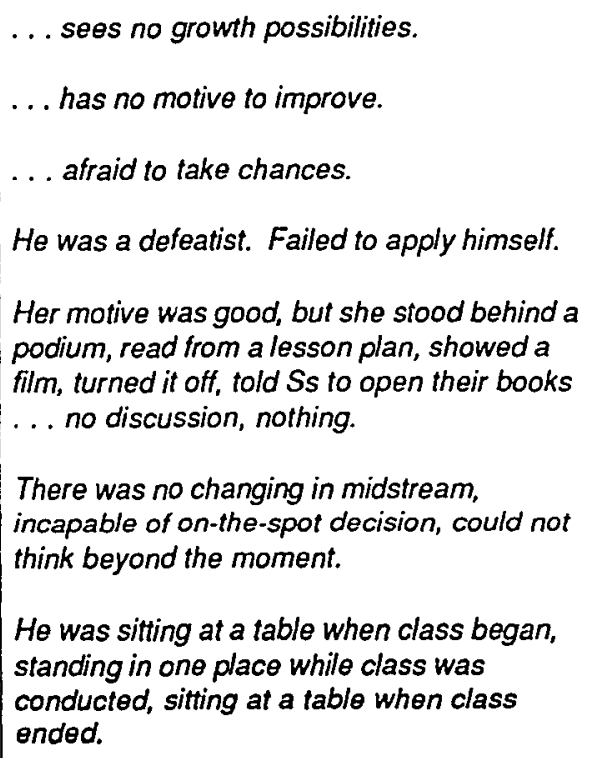 & $\begin{array}{l}\text { adaptability (4) } \\
\text { creativity (1) } \\
\text { risk-averse (3) } \\
\text { implements } \\
\text { suggestions (3) } \\
\text { growth-oriented (3) } \\
\text { frozen (1) } \\
\text { constricted (1) } \\
\text { rooted in one spot (1) } \\
\text { stiff (1) }\end{array}$ & $\begin{array}{l}\text { Examine for applicability of Garmston's } \\
\text { definition } \\
\text { Explore connection between psych and } \\
\text { physical manifestations } \\
\text { Explore etymology, reflection'flexibility } \\
\text { Look for refs to failure to take Ss perspective, } \\
\text { larger view }\end{array}$ & 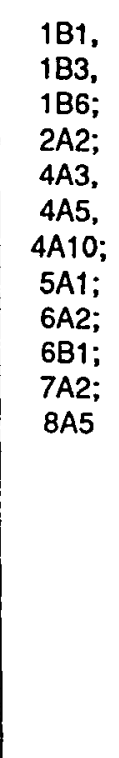 \\
\hline
\end{tabular}


TABLE IV

DATA SORT BY ATTRIBUTE/DOMAIN AND RESPONDENT/STUDENT TEACHER (continued)

\begin{tabular}{|c|c|c|c|c|}
\hline ATTRIBUTE & RESPONDENT ELABORATIONS & OTHER INCLUDED & INVESTIGATOR NOTES & $\mathbf{R} / \mathbf{S T}$ \\
\hline $\begin{array}{l}\text { REFLECTION } \\
\text { Intrapersonal } \\
\text { (19) }\end{array}$ & $\begin{array}{l}\text {... she was unwilling or incapable of looking } \\
\text { critically at herself. } \\
\text {.. he was too hard on himself; frustrated all } \\
\text { the time because he knew what he should do } \\
\text { and couldn't quite pull it off. } \\
\text {.. adequate was good enough. I could } \\
\text { never get him to look beyond adequate. } \\
\text { She was reflective, made changes, } \\
\text { adjusted, asked for help, wanted to improve. } \\
\text {. had everyone agreeing she had } \\
\text { everything it takes, and everyone helping } \\
\text { her with a serious problem class, and finally } \\
\text { she says, "Forget it. l'm outta here." She } \\
\text { was also really bright. }\end{array}$ & $\begin{array}{l}\text { honesty w/self (2) } \\
\text { self-analytical (2) } \\
\text { self-critical (4) } \\
\text { arrogant/know-it-all (3) } \\
\text { listen (1) } \\
\text { seek input (1) } \\
\text { motive to improve (2) }\end{array}$ & $\begin{array}{l}\text { Clearly, a continuum. Explore this. } \\
\text { Relate to flexibility in Garmston terms, } \\
\text { adaptability, willingness to change, implement } \\
\text { new learnings... } \\
\text { Cf locus, commitment, belief system, passion } \\
\text { and energy } \\
\text { Re: ST who dropped out, cross ref. } \\
\text { irremediables: Intelligence }\end{array}$ & $\begin{array}{l}\text { 1B7; } \\
\text { 1B8; } \\
\text { 2A3; } \\
\text { 2B4; } \\
3 A 8 ; \\
6 B 1 ; \\
7 A 4 ; \\
7 A 5 ; \\
7 A 6 ; \\
8 A 2\end{array}$ \\
\hline
\end{tabular}


TABLE IV

DATA SORT BY ATTRIBUTE/DOMAIN AND RESPONDENT/STUDENT TEACHER (continued)

\begin{tabular}{|c|c|c|c|c|}
\hline ATTRIBUTE & RESPONDENT ELABORATIONS & OTHER INCLUDED & INVESTIGATOR NOTES & R/ST \\
\hline $\begin{array}{l}\text { LOCUS } \\
\text { Intrapersonal } \\
(15)\end{array}$ & $\begin{array}{l}\text { R4A: When it's always somebody else's } \\
\text { fault there is an inability to connect with } \\
\text { child, inability to help child grow, inability to } \\
\text { communicate with parents; in other words, } \\
\text { total failure as a teacher. } \\
\text { When it went wrong, it was everybody else's } \\
\text { fault - - students, bad advice from the CT.- } \\
\text { but the interesting thing is, she also did not } \\
\text { take credit when things went right. } \\
\text { It's optimism: she believes in her OWN } \\
\text { prospects to make it, given a little more time, } \\
\text { a little more work. } \\
\text { "The blaming thing" -. when you aren't taking } \\
\text { responsibility yourself to make changes that } \\
\text { have to be made. } \\
\text { I had one threaten to quit because he found } \\
\text { school a depressing place to work, } \\
\text { complained of low morale and negativism in } \\
\text { teacher's lounge, teacher's conversations: } \\
\text { "That won't work. These kids don't care. } \\
\text { This kid comes from this or that kind of } \\
\text { family." And so on. Italked him out of it. I } \\
\text { told him it isn't always like that. }\end{array}$ & $\begin{array}{l}\text { blaming others } \\
\text { defensiveness } \\
\text { pessimism } \\
\text { external locus of } \\
\text { control (9) }\end{array}$ & $\begin{array}{l}\text { Explore relationship with risk aversion, } \\
\text { stability (as in learned helplessness,) } \\
\text { defensiveness; ability to reflect, seek input, } \\
\text { grow } \\
\text { Specific term external locus of control used } \\
\text { w/ref to } 9 \text { cases reported } \\
\text { Note sheer weight of verbiage around this one: } \\
\text { high \# of appearances and numerous } \\
\text { rephrasings } \\
\text { Explore continuum: STs lacking in } \\
\text { self-esteem may internalize, blame self in } \\
\text { everything. } \\
\text { Note that cB } 8 \text { (p. } 5 \text { - as defensiveness), } 6 \mathrm{~B} \text {, } \\
\text { and } 3 \mathrm{~B} 11 \text { (p. } 11 \text { ) agree this set is present in } \\
\text { EVERY case of failure. } \\
\text { Explore relationship between high } \\
\text { externalizing, and low reflection } \\
\text { Externalizing might not intertere with the } \\
\text { performance of a bricklayer or bartender or } \\
\text { even a brain surgeon. It might be an asset to } \\
\text { a criminal attorney. But it's disaster in a } \\
\text { teacher, and R's cite the reasons. }\end{array}$ & $\begin{array}{c}1 B 2 \\
1 B 6 ; \\
2 A 3 ; \\
2 B G ; \\
3 A 5 ; \\
3 B 1 \\
3 B 2 \\
3 B 3 ; \\
4 A 7 \\
4 A 9 \\
4 A 10 ; \\
6 A 4 ; \\
6 B 1 \\
6 B 2 \\
6 B 3 ; \\
7 A 1 \\
8 A 2 \\
8 A 4\end{array}$ \\
\hline
\end{tabular}


TABLE IV

DATA SORT BY ATTRIBUTE/DOMAIN AND RESPONDENT/STUDENT TEACHER (continued)

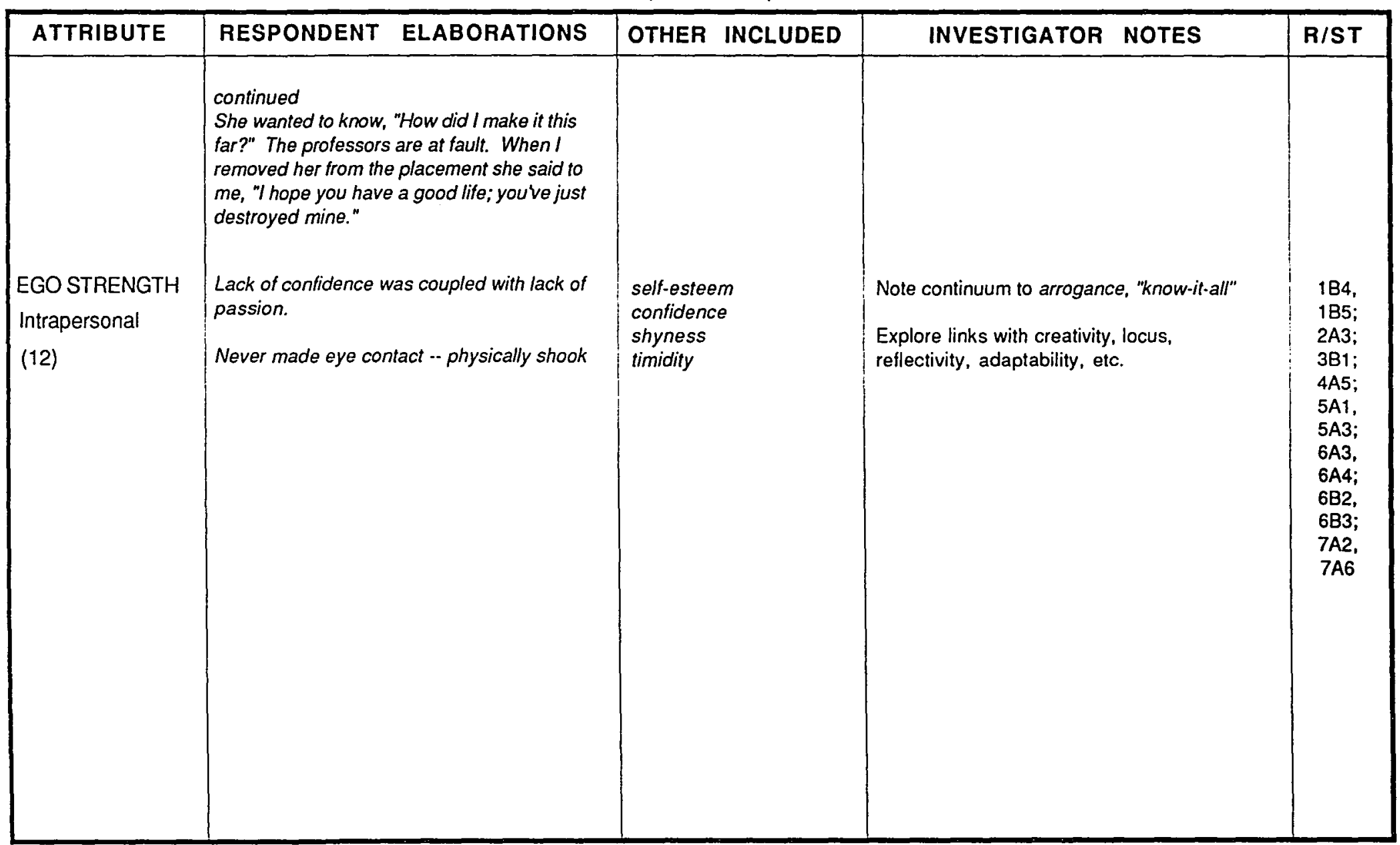


TABLE IV

DATA SORT BY ATTRIBUTE/DOMAIN AND RESPONDENT/STUDENT TEACHER (continued)

\begin{tabular}{|c|c|c|c|c|}
\hline ATTRIBUTE & RESPONDENT ELABORATIONS & OTHER INCLUDED & INVESTIGATOR NOTES & R/ST \\
\hline $\begin{array}{l}\text { EFFORT } \\
\text { Intrapersonal } \\
(17)\end{array}$ & $\begin{array}{l}\text { For some, it's the path of least resistance. } \\
\text {. looking for an easy job, summers off, } \\
\text { compatible hours. } \\
\text { He'd used up all his energy trying to beat the } \\
\text { system, get by with minimum amount of } \\
\text { effort. } \\
\text { Instead of going home and working, she } \\
\text { cried. Saw me as a hurdle she couldn't jump } \\
\text { - always had been able to before. } \\
\text { He had gotten his way by whining all his life. } \\
\text { Thought he should pass because he'd been } \\
\text { at it for } 7 \text { years and needed to start earning } \\
\text { money. } \\
\text { Realized he wasn't cut out for teaching as } \\
\text { soon as he saw how hard he'd have to work. } \\
\text { Alaska-bound, counting on those lucrative } \\
\text { summers, amazed by faculty's effort, hours: } \\
\text { "None of these people has a life." } \\
\text { If they're willing to look this bad when they're } \\
\text { under scrutiny and on trial, what happens } \\
\text { after they're hired, and they close the } \\
\text { classroom door? }\end{array}$ & $\begin{array}{l}\text { rigor (2) } \\
\text { diligence(1) } \\
\text { hard work (4) } \\
\text { self-discipline (1) } \\
\text { initiative (1) } \\
\text { follow-through (2) }\end{array}$ & $\begin{array}{l}\text { A subset of commitment? } \\
\text { Possible continuum leading to burnout }\end{array}$ & $\begin{array}{l}1 B 1, \\
1 B 2, \\
1 B 3 ; \\
3 A 2, \\
3 A 4 ; \\
4 A 2, \\
4 A 3, \\
4 A 7, \\
4 A 8, \\
4 A 10 ; \\
6 A 1, \\
6 A 4, \\
6 A 6 ; \\
6 B 2, \\
6 B 3 ; \\
7 A 1, \\
7 A 4 ; \\
8 A 2, \\
8 A 3, \\
8 A 4, \\
8 A 7\end{array}$ \\
\hline
\end{tabular}


TABLE IV

DATA SORT BY ATTRIBUTE/DOMAIN AND RESPONDENT/STUDENT TEACHER

(continued)

\begin{tabular}{|c|c|c|c|c|}
\hline ATTRIBUTE & RESPONDENT ELABORATIONS & OTHER INCLUDED & INVESTIGATOR NOTES & R/ST \\
\hline $\begin{array}{l}\text { PASSION } \\
\text { Intrapersonal } \\
(20)\end{array}$ & $\begin{array}{l}\text {... believes in her heart of hearts that she } \\
\text { can make a difference. } \\
\text {, , manages to maintain his idealism } \\
\text { throughout all his personal stresses. } \\
\text { She overcame all the difficulties with } \\
\text { dedication and discipline, because she had a } \\
\text { certainty about what she wanted to teach } \\
\text { others. }\end{array}$ & $\begin{array}{l}\text { optimism (1) } \\
\text { belief (2) } \\
\text { idealism (1) } \\
\text { heartteltedness (2) } \\
\text { positivety/negativety (5) } \\
\text { enthusiasm (5) }\end{array}$ & $\begin{array}{l}\text { the affective component of the acted-out } \\
\text { commitment? combine? } \\
\text { relationship drawn in } 1 \mathrm{~B} 4,5 \text { between } \\
\text { confidence level and degree of } \\
\text { child-centeredness (which } 1 \mathrm{~B} \text { calls passion } \\
\text { for kids) Which comes first, confidence and } \\
\text { then passion or the other way around? Is it } \\
\text { confidence or absence of self-absorption? } \\
\text { See story } 1 \text { B6 of ST with multiple strikes .. } \\
\text { specify -- against him, SHOULD HAVE FAILED } \\
\text { and did not because of positivety, optimism, } \\
\text { love, commitment to children, belief in mission }\end{array}$ & $\begin{array}{l}1 B 3, \\
1 B 4, \\
1 B 5 \\
1 B 6 ; \\
3 A 3, \\
3 A 5 \\
3 A 9 ; \\
3 B 3 \\
3 B 4 \\
3 B 5 \\
3 B 6 \\
6 A 2 ; \\
6 B 2 ; \\
7 A 2, \\
7 A 4 \\
7 A 6 \\
8 A 4\end{array}$ \\
\hline $\begin{array}{l}\text { ENERGY } \\
\text { Intrapersonal? } \\
\text { (6) }\end{array}$ & $\begin{array}{l}\text { With it, Ts see the task as problem-solving, } \\
\text { figuring out what will work, what I can do to } \\
\text { help you learn... the fun part. The } \\
\text { essence. } \\
\text { They don't have the energy into it that they } \\
\text { can pull back out. Time. Value. } \\
\text { Commitment. Part of themselves. Without } \\
\text { that they burn out fast. } \\
\text { They're "bubbly." Their kids can't wait to see } \\
\text { what's going to happen next. They act } \\
\text { happy to be there, energetic, positive. }\end{array}$ & $\begin{array}{l}\text { heart not in it } \\
\text { running on empty } \\
\text { not enjoying }\end{array}$ & $\begin{array}{l}\text { When } 3 A \text { talks about energy, she acts it out, } \\
\text { animated, thumping the table. See transcript. }\end{array}$ & $\begin{array}{l}3 A 5 \\
6 A 1\end{array}$ \\
\hline
\end{tabular}


TABLE IV

DATA SORT BY ATTRIBUTE/DOMAIN AND RESPONDENT/STUDENT TEACHER (continued)

\begin{tabular}{|c|c|c|c|c|}
\hline ATTRIBUTE & RESPONDENT ELABORATIONS & OTHER INCLUDED & INVESTIGATOR NOTES & R/ST \\
\hline $\begin{array}{l}\text { BELIEF SYSTEM } \\
\text { Intrapersonal } \\
\text { (5) }\end{array}$ & $\begin{array}{l}\text {.. couldn't tell me a good reason why he's in } \\
\text { teaching. Didn't know how he could make a } \\
\text { difference or why he'd want to. } \\
\text { You have to make all these decisions, every } \\
\text { day. You have to be grounded } \\
\text { philosophically to know where you're going } \\
\text { with kids, what's appropriate for kids, what to } \\
\text { teach and why. } \\
\text {.. couldn't take off a very old set of glasses } \\
\text { and see teaching as more than telling. }\end{array}$ & & & $\begin{array}{l}285 ; \\
6 A 3\end{array}$ \\
\hline $\begin{array}{l}\text { COMMITMENT } \\
\text { Intrapersonal } \\
(16)\end{array}$ & $\begin{array}{l}\text { R1B1: He left a good job, already furned } \\
\text { down another offer, has a family, must drive } \\
10 \text { hours each way to go home and work } 20 \\
\text { hours every weekend... and he's still } \\
\text { convinced he made the right decision. He's } \\
\text { got the grit. } \\
\text { Being uncertain of her career choice, } \\
\text { questioning her commitment created } \\
\text { problems: capable, but coming unprepared, } \\
\text { arriving late and making excuses, getting in } \\
\text { the car and driving at the lunch break, just to } \\
\text { collect herself. She ultimately dropped out. }\end{array}$ & $\begin{array}{l}\text { grit (1) } \\
\text { spunk (1) } \\
\text { will (1) } \\
\text { determination (3) } \\
\text { drive (2) } \\
\text { investment (1) } \\
\text { purposefulness (1) } \\
\text { optimism }\end{array}$ & $\begin{array}{l}\text { close association with PASSION } \\
\text { Cf. motive for teaching, path of least } \\
\text { resistance syndrome } \\
\text { R. } 7 \text { A doesn't blame marginality on attributes } \\
\text { noted, but rather the attributes on the } \\
\text { student's lack of certainty about teaching as a } \\
\text { choice (note capable) }\end{array}$ & 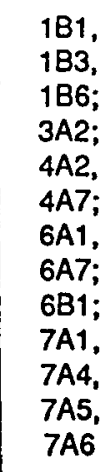 \\
\hline
\end{tabular}


TABLE IV

DATA SORT BY ATTRIBUTE/DOMAIN AND RESPONDENT/STUDENT TEACHER (continued)

\begin{tabular}{|c|c|c|c|c|}
\hline ATTRIBUTE & RESPONDENT ELABORATIONS & OTHER INCLUDED & INVESTIGATOR NOTES & $\mathrm{R} / \mathrm{ST}$ \\
\hline $\begin{array}{l}\text { DEFENSIVE- } \\
\text { NESS } \\
\text { Intrapersonal? } \\
(8)\end{array}$ & $\begin{array}{l}\text {... the yeah, but. .. syndrome } \\
\ldots \text { threatened by kids, suspected their } \\
\text { motives toward him } \\
\text { They respond to feedback with antagonism } \\
\text { and see the supervisor as hostile. }\end{array}$ & & $\begin{array}{l}\text { Explore links with openness to input and } \\
\text { feedback, motivation to grow, capacity for } \\
\text { self-criticism } \\
\text { Are cries easily (1) and knows it all (2) just } \\
\text { stylistically different manifestations of this } \\
\text { attribute? }\end{array}$ & $\begin{array}{l}2 A 2 \\
2 A 3 ; \\
3 A 1 ; \\
3 A 2 ; \\
3 B 6 ; \\
4 A 5 ; \\
6 A 6 ; \\
8 A 7\end{array}$ \\
\hline $\begin{array}{l}\text { WITHITNESS } \\
\text { Intrapersonal? } \\
\text { (4) }\end{array}$ & $\begin{array}{l}\text {... oblivious to the real concerns of } \\
\text { teaching. what's happening } \\
\text {... incapable of seeing effects of his } \\
\text { teaching and making a mid-course } \\
\text { correction. He couldn't deal with more than } \\
\text { one thing at a time. } \\
\text { Seemed not to notice her kids were lost. }\end{array}$ & & $\begin{array}{l}\text { See also empathy and relating to kids } \\
\text { Revisit Kounin's definition }\end{array}$ & $\begin{array}{l}\text { 2A2; } \\
6 A 2 ; \\
\text { 7A2; } \\
8 A 5\end{array}$ \\
\hline $\begin{array}{l}\text { PEOPLE SKILLS } \\
\text { Interpersonal } \\
\text { (18) }\end{array}$ & $\begin{array}{l}\text {... zero social skills, in their face (faculty); } \\
\text { once she ate a bowl of chili and onions in } \\
\text { front of her (university) advisor during an } \\
\text { appointment; called other STs and talked for } \\
\text { hours regardless of their needs } \\
\text { (kindergarten ST) Just monitored, really; no } \\
\text { warmth, no enthusiasm. } \\
\text { She'd look away and not respond when other } \\
\text { T's greeted her in the hall. }\end{array}$ & $\begin{array}{l}\text { outgoingness } \\
\text { pleasing personality (2) } \\
\text { abrasive, insensitive (2) } \\
\text { hypersensitive } \\
\text { unprofessional (in the } \\
\text { sense of too personal) } \\
\text { (2) } \\
\text { aloof, loner (2) } \\
\text { untriendly, cold }\end{array}$ & $\begin{array}{l}\text { All includeds refer to adult relationships; } \\
\text { however, closely linked in transcripts to } \\
\text { deficits in relatedness w/students. With one } \\
\text { exception (I found him hard to like), R's } \\
\text { couched these in objective terms } \\
\text { See also Empathy, Relate }\end{array}$ & $\begin{array}{l}\text { 2A; } \\
2 \mathrm{~B} 1 \text {; } \\
\text { 2BG; } \\
\text { 3A2; } \\
3 \mathrm{~B} 1 \text {; } \\
3 \mathrm{~B} 3 ; \\
6 \mathrm{~A} \text {; } \\
6 \mathrm{A4} ; \\
8 \mathrm{AA6}\end{array}$ \\
\hline
\end{tabular}


TABLE IV

DATA SORT BY ATTRIBUTE/DOMAIN AND RESPONDENT/STUDENT TEACHER (continued)

\begin{tabular}{|c|c|c|c|c|}
\hline ATTRIBUTE & RESPONDENT ELABORATIONS & OTHER INCLUDED & INVESTIGATOR NOTES & R/ST \\
\hline $\begin{array}{l}\text { ARTICULATE- } \\
\text { NESS } \\
\text { Interpersonal } \\
\text { (4) }\end{array}$ & & $\begin{array}{l}\text { communicative (1) } \\
\text { expressive (of feeling) } \\
\text { (1) }\end{array}$ & & $\begin{array}{l}\text { 6A2; } \\
\text { 7A6 }\end{array}$ \\
\hline $\begin{array}{l}\text { EMPATHY } \\
\text { Interpersonal } \\
(12)\end{array}$ & $\begin{array}{l}\text { They understand and can relate to students' } \\
\text { needs. } \\
\text { In tune with children. } \\
\text { Her own emotional needs came first; she was } \\
\text { doing actual harm by 'hooking' children } \\
\text { emotionally, manipulatively to meet her } \\
\text { needs. } \\
\text { He was unable to look at a group, sense their } \\
\text { response and do something with it. Had no } \\
\text { sense of what they liked. (Note this } \\
\text { description common but happens here to be } \\
\text { describing a student diagnosed bipolar } \\
\text { depressive. Next description, also hers, refs } \\
\text { to "normal" ST) } \\
\text { Failed to sense the right thing to do at critical } \\
\text { times, had no "feel" for it. } \\
\text { A lack of ability to feel what students are } \\
\text { feeling so often translates into anger at the } \\
\text { students because they aren't doing what the } \\
\text { teacher wants. Cf LOCUS }\end{array}$ & $\begin{array}{l}\text { flat affect (4) } \\
\text { intuitive } \\
\text { warm } \\
\text { responsive }\end{array}$ & $\begin{array}{l}\text { Investigate further withitness... two } \mathrm{R} \\
\text { explicitly relate empathy to ability to notice } \\
\text { what's going on in the classroom, in the sense } \\
\text { of T's effect on Ss, and term it withitness } \\
\text { see also insensitive (adult relationships) } \\
\text { note connection with physical rootedness in } \\
\text { the classroom }\end{array}$ & $\begin{array}{l}181 ; \\
2 A 2, \\
2 A 3 ; \\
2 B 1 ; \\
2 B 2, \\
2 B 3 ; \\
3 B 1 ; \\
3 B 2 ; \\
4 A 6, \\
4 A 7 ; \\
5 A 1 ; \\
7 A 2, \\
7 A 5 ; \\
7 A 6\end{array}$ \\
\hline
\end{tabular}


TABLE IV

DATA SORT BY ATTRIBUTE/DOMAIN AND RESPONDENT/STUDENT TEACHER

(continued)

\begin{tabular}{|c|c|c|c|c|}
\hline ATTRIBUTE & RESPONDENT ELABORATIONS & OTHER INCLUDED & INVESTIGATOR NOTES & $\mathbf{R} / \mathrm{ST}$ \\
\hline $\begin{array}{l}\text { RELATE TO } \\
\text { STUDENTS } \\
\text { Interpersonal } \\
(12)\end{array}$ & $\begin{array}{l}\text { She never got beyond me to kids stage. } \\
\text { It means he visits with kids, greets kids, } \\
\text { acts happy kids are there, seeks their } \\
\text { company. } \\
\text { This combined with inadequate skills can't be } \\
\text { helped; it won't work. If it's there, all they } \\
\text { may need is an extended student-leaching. }\end{array}$ & $\begin{array}{l}\text { love of kids (1) } \\
\text { comfortable with kids (2) } \\
\text { warmth (with kids, 1) }\end{array}$ & $\begin{array}{l}\text { Note no instance reported of ability to relate } \\
\text { well to adults in the absence of ability } \\
\text { to relate well to students. Consider including } \\
\text { in same category with references to } \\
\text { interpersonal competence in general } \\
\text { See also EMPATHY } \\
\text { CF Katz \& Raths, P. } 380\end{array}$ & $\begin{array}{l}1 B 1 ; \\
5 A 1 \\
6 A 5 \\
8 A 1 \\
8 A 2 \\
8 A 4 \\
8 A 5 \\
8 A 6\end{array}$ \\
\hline $\begin{array}{l}\text { SELF- } \\
\text { ASSERTION } \\
\text { Interpersonal } \\
(15)\end{array}$ & $\begin{array}{l}\text { Just sits there (in conference) and lets the } \\
\text { supervisor do all the talking. } \\
\text { Doesn't set or waivers about limits for } \\
\text { students. } \\
\text { Could not project. No voice. No presence. }\end{array}$ & $\begin{array}{l}\text { passive, } \\
\text { nonconfrontational, } \\
\text { doesn't set rules (3) } \\
\text { docile, timid, shy, } \\
\text { quiet (3) } \\
\text { wishy-washy, } \\
\text { subdued, hangs back }\end{array}$ & $\begin{array}{l}\text { Another continuum, from passive to } \\
\text { overbearing } \\
\text { R's suggest these behaviors don't necessarily } \\
\text { reflect lack of passion and/or commitment } \\
\text { Same-breath physical descriptions suggest } \\
\text { the FLEXIBILITY cover }\end{array}$ & $\begin{array}{l}1 B 7 \\
1 B 8 ; \\
2 A 1 \\
2 A 2 \\
3 A 4 ; \\
3 B 1 ; \\
5 A 1 \\
5 A 3 ; \\
6 B 2, \\
6 B 3 ; \\
7 A 2, \\
7 A 3 \\
7 A 4 ; \\
8 A 5\end{array}$ \\
\hline
\end{tabular}


TABLE IV

DATA SORT BY ATTRIBUTE/DOMAIN AND RESPONDENT/STUDENT TEACHER (continued)

\begin{tabular}{|c|c|c|c|c|}
\hline ATTRIBUTE & RESPONDENT ELABORATIONS & OTHER INCLUDED & INVESTIGATOR NOTES & $R / S T$ \\
\hline $\begin{array}{l}\text { AUTHENTICITY } \\
\text { Interpersonal } \\
(11)\end{array}$ & $\begin{array}{l}\text { Tried to sell her supervisors a bill of goods. } \\
\text { Her charm and people skills covered lack of } \\
\text { teaching skills. Got her CT and me to } \\
\text { cooperate in 'enabling' her. We had to be a } \\
\text { support group for each other when it was } \\
\text { over. } \\
\text { Lacks integrity; can't be trusted } \\
\text { Says what he thinks you want to hear. } \\
\text { It was all an act. He's clever enough to be } \\
\text { genuinely dangerous. }\end{array}$ & $\begin{array}{l}\text { manipulative (2) } \\
\text { lies (3) } \\
\text { consonance: says one } \\
\text { thing/does another (2) } \\
\text { an act }\end{array}$ & & $\begin{array}{l}\text { 1B8; } \\
4 A 3 \\
4 A 4 ; \\
5 A 1 ; \\
6 A 4 ; \\
7 A 3\end{array}$ \\
\hline
\end{tabular}

